University of Michigan Law School

University of Michigan Law School Scholarship Repository

\title{
Are Litigation Outcome Disparities Inevitable? Courts, Technology, and the Future of Impartiality.
}

\author{
Avital Mentovich \\ University of Haifa \\ J.J. Prescott \\ University of Michigan Law School, jprescott@umich.edu \\ Orna Rabinovich-Einy \\ University of Haifa
}

Available at: https://repository.law.umich.edu/articles/2172

Follow this and additional works at: https://repository.law.umich.edu/articles

Part of the Courts Commons, Law and Society Commons, and the Science and Technology Law Commons

\section{Recommended Citation}

Mentovich, Avital. "Are Litigation Outcome Disparities Inevitable? Courts, Technology, and the Future of Impartiality." J.J. Prescott and Orna Rabinovich-Einy, co-authors. Ala. L. Rev. 73, no. 4 (2020): 893-979.

This Article is brought to you for free and open access by the Faculty Scholarship at University of Michigan Law School Scholarship Repository. It has been accepted for inclusion in Articles by an authorized administrator of University of Michigan Law School Scholarship Repository. For more information, please contact mlaw.repository@umich.edu. 


\title{
ARE LITIGATION OUTCOME DISPARITIES INEVITABLE? COURTS, TECHNOLOGY, AND THE FUTURE OF IMPARTIALITY
}

\author{
Avital Mentovich, J.J. Prescott, \& Orna Rabinovich-Einy
}

INTRODUCTION

I. IMPARTIALITY AND DiSPARITIES IN LEGAL OUTCOMES .........................899

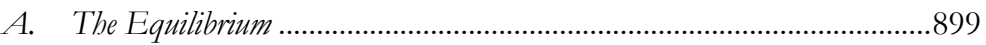

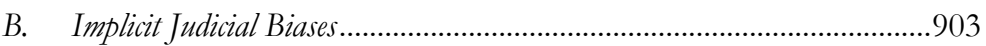

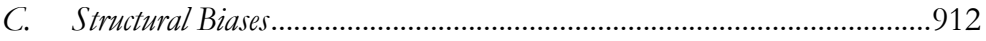

D. Attempts to Reduce Outcome Disparities..................................................919

E. Reducing Disparities Through Online Proceedings?...................................924

II. EMPIRICAL STUdy Of LEGAL OUTCOMES ONLINE AND OfFLINE:

DisPaRITIES AND POTENTIAL BIASES .......................................................... 927

A. Background: Online Court Proceedings....................................................927

B. Online and Offline Legal Proceedings ........................................................934

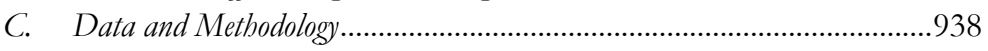

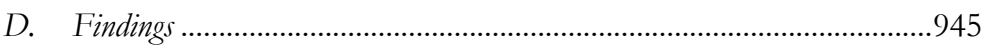

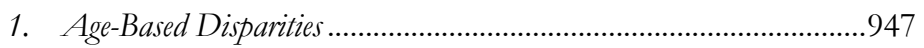

2. Gender-Based Disparities ................................................................ 951

3. Race-Based Disparities ..................................................................953

4. Intersectional Identity Biases ..........................................................955

5. Limitations, Caveats, and Extensions .............................................956

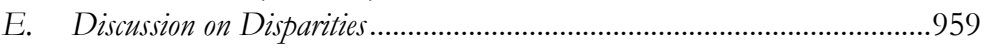

III. Impartiality IN THE AGE OF Digital CourTs .....................................961

A. Toward a New Impartiality Equilibrium? ...............................................961

B. Beyond Impartiality: Costs Associated with Online Court Proceedings ....... 967

1. Substantive Justice ..........................................................................967

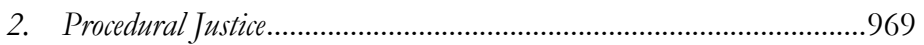

3. Access to Justice, the Digital Divide, and Structural Disparities.........971

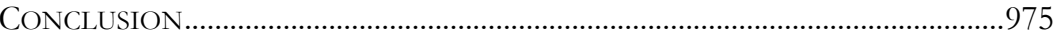

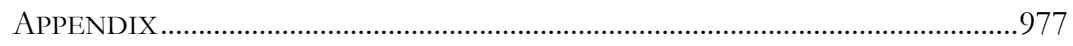




\title{
ARE LITIGATION OUTCOME DISPARITIES INEVITABLE? COURTS, TECHNOLOGY, AND THE FUTURE OF IMPARTIALITY
}

\begin{abstract}
Avital Mentovich, J.J. Prescott, \& Orna Rabinovich-Einy*
This Article explores the ability of technology—specifically, online judicial procedures— to eliminate systematic group-based litigation outcome disparities (i.e., disparities correlated with the visible identity markers of litigants). Our judicial system has long operated under the assumption that it can only be "impartial enough." After all, judges, like all buman beings, harbor implicit biases that often are sizable, unconscious, and triggered automatically, and research indicates that strategies to curb implicit biases in buman decision-making may be ineffective, especially in the face of the resource and caseload constraints of modern-day adjudication. The recent emergence of online court proceedings, however, offers new bope for curtailing disparities. By allowing hearings to occur without face-to-face interactions, online legal proceedings may lessen the salience of group-identity traits, thereby mitigating unwarranted disparities and enhancing the impartiality of the justice system. Yet online proceedings differ from in-person hearings in ways beyond merely reducing the salience of age, gender, and race — and these differences may also influence group-based outcome disparities. Using state-court data, we study group-based disparities in online and offline civil-infraction cases. We present evidence that is consistent with the existence of implicit or other structural biases in face-to-face proceedings; all else equal, legal outcomes appear to vary by litigant age and race but not by gender. These disparities fade with the change in medium, possibly by circumventing implicit biases. We explore the implications of our findings for system impartiality and weigh the challenges confronting efforts to realize substantive, procedural, and digital justice in online courts.
\end{abstract}

* Assistant Professor, School of Criminology, University of Haifa; Henry King Ransom Professor of Law, University of Michigan Law School; and Associate Professor, Law Faculty, University of Haifa, respectively. We are grateful to the staff at Court Innovations Inc. and two Michigan district courts for sharing their data, expertise, and time; and to German Marquez Alcala, Cade Boland, Jonathan Edelman, Simmon Kim, Tomer Hazut, Chris Pryby, Chelsea Rinnig, and Jeremy Shur for excellent research assistance. We are also grateful to Judge Ketanji Brown Jackson of the U.S. District Court for the District of Columbia, Bert Huang, Carrie Menkel-Meadow, Janet Martinez, as well as faculty at the University of Haifa and the Courts \& Legal Process Workshop at Columbia Law School for insightful comments. Conflict disclosure: Prescott is a cofounder and has an equity interest in Court Innovations Inc., a company that develops and implements online dispute-resolution systems, including Matterhorn, which the Article discusses and evaluates. 


\section{INTRODUCTION}

Impartiality stands as a long-established and central pillar of a just legal system, ${ }^{1}$ and an impartial decision maker ${ }^{2}$ — someone who is independent, neutral, disinterested, unbiased, and guided solely by law- has long been seen as an indispensable feature of fair and legitimate judicial proceedings. ${ }^{3}$ Recently, however, research has cast significant doubt on the ability of human decision makers to achieve complete or full impartiality by uncovering persistent disparities in judicial decisions, many of which correlate with the visible group-identity markers of parties. ${ }^{4}$ One plausible explanation for these disparities is grounded in social-science research, which has exposed widespread and inevitable biases, heuristics, and stereotypes in human thought processes that operate on behavior automatically and, at times, unconsciously. 5 These findings, when applied to the legal realm, illuminate the many ways in which "implicit bias" may shape judicial decision-making, resulting in disparities in legal outcomes that are a direct function of a litigant's group identity. ${ }^{6}$

Judicial biases of any sort in decision-making are not the only plausible explanation of identity group-based outcome disparities, however. ${ }^{7}$ Legal systems

1. See Charles Gardner Geyh, The Dimensions of Judicial Impartiality, 65 FLA. L. REV. 493, 498-506 (2014) (tracking judicial impartiality as a value in Western history, philosophy, and literature); Martin Jay, Must Justice Be Blind? The Challenge of Images to the Law, in LAW AND THE IMAGE: THE AUTHORITY OF ART AND THE Aesthetics OF LAW 65, 68-69 (Costas Douzinas \& Lynda Nead eds., 1999) (tracing the history of the blindfolded Lady Justice and stating that, although initially satirical, "[b]y 1530 . . the blindfold was transformed instead into a positive emblem of impartiality and equality before the law" and that "this impartiality was required by the new urban, secular, bourgeois culture of the early modern period, which left behind the personalism of private, feudal justice").

2. Leviticus 19:15 ("Ye shall do no unrighteousness in judgment: thou shalt not respect the person of the poor, nor honour the person of the mighty: but in righteousness shalt thou judge thy neighbour."); see also Geyh, supra note 1, at 512 ("For over two thousand years, being a good judge has meant being an impartial judge.").

3. See Martin Shapiro, Courts: A Comparative And Political Analysis 1-8 (1981).

4. See, e.g., Carlos Berdejó, Criminaližng Race: Racial Disparities in Plea-Bargaining, 59 B.C. L. REv. 1187, 1207-40 (2018) (demonstrating racial disparities in sentencing and plea bargaining, where black defendants are more likely than white defendants to be convicted for crimes carrying the possibility of imprisonment and less likely to receive sentence reductions); Brian D. Johnson, Racial and Ethnic Disparities in Sentencing Departures Across Modes of Conviction, 41 CRIMINOLOGY 449, 464-78, 482 (2003) (analyzing “departures"-where defendants receive sentences that depart from the recommended range of punishment for a certain crime-and finding that black and Hispanic defendants are more likely than white defendants to receive upward departures and less likely to receive downward departures).

5. See infra notes 60-64 and accompanying text.

6. See infra Part I.B. Importantly, attempts to reduce outcome disparities through measures like requiring more deliberate decision-making and reducing judicial discretion have proved to be at least somewhat unsuccessful. See infra Part I.D (examining the nature of implicit biases and the practical constraints to resolving them in the modern court system).

7. Litigation procedure may cause disparate outcomes if it systematically influences substantive trial outcomes - and this seems to be the case even in relatively minor disputes. See, e.g., Roselle L. Wissler, Mediation and Adjudication in the Small Claims Court: The Effects of Process and Case Characteristics, 29 LAW \& SOC'Y REV. 323, 335-37 \& tbl.1 (1995). Wissler's empirical analysis of small-claims disputes finds that "the successful mediation and adjudication groups could be distinguished with $85 \%$ accuracy on the basis of . . 10 process characteristics," including session length, whether the presiding official is hurried, whether few solutions were 
must rely on innumerable procedures for courts to arrive at outcomes with some measure of consistency, ${ }^{8}$ and even facially neutral procedures can result in disparate playing fields vis-à-vis social groups-echoing socioeconomic and cultural differences and ending in identity-group-based disparities in the substantive outcomes of litigated disputes. ${ }^{9}$ Difficult to detect or isolate empirically, or even to predict ex ante, these structural biases detract from our justice system's impartiality even though they do not stem from explicit or implicit judicial bias. Instead, by definition, they are rooted in and emanate from fixed and uniformly applied litigation procedures. ${ }^{10}$ An illustration of this dynamic can be found in the now-standard methods by which U.S. tribunals assemble evidence (e.g., defaulting to requiring parties to testify in person in open court), which might in fact impede the ability of particular social groups to effectively convey their observations or preferences. ${ }^{11}$

discussed, whether parties were given control over the presentation or opportunity to tell their story, whether the discussion was thorough, whether parties had control over the outcome, whether the procedure was formal and/or open, whether the procedure was understandable, and whether there was discussion or argument. Id. at 335. Although not a consideration in this analysis, representation—and its quality-factors heavily into disparate court outcomes. See L. Song Richardson \& Phillip Atiba Goff, Implicit Racial Bias in Public Defender Triage, 122 YALE L.J. 2626, 2635-41 (2013); Molly J. Walker Wilson, Defense Attorney Bias and the Rush to the Plea, 65 U. KAN. L. REV. 271, 283 (2016) ("Differences in socio-economic background, education, and race can influence even diligent defense attorneys powerfully, and without the attorneys being conscious of them."). Cf. Leandra Lederman \& Warren B. Hrung, Do Attorneys Do Their Clients Justice? An Empirical Study of Lanyers' Effects on Tax Court Litigation Outcomes, 41 WAKE FOREST L. REV. 1235, 1253 (2006) (contending that lawyers have "more accurate information than pro se litigants do about likely outcomes at trial" and that legal representation leads to statistical improvements for client outcomes in Tax Court litigation).

8. See, e.g., Brian J. OStrom et Al., NAT’L CTR. For StATE Courts, ASSESSing CONSISTENCy AND FAIRNESS IN SENTENCING: A COMPARATIVE STUdy IN THREe STATES 1 (2008), https://www.ncsc.org/ / media/Microsites/Files/CSI/Assessing\%20Consistency.ashx (positing that sentencing guidelines are procedures designed, in part, to ensure consistent sentencing outcomes).

9. For example, assume that groups with different identity markers vary in their preferred mode of argument in a face-to-face setting. See, e.g., Janet E. Ainsworth, In a Different Register: The Pragmatics of Powerlessness in Police Interrogation, 103 YALE L.J. 259, 271-92 (1993) (explaining that vocal registers and linguistic patterns are linked to gender, ethnicity, socioeconomic class, and the power dynamics in the particular interaction). If these different argument modes are differentially effective in a courtroom setting, we might find outcome disparities that have nothing to do with implicit biases. In principle, any observable, grouplevel, procedurally relevant differences could be measured and accounted for in empirical work, but data challenges abound in studying litigation procedures, dynamics, and outcomes. But see Brian D. Johnson, Contextual Disparities in Guidelines Departures: Courtroom Social Contexts, Guidelines Compliance, and Extralegal Disparities in Criminal Sentencing, 43 CRIMINOLOGY 761, 786-89 (2005) (finding that seemingly neutral factors such as courtroom size affect rates of sentencing departures).

10. As an illustration, scholars have suggested that the Court's decision in Ashcroft v. Iqbal, 556 U.S. 662 (2009), which heightened the standard of review for Rule 12(b)(6) motions, embeds bias within the Federal Rules of Civil Procedure. See, e.g., Jerry Kang et al., Implicit Bias in the Courtroom, 59 UCLA L. REv. 1124, 115963 (2012) (arguing that the facially neutral plausibility standard suffers from the fact that plausibility is ultimately subjective); Ramzi Kassem, Implausible Realities: Iqbal's Entrenchment of Majority Group Skepticism Towards Discrimination Claims, 114 PeNn ST. L. REV. 1443, 1458-64 (2010) (same).

11. For instance, the requirement that a litigant be physically present in court can hurt low-income individuals and their families. See Maximilian A. Bulinski \& J.J. Prescott, Online Case Resolution Systems: Enhancing Access, Fairness, Accuracy, and Efficiency, 21 MICH. J. RACE \& L. 205, 224-25 (2016) (explaining how spending half a day at court may be prohibitively expensive for low-income workers, who are disproportionately from minority groups). 
As it became too much to expect modern judicial systems to achieve absolute impartiality in legal outcomes, debate simmered over how best to address the myth or paradox of judicial impartiality. ${ }^{12}$ An equilibrium of sorts eventually emerged: on the one hand, impartiality continues to serve as an abstract and aspirational ideal for our courts, and on the other hand, full or true impartiality is taken to be impossible given human and structural constraints associated with conventional legal process, which can produce at best "impartial enough" legal outcomes. ${ }^{13}$ This equilibrium status quo has long seemed fixed and inevitable, given the architecture of judicial proceedings in which the decision-making process revolves around face-to-face oral interaction. ${ }^{14}$

And yet the recent rise of online hearings and other court proceedings, ${ }^{15}$ which transport evidentiary and decision-making processes to the online sphere (accessed through computers and mobile devices), holds promise as a catalyst for disrupting this "impartial enough" status quo, hopefully mitigating many of the remaining-and stubborn-group-based outcome disparities in our system. ${ }^{16}$ These technological innovations not only have the ability to make physical identity attributes of litigating parties (such as age, gender, and race) less salient during proceedings but also may change the nature of communication in litigation and rearrange the structure of the process, and any such disruption has the potential to reveal any long-hidden structural tendencies toward disparity, if not implicit bias in judicial decision-making. Thus, the arrival of online procedures presents an opportunity to better understand "impartiality" and the

12. See, e.g., Pat K. Chew \& Robert E. Kelley, Myth of the Color-Blind Judge: An Empirical Analysis of Racial Harassment Cases, 86 WASH. U. L. REV. 1117, 1156-58 (2009) (finding that, in federal workplace racial-harassment suits, a judge's race and political affiliation affects their adjudication); Sherrilyn A. Ifill, Judging the Judges: Racial Diversity, Impartiality and Representation on State Trial Courts, 39 B.C. L. REV. 95, 119-28 (1997) (contending that impartiality is more likely with a racially representative judiciary); Kathleen Mahoney, Judicial Bias: The Ongoing Challenge, 2015 J. Disp. RESOL. 43, 66 (advocating that judges be educated about the social factors that threaten their impartiality); Fatma E. Marouf, Implicit Bias and Immigration Courts, 45 NEW ENG. L. REV. 417, 431-34 (2011) (reasoning that extraordinarily high caseloads, among other factors, leave little time for immigration judges to engage in deliberate thinking, which threatens their impartiality). Various scholars have referred to impartiality in the court setting as a "myth," a "fiction," or an "elusive ideal." E.g., Geyh, supra note 1, at 495, 510; Kathleen E. Mahoney, Essay, The Myth of Judicial Neutrality: The Role of Judicial Education in the Fair Administration of Justice, 32 WiLLAMETTE L. REV. 785 (1996) [hereinafter Mahoney, The Myth of Judicial Neutrality]. Even the goal of being "impartial enough" is elusive. See Geyh, supra note 1, at 510.

13. See Geyh, supra note 1, at 493, 510 .

14. See, e.g., U.S. CONST. amend. VI (Confrontation Clause); Coy v. Iowa, 487 U.S. 1012, 1020-22 (1988) (holding that a defendant's confrontation right was violated when the state used a screen at trial to prevent his alleged child victims from seeing him while they testified); In re Gust, 345 N.W.2d 42, 45 (N.D. 1984) (reasoning that telephonic depositions are strongly disfavored because they inhibit insight into the witness's credibility). But see Maryland v. Craig, 497 U.S. 836, 857 (1989) (holding that the Confrontation Clause permits testimony by one-way closed-circuit television "where necessary to protect a child witness from trauma that would ... impair the child's ability to communicate").

15. See J.J. Prescott, Improving Access to Justice in State Courts with Platform Technology, 70 VAND. L. ReV. 1993, 1999-2000 (2017) (surveying court adoption of ODR); Zack Quaintance, Judges, Private Sector Spread Online Dispute Resolution in Courts, GOV'T TECH. (Mar. 20, 2019), https://www.govtech.com/publicsafety/Judges-Private-Sector-Spread-Online-Dispute-Resolution-in-Courts.html (discussing the growth of online dispute resolution).

16. See infra Part II. 
varied sources of group-based outcome disparities in our courts and, on a broader level, to underscore the connection between the design of legal processes and courts and the fairness of the outcomes they produce.

In this Article, we explore the consequences of introducing online procedures on social-group-identity outcome disparities. We posit that the obscuring of identity attributes - coupled with the enhanced structure (i.e., less procedural discretion) that comes with software design and the ability to testify or communicate over the Internet from afar-will engender fewer disparities in outcomes across social groups and more consistency (and hence impartiality) in legal decision-making. ${ }^{17}$ We test our hypothesis empirically with case-level data using a quasi-experiment: the plausibly exogenous adoption and implementation of online dispute-resolution (ODR) procedures in two state district courts in the United States. Our data allow us to compare differences in litigation outcomes reached in face-to-face procedures relative to ODR-style hearings for civil infractions by party age, gender, and race.

We find that the shift from traditional in-person judicial proceedings to online (or at least differently organized) proceedings reduces measured age- and race-based disparities in litigation outcomes. ${ }^{18}$ On the basis of these results, we contend that online proceedings (when otherwise legally and ethically appropriate) may succeed at diminishing group-based disparities that arise from face-toface traditional hearings as they are currently structured. ${ }^{19}$ At the same time, we recognize that any gains in impartiality may, at times, come with accuracy and legitimacy costs when interpersonal interaction and attention to the particulars of the case and party identity are important. ${ }^{20}$ In addition, we acknowledge that our empirical results emerge from a particular court system, a narrow range of case types, and a specific ODR platform technology. ${ }^{21}$ Nevertheless, our work confirms the practical significance of process design to legal-system impartiality and fairness, and it does so contemporaneously with the nascent exponential growth - both nationally and globally - in the use of digital technology in dispute resolution and the availability of online proceedings. ${ }^{22}$

17. Precedent for this idea can be found within the medical profession, which has been exploring identity obfuscation as a way to reduce healthcare disparities. See, e.g., Sande Okelo et al., Race and the Decision to Refer for Coronary Revascularization: The Effect of Physician Awareness of Patient Ethnicity, 38 J. AM. C. CARDIOLOGY 698, 701-02 (2001) (finding that examining only clinical factors leads to similar treatment of white and black patients but that disparities arise when race is introduced into files).

18. See infra Part II.D.

19. See infra Part III.A.

20. And as courts shift from physical to textual or virtual interaction, different biases may shape judicial decisions reached online. For a short discussion of the challenges and trade-offs associated with the shift to online courts, see infra Part III.B.

21. See infra Part II.D.5.

22. See, e.g., Quaintance, supra note 15 (describing the expansion of online dispute resolution and how the technology fosters efficiency and "genial solutions to disputes"). 
Our Article proceeds as follows. In Part I, we describe the gap between the quest for impartiality and the reality of disparate judicial outcomes across identifiable groups. We elaborate on two possible sources for this reality: the influence of implicit biases in decision-making and the existence of structural biases stemming from the specifics of legal-process design. ${ }^{23}$ We note particularly that the salience of identity features in the face-to-face court setting, combined with the spread of managerial judging practices and informal hearings that broaden the scope of judicial discretion, can exacerbate implicit biases, ${ }^{24}$ perhaps adding to any existing structural biases. Part II presents empirical analysis from realworld adoption and use of online court proceedings. We demonstrate that the shift from typical face-to-face court proceedings to online hearings appears to reduce measured litigant age- and race-based disparities in legal outcomes, with little evidence of it affecting gender dynamics. Part III situates our case study and its results within the broader context of fair, just, and effective court proceedings in the digital age, exploring both the benefits and the costs associated with the vision of realizing impartiality in the online setting.

\section{IMPARTIALITY AND DISPARITIES IN LEGAL OUTCOMES}

\section{A. The Equilibrium}

Impartiality is perhaps the basic principle of a just legal system. ${ }^{25}$ It is seen as a normative prerequisite for legal judgment, ${ }^{26}$ and it is essential for ensuring the legitimacy of the legal system and the judicial branch of government in particular. ${ }^{27}$ Although it is likely that virtually all agree on the centrality of impartiality as a fundamental legal principle, its formal definition is more elusive, with many referring alternatively to various facets of this complex notion. Typically, discussions of impartiality focus on the necessity of evenhanded decision makers (in the legal setting, of judges and their staffs), ${ }^{28}$ although the impartiality of

23. See infra Parts I.A-C.

24. See infra Part I.C.

25. See supra note 1.

26. The centrality of impartiality in the rule of law has roots in moral philosophy, both in the sense of identity blindness and in the requirement for a consistent application of any moral principle. The supremacy of principle over the characteristics and interests of the parties or the decision maker is echoed in the Kantian notion of "moral maxims" and in the Rawlsian notion of the "veil of ignorance." The moral maxims were portrayed as a priori moral principles that must be applied in all contexts by all humans to all humans. See, e.g., IMMANUEL KANT, GROUNDWORK FOR THE METAPHYSICS OF MORALS 40 (Allen W. Wood ed. \& trans., Yale Univ. Press 2002) (1785); JOHN RAWLs, A TheORY OF JustiCE 114 (rev. ed. 1999). The identity and contextual blindness for which the philosophical traditions of Kant and Rawls advocate, however, have been the subject of critique regarding both the desirability and feasibility of this abstraction in realizing substantive justice. See infra note 389; infra Part III.B.1.

27. See Anne Richardson Oakes \& Haydn Davies, Process, Outcomes and the Invention of Tradition: The Growing Importance of the Appearance of Judicial Neutrality, 51 SANTA CLARA L. REV. 573, 573 (2011).

28. See Henry T. Lummus, Our Heritage of Impartial Justice, 22 J. AM. Judicature SOC’Y 243, 243-44 (1939) (reasoning that impartial justice demands decisions based solely on law and evidence, without regard 
legal proceedings or of the justice system as a whole of course remains in jeopardy even without decision-maker biases of any sort. We consider these latter, facially neutral phenomena below when we address structural-design disparities in adjudication. We begin here with judicial impartiality, the more common arena in which scholars examine and defend impartiality.

The first sense in which we expect impartiality from judges can be labeled a negative view of impartiality. This notion captures the need for judges to withdraw from judicial decision-making when they would not be neutral, objective, disinterested, or "unswayed by personal interest." 29 This negative take on a judge's duty is perhaps the most intuitive understanding of impartiality. At the same time, it is a rather narrow understanding of the term, which simply announces when judges should be disqualified from deciding entire cases or disputes but provides little positive instruction on how to maintain, actively develop, or foster impartiality in the real-world situations in which judges must - in order to avoid an unfair status quo_-make decisions.

The more affirmative or substantive component of judicial impartiality is defined positively; it relates to the necessary environmental conditions or steps judges or a justice system must take to ensure impartial decision-making when judges are qualified in the negative sense we describe above or are otherwise required to adjudicate a dispute. If the negative understanding of impartiality instructs judges about what they should avoid (such as adjudicating cases that affect their interests or ruling on issues using their personal preferences and prejudices as touchstones), the positive element guides judges in how and what they ought to consider in arriving at their decisions (that is, the law-both procedural and substantive - and facts that are germane to the law). ${ }^{30}$ When both aspects of impartiality are firmly in place, we assume that judges should "[b]e able to think dispassionately and submerge private feelings on every aspect of

to external pressures); see also Melissa E. Loewenstern, The Impartiality Paradox, 21 YALE L. \& POL’Y REV. 501, 503-05 (2003) (characterizing the neutral judge as the central precept of the adversary system).

29. Impartial, BLACK'S LAW DictionARY (10th ed. 2014); see also 28 U.S.C. \ 455(a) (2018) (“Any justice, judge, or magistrate judge of the United States shall disqualify himself in any proceeding in which his impartiality might reasonably be questioned.”).

30. For an analysis of the ways various procedural arrangements subtly enhance judicial impartiality by preventing prejudgment and allowing for appellate review, see Geyh, supra note 1, at 520-29. 
the case,"31 conduct fair proceedings that are likely to produce accurate results, and announce principled and reasoned decisions. ${ }^{32}$

If the arrangements guaranteeing both positive and negative aspects of impartiality are successful in producing unbiased decision-making by judges, then we would expect similar cases to be handled with similar (i.e., consistent) legal proceedings and to result in similar outcomes. ${ }^{33}$ In this sense, consistency can serve as an important signal of judicial commitment to impartiality, and likewise, the lack thereof may indicate that a judge's decision may have been based on irrelevant or inappropriate considerations. ${ }^{34}$ In this framework, the impartial application of judicial discretion does tolerate certain variations in outcomes across similar cases (for example, legitimate differences across judges in punishment philosophies), but for outcomes to be "impartial," such variation-so long as it is not grounded in bias_-should not correlate with whether litigants are members of a particular identity group (e.g., age, gender, or race) or any other characteristic or consideration irrelevant to the dispute or task..$^{35}$

Reality, however, is at odds with this aspiration. Over the years, it has become increasingly clear that a system's or judge's explicit commitment (and even strong devotion) to impartiality in both the negative and positive senses

31. Peter M. Friedman, Comment, Don't I Know You from Somewhere?: Why Due Process Should Bar Judges from Presiding over Cases When They Have Previously Prosecuted the Defendant, 88 J. CRIM. L. \& CRIMINOLOGY 683, 703 (1998) (alteration in original) (quoting Pub. Util. Comm'n v. Pollak, 343 U.S. 451, 466 (1952)). But see Kathy Mack \& Sharyn Roach Anleu, Performing Impartiality: Judicial Demeanor and Legitimacy, 35 LAW \& SOC. INQUIRY 137, 138 (2010) ("[A] legitimate exercise of judicial authority . . . requires a judicial demeanor that displays detachment as well as engagement."); Richard Zorza, The Disconnect Between the Requirements of Judicial Neutrality and Those of the Appearance of Neutrality When Parties Appear Pro Se: Causes, Solutions, Recommendations, and Implications, 17 GEO. J. LEGAL ETHICS 423, 431 (2004) (offering a different understanding of neutrality as nonpassive, at least in certain contexts and settings). This concept is premised on the distinction between impartiality toward the parties and neutrality toward the issues in the case. See Joe Cutler, Oops! I Said It Again: Judicial Codes of Conduct, the First Amendment, and the Definition of Impartiality, 17 GEO. J. LEGAL ETHICS 733, 740 (2004); Ralph Slovenko, “Je Recuse!”: The Disqualification of a Judge, 19 LA. L. REv. 644, 648 (1959). But one might question the ability to separate the two because identity may influence how someone thinks about an issue. See infra Part I.D (discussing the justifications for judicial diversification).

32. The most immediate and obvious arrangements that encourage judges to be impartial are court procedures such as recusal rules (part of the due process requirement), see Geyh, supra note 1, at 515-18, and judicial ethical rules (and related disciplinary proceedings), see id. at 515-18, 523-29.

33. William E. Nelson, History and Neutrality in Constitutional Adjudication, 72 VA. L. REV. 1237, 1265 (1986).

34. Of course, tying impartiality or neutrality to consistency in outcomes depends on one's approach toward the meaning of neutrality. In recent years, in the dispute-resolution literature, an alternative view of neutrality has been advanced in which decision makers do not distance themselves from the parties but are instead equally close to each. See, e.g., Sara Cobb \& Janet Rifkin, Practice and Paradox: Deconstructing Neutrality in Mediation, 16 LAW \& SOC. INQUIRY 35, 41-46 (1991) (describing the discontinuity between two different notions of neutrality in mediation: "neutrality-as-impartiality," which requires detachment, and "neutralityas-equidistance," which requires proactive involvement); Susan Sturm \& Howard Gadlin, Conflict Resolution and Systemic Change, 2007 J. DiSP. RESOL. 1, 4 (advocating for "multi-partiality," a form of neutrality involving "critically analyzing a conflict from multiple vantage points ... as a way to check the inevitable biases in decision making that must be continually surfaced and corrected").

35. See H.L.A. HART, THE CONCEPT OF LAW 156-57 (1961) (equating impartiality in the law with objectivity and reasoning that both demand the "law [be] applied to all those and only to those who are alike in the relevant respect marked out by the law itself'). 
can neither eliminate outcome disparities nor fully inoculate judges against potential biases, chiefly unconscious ones. This realization emerged from developments on at least two fronts. The first is the large and growing body of work in the social sciences exposing the existence and indeed pervasiveness of unconscious human biases, stereotypes, and heuristics. ${ }^{36}$ These systematic distortions affect both decision-making and behavior and therefore have important consequences for all human institutions. ${ }^{37}$ The second significant development is the evolving and now-extensive volume of research uncovering and documenting systematic disparities in legal outcomes in what are similar cases-differences that align with a party's group-identity markers (mainly race) even after controlling for other individual dissimilarities. ${ }^{38}$

These disparities cannot easily be attributed to explicit violations of either the negative notion of impartiality (i.e., that judges refrain from deciding cases in which they have a personal interest in or a connection to the parties or issues at stake) or the positive concept of impartiality (i.e., that judicial decision-making should be expressly reasoned in a way that places any outcome in question within the boundaries of the law). Thus, one explanation for the prevalence of disparities in litigation outcomes is that they derive 1) from the structure of legal process itself and/or 2) from systematic cognitive and behavioral biases that

36. E.g., Mahzarin R. Banaji \& Anthony G. Greenwald, Blindspot: Hidden Biases of GOOD PEOPLE 47-49 (2013) (“[A]lmost 75 percent of [Americans] who take the Race IAT [Implicit Association Test] ... reveal automatic White preference. .. The meta-analysis ... clearly showed that the Race IAT predicted racially discriminatory behavior.”); see also Anthony G. Greenwald \& Linda Hamilton Krieger, Implicit Bias: Scientific Foundations, 94 CALIF. L. REV. 945, 955-57 \& tbl.1 (2006) (“[O]nly 18\% of respondents demonstrated sufficiently small implicit bias to be judged implicitly neutral.”).

37. E.g., BANAJI \& GREENWALD, supra note 36, at 47 (“[A]utomatic White preference expressed on the Race IAT is now established as signaling discriminatory behavior."). Such preferences manifest, for example, as preferring white over black job applicants or more readily perceiving anger in black faces than in white faces. $I d$. at 49.

38. See, e.g., Joan Petersilia, Racial Disparities in the Criminal Justice System: A Summary, 31 CrimE \& DELINQ. 15, 20-21 \& tbl.2 (1985) (finding that, starting with similar charges, black and Hispanic suspects are less likely than white suspects to receive felony-misdemeanor charge reductions and more likely to receive prison sentences); Katherine B. Spencer et al., Implicit Bias and Policing, 10 SoC. \& Personality Psychol. COMPASS 50, 53 (2016) (citing Jack Glaser, The Efficacy and Effect of Racial Profiling: A Mathematical Simulation Approach, 25 J. POL’Y ANALYSIS \& MGMT. 395 (2006)) (“[F]ocusing law enforcement on members of a minority group can create and exaggerate disparities in criminal justice outcomes ...."); Michael Tonry, The Social, Psychological, and Political Causes of Racial Disparities in the American Criminal Justice System, 39 CRIME \& JusT. 273, 274 (2010) ("[A] combination of police practices and legislative and executive policy decisions... systematically treat black offenders differently, and more severely, than whites."); Patricia Warren et al., Driving While Black: Bias Processes and Racial Disparity in Police Stops, 44 CriminOLOGy 709, 731 (2006) ("In general, we find a fairly large race disparity in local police officer stops and a very small one in highway patrol stops.”). These studies investigate the criminal justice system, but the same phenomenon appears to exist elsewhere in our justice system. See, e.g., Kang et al., supra note 10, at 1164 (speculating that implicit biases affect juror decision-making in the context of civil trials); Loren D. Goodman, Note, For What It's Worth: The Role of Race- and Gender-Based Data in Civil Damages Awards, 70 VAND. L. REV. 1353, 1356 (2017) (discussing the continued use of race- and gender-based data in the calculation of civil damages); cf. Gary LaFree \& Christine Rack, The Effects of Participants' Ethnicity and Gender on Monetary Outcomes in Mediated and Adjudicated Civil Cases, 30 LAW \& SOC'Y REV. 767, 788-89 (1996) (reporting that "bivariate results offer considerable support for a disparity hypothesis" but conceding that multivariate analysis indicates the disparities may be explained by case-specific and repeat-player variables rather than by race and gender). 
can impact judicial decision-making. ${ }^{39}$ Judges are likely unaware of either dynamic, but implicit biases, ${ }^{40}$ in particular, operate in subtle, untraceable ways, tied inextricably to the identities of the judges and the parties. ${ }^{41}$

\section{B. Implicit Judicial Biases}

What constitutes a judicial "bias"? As we use the term, judicial biases exist when judges make legal decisions that are based in part on parties' social identity traits. Outcomes are thus systematically influenced by information that is irrelevant from a legal perspective. ${ }^{42}$ In this Article, we examine group-based biases that may be traceable to a party's age, gender, or race. Scholars have defined and studied group-based biases in judicial decision-making by drawing on social-scientific insights where the term group-based biases refers to systematic differences in how someone perceives specific individuals as a function of their group affiliations or social identities. ${ }^{43}$ When apparent differential treatment

39. See Kang et al., supra note 10, at 1126; see also infra Part I.B.

40. See, e.g., Jeffrey J. Rachlinski et al., Does Unconscious Racial Bias Affect Trial Judges?, 84 NOTRE DAME L. REV. 1195, 1209-11 (2009) (presenting results from an Implicit Association Test (IAT) demonstrating unconscious racial biases among judges).

41. See, e.g., Kang et al., supra note 10, at 1146-48; Rachlinski et al., supra note 40, at 1210 (observing in their data that white judges displayed a strong white preference on the IAT while black judges "demonstrated no clear preference overall").

42. This definition includes a wide array of possible biases, some stemming from judges' predisposition toward or against specific people or groups or their preexisting views on specific issues. Other biases can arise from influences that the law deems irrelevant or inappropriate, such as evidence obtained in violation of due process or the characteristics of a defendant, like a prior criminal record. See generally A. N. Doob \& H. M. Kirshenbaum, Some Empirical Evidence on the Effect of s. 12 of the Canada Evidence Act Upon an Accused, 15 CRIM. L.Q. 88 (1972) (prior criminal record); Edith Greene \& Mary Dodge, The Influence of Prior Record Evidence on Juror Decision Making, 19 LAW \& HuM. BEHAV. 67 (1995) (prior convictions and prior acquittals); Kerri L. Pickel, Inducing Jurors to Disregard Inadmissible Evidence: A Legal Explanation Does Not Help, 19 LAW \& HuM. BEHAV. 407 (1995) (inadmissible hearsay and prior criminal record).

43. The term social identity refers to one's group identity. For the formulation of social identity theory, see generally Henri Tajfel \& John C. Turner, The Social Identity Theory of Intergroup Behavior, in PSYCHOL. INTERGROUP RELATIONS 276 (Stephen Worchel \& William G. Austin eds., 1986). Group-based biases are typically assessed by examining how people perceive target individuals belonging to different social groups (for example, women versus men, black versus white). This is done by either providing perceivers with no information on the targets they judge apart from their group identities, which is the zero-information paradigm of the IAT, see Rachlinski et al., supra note 40, at 1209 \& n.72, and infra notes 72-73 and accompanying text, or by providing perceivers with the exact same information about the targets they judge, see, e.g., Corrine A. Moss-Racusin et al., Science Faculty's Subtle Gender Biases Favor Male Students, 109 PROC. NAT’L ACAD. SCI. 16,474, 16,474-75 (2012). The Moss-Racusin et al. study provided participants with identical job application materials - other than the gender of the job candidate. Id. at 16,475. Given the study's design, any outcome discrepancies between groups could not be attributed to relevant considerations because such considerations were either not provided or were held constant. Id. at 16,478. Rather, discrepancies must have been due to implicit or explicit prejudices about different social groups. The study of courtroom biases relies on similar logic: examining whether systematic discrepancies in judicial decisions exist as a function of the parties' or the adjudicators' group identities, where all legally relevant information is held constant. See, e.g., Jennifer L. Eberhardt et al., Looking Deathworthy: Perceived Stereotypicality of Black Defendants Predicts Capital-Sentencing Outcomes, 17 Psychol. SCI. 383, 383 (2006); Guy Grossman et al., Descriptive Representation and Judicial Outcomes in Multiethnic Societies, 60 AM. J. POL. SCI. 44, 45 (2016). 
across these groups cannot be linked to legally valid considerations, researchers often ascribe the outcome disparities to explicit or implicit judicial bias. ${ }^{44}$

One important line of research examines how judicial characteristics, such as race and gender, affect a judge's decision-making. ${ }^{45}$ The initial goal of this area of research was not to detect biases per se but rather to examine the impact of policymaker efforts to diversify the judiciary. ${ }^{46}$ Perhaps surprisingly, the findings of these studies tend to indicate that, apart from a few exceptions, judges' group identities - their gender, race, and even political ideology — do not have sweeping consequences for their judicial approach, reasoning, or decision-making. ${ }^{47}$ Before researchers arrived at this general conclusion, more than a few commentators proposed that female judges might "adjudicate in a "different voice' . . . to favor community concerns and family preservation." 48 Some predicted that female judges, for example, would be more lenient in sentencing because "women are slightly more liberal than men on a variety of issues, including those related to crime control." 49 Research does not support this hypothesis. ${ }^{50}$ Indeed, contrary to stereotypes, at least some research demonstrates that women may be harsher than men when they sentence individuals. ${ }^{51}$ That said, much of this evidence is anecdotal; more rigorous research concludes that "while feminist ... theories of judging abound, female judges do not appear to adopt significantly different approaches to judging from those taken by their

44. Looking to individual characteristics to explain disparities forms the methodological basis for much of the judicial-bias-in-sentencing literature. See, e.g., David B. Mustard, Racial, Ethnic, and Gender Disparities in Sentencing: Evidence from the U.S. Federal Courts, 44 J.L. \& ECON. 285, 296-98 \& tbl.6 (2001) (using race and gender as explanatory variables for sentence length).

45. Although this literature does examine whether a judge's group-based identity affects judicial outcomes, it is usually framed as exploring whether "extralegal considerations"- rather than "biases"-influence judicial decision-making. These findings tend not to be classified under the rubric of "biases" because it is difficult to determine what constitutes the benchmark for a nonbiased decision. For example, with genderbased disparities in judicial decisions pertaining to sexual crimes, it is unclear who would represent the standard of unbiased, neutral judgments: female judges and their harsher standards (perhaps better informed) or male judges who may be more lenient (perhaps more objective)? Even if not framed as "biases," these findings nevertheless show that extralegal considerations affect judicial decision-making, so we see them as challenges to the goal of judicial neutrality. Ostensibly attempting to restore impartiality, advocates have used these findings to make claims about the importance of judicial diversity. See infra Part I.D.

46. This research was catalyzed by the Carter Administration's push to diversify the judiciary. See Tracey E. George, Court Fixing, 43 ARIZ. L. REV. 9, 19 (2001) ("Jimmy Carter's efforts to diversify the federal bench resulted in the appointment of two Hispanics, one Asian American, and nine African Americans to the courts of appeals (representing twenty-one percent of his circuit appointments).”).

47. Id. at $23-25$.

48. Id. at 20 .

49. John Gruhl et al., Women as Policymakers: The Case of Trial Judges, 25 AM. J. POL. SCI. 308, 311 (1981).

50. In a study of more than 30,000 cases, the researchers tested for evidence of disparities as a function of judges' gender. See id. at 314 .

51. See, e.g., Darrell Steffensmeier \& Chris Hebert, Women and Men Policymakers: Does the Judge's Gender Affect the Sentencing of Criminal Defendants?, 77 SOC. FORCES 1163, 1174-77 (1999) (showing that women judges tend to be harsher in sentencing decisions and slightly harsher against young and black defendants). Despite these findings, the researchers conclude that similarities in both reasoning and decisions between female and male judges outweigh the differences between them. Id. at 1179, 1181-82. 
male colleagues." 52 Scholars have drawn a similar conclusion with respect to whether a judge's race or ethnicity affects their legal decision-making. ${ }^{53}$ Even when research does document effects of a judge's race in particular contexts, such effects are typically small and inconsistent, and they pale in importance when compared to individual differences between judges. ${ }^{54}$

Other lines of research speculate that a judge's group identity may not comprehensively influence all aspects of decision-making but instead may operate on a narrower scope, perhaps just in those domains specifically "linked" to the group's distinguishing trait. For instance, scholars have hypothesized that female judges might sentence individuals convicted of sexual crimes with greater punitiveness because women are the primary victims of such crime and because of their unique experience with, and perspective regarding, sexual violence. ${ }^{55}$ And research has shown that female judges are harsher than their male counterparts in sex offense and sex discrimination cases, displaying a tendency both to find liability more often and to impose more severe punishments. ${ }^{56}$ Similarly, research also suggests that black judges are more likely to rule in favor of affirmative-action plans and for plaintiffs in race-based discrimination cases when compared to their nonblack counterparts, intimating the possibility of a distinct approach to cases involving race-related issues. ${ }^{57}$ Interestingly, in a study of asylum decisions, scholars found that a judge's gender had a significant impact on a case's expected outcome, with asylum applicants having a $44 \%$ higher chance

52. George, supra note 46, at 21-22 (footnote omitted).

53. See, e.g., Thomas M. Uhlman, Black Elite Decision Making: The Case of Trial Judges, 22 AM. J. POL. SCI. 884, 891-92 (1978). But see Oren Gazal-Ayal \& Raanan Sulitzeanu-Kenan, Let My People Go: Etbnic In-Group Bias in Judicial Decisions_Evidence from a Randomized Natural Experiment, 7 J. EMPIRICAL LEGAL STUD. 403, 420-23 (2010); Moses Shayo \& Asaf Zussman, Judicial Ingroup Bias in the Shadow of Terrorism, 126 Q.J. ECON. 1447, 1448-49 (2011) (demonstrating the existence of judicial biases in Israel based on judges' ethnic affiliations).

54. George, supra note 46, at 23-25. Despite no general differences among judges, some race-based differences in outcomes emerge with respect to a defendant's race within specific contexts. See infra notes 7991 and accompanying text.

55. Cassia Spohn, Decision Making in Sexual Assault Cases: Do Black and Female Judges Make a Difference?, in 2 WOMEN \& CRIMINAL JustiCE 83, 87-88 (1990).

56. On finding liability, see, for example, Jennifer L. Peresie, Note, Female Judges Matter: Gender and Collegial Decisionmaking in the Federal Appellate Courts, 114 YALE L.J. 1759, 1778 (2005) (finding that the presence of a female judge on a panel increases the likelihood of ruling in favor of plaintiffs in cases involving sexual harassment or sex-related discrimination). See also Christina L. Boyd et al., Untangling the Causal Effects of Sex on Judging, 54 AM. J. POL. SCI. 389, 402-06 (2010) (reporting similar results). On sentencing severity, see Spohn, supra note 55, at 91 (concluding that although female judges do not appear to convict defendants in sexual assault cases more frequently than do their male counterparts, when sexual assault defendants are found guilty, female judges give these defendants harsher sentences-four years longer on average).

57. Jonathan P. Kastellec, Racial Diversity and Judicial Influence on Appellate Courts, 57 AM. J. POL. SCI. 167, 177 (2013) (finding that black judges are significantly more likely to support affirmative-action programs than white judges and that the presence of a single black judge on a panel increases the panel's likelihood of ruling in favor of affirmative action). 
of succeeding when assigned to a female judge. ${ }^{58}$ Some have viewed these findings as part of a larger trend in decision-making research toward identifying new instances in which a judge's gender influences litigation outcomes, at least when mixed judicial panels are involved.59 But, at present, the full significance and contours of any effect of a judge's group identity on judicial decision-making and outcomes remains, for the most part, unclear.

By contrast, the group identities and roles of parties have proven to be a significant factor in shaping judicial decisions, casting a deep shadow on our aspiration for judicial impartiality. The social psychology literature that documents the origin, meaning, manifestation, and measurement of implicit groupbased biases gives a convincing account for these patterns. Broadly speaking, implicit biases are rooted in "social categorization processes."60 Psychologists consider these processes a cognitive necessity because they impose order on an otherwise overly complex social environment and conserve limited cognitive resources. ${ }^{61}$ In the past, due to the social acceptability of certain beliefs, people could express their biases knowingly and willfully, either by consciously harboring stereotypes of certain social groups or by explicitly preferring people from their own group ("in-group") over outsiders ("out-group"). ${ }^{62}$ But in recent decades, changing social norms have made it socially unacceptable (and, for many,

58. Jaya Ramji-Nogales et al., Refugee Roulette: Disparities in Asylum Adjudication, 60 STAN. L. REv. 295, 342 (2007).

59. See generally Carrie Menkel-Meadow, Asylum in a Different Voice: Judging Immigration Claims and Gender, in Refugee Roulette: Disparities in ASylum Adjudication AND Proposals FOR ReForm 202 (Jaya Ramji-Nogales et al. eds., 2009).

60. Henri Tajfel et al., Social Categorization and Intergroup Behaviour, 1 EUR. J. SOC. PSYCHOL. 149, 153 (1971); see also Anthony G. Greenwald \& Mahzarin R. Banaji, Implicit Social Cognition: Attitudes, Self-Esteem, and Stereotypes, 102 Psychol. ReV. 4 (1995). For reviews, see generally Russell H. Fazio \& Michael A. Olson, Implicit Measures in Social Cognition Research: Their Meaning and Use, 54 ANN. REV. PsychOL. 297 (2003), and Anthony G. Greenwald et al., Understanding and Using the Implicit Association Test: III. Meta-Analysis of Predictive Validity, 97 J. PERSONALiTy \& SOC. PSYCHOL. 17 (2009). For an overview of "social categorization," see Richard J. Crisp \& Miles Hewstone, Multiple Social Categorization, 39 AdvanCES EXPERIMENTAL SoC. PSYCHOL. 163, 218-19 (2007).

61. Tajfel et al., supra note 60 , at 153 . The human need for social categorization has been linked to stereotypes - the attribution of qualities to individuals based solely on their group memberships-as well as to conflicting intergroup relations, because it facilitates an "us-versus-them" division. See generally Crisp \& Hewstone, supra note 60 (analyzing the complex links between social categorization and stereotypes). In the past, these manifestations of social categorization were largely explicit; that is, people knowingly harbored stereotypes for or against different social groups and willfully preferred those from their own group to outsiders. Katherine Cramer, Understanding the Role of Racism in Contemporary US Public Opinion, 23 ANN. REV. POL. SCI. 9.1, 9.2-9.5 (2019). In recent decades, as the explicit manifestation of stereotypes and biases has become socially unacceptable, people have embraced more egalitarian norms. John F. Dovidio \& Samuel L. Gaertner, Aversive Racism, 36 Advances Experimental Soc. Psychol. 1, 3-6 (2004); Simo V. Virtanen \& Leonie Huddy, Old-Fashioned Racism and New Forms of Racial Prejudice, 60 J. Pol. 311 (1998). This change, however, did not erase (and in some cases did not even much reduce) age-old gaps between individuals in dominant and marginalized groups in various areas, including health, education, and wealth. Cramer, supra, at 9.3-9.4. This paradox gave rise to theories highlighting the implicit and nuanced manifestations of contemporary prejudice. See, e.g., Dovidio \& Gaertner, supra, at 1.

62. Dovidio \& Gaertner, supra note 61, at 5. 
undesirable) to harbor or express such stereotypes and biases explicitly. ${ }^{63}$ This normative pressure toward egalitarianism has not eliminated the existence of these biases but has instead pushed at least some of them into the implicit, unconscious realm. ${ }^{64}$

The growing recognition of the prevalence and potential impact of implicit biases in decision-making and behavior is a consequence of two interrelated realizations. First, despite a significant normative commitment to egalitarian values and the rejection of explicit manifestations of stereotypes or biases, group-based disparities persist. ${ }^{65}$ Historically disadvantaged groups continue to lag on many dimensions, including health, education, income, and wealth. ${ }^{66} \mathrm{Sec}-$ ond, many social psychologists concluded that implicit attitudes and biases can be objectively and usefully measured. After devising several tools to assess the existence and strength of implicit bias, the most common and well-known of which is the Implicit Association Test (IAT), ${ }^{67}$ these scholars found that such biases are pervasive and systemic in society.

Like all tools and tests assessing implicit attitudes, the IAT is based on response latencies - that is, the time it takes for people to respond to specific

63. See id. at 3-6.

64. Id. at 3 ("Aversive racists, in comparison, sympathize with victims of past injustice, support the principle of racial equality, and regard themselves as nonprejudiced, but, at the same time, possess negative feelings and beliefs about blacks, which may be unconscious."); see also Tessa E. S. Charlesworth \& Mahzarin R. Banaji, Patterns of Implicit and Explicit Attitudes: I. Long-Term Change and Stability from 2007 to 2016, 30 PSYCHOL. SCI. 174, 182 (2019) (explaining the decreasing correlation between explicit and implicit biases, at least in part, by the changing social desirability of certain attitudes); Allison L. Skinner \& Jacob E. Cheadle, The "Obama Effect"? Priming Contemporary Racial Milestones Increases Implicit Racial Bias Among Whites, 34 Soc. COGNITION 544, 551 (2016) ("[P]riming the election of Barack Obama as a contemporary racial milestone increases implicit racial bias among Whites.").

65. Dovidio \& Gaertner, supra note 61, at 2. Long before the empirical advancement in the study of implicit attitudes, Charles Lawrence proposed the idea that motive-centered legal doctrines are insufficient to combat most forms of racial discrimination. He argued that because racial stereotypes are often harbored unconsciously, racial discrimination should be legally recognized based on discriminatory impact, irrespective of decision-maker motives. See Charles R. Lawrence III, The Id, the Ego, and Equal Protection: Reckoning with Unconscious Racism, 39 STAN. L. REV. 317, 343-44 (1987).

66. See, e.g., Alicia H. Munnell et al., Mortgage Lending in Boston: Interpreting HMDA Data, 86 AM. ECON. REV. 25, 50 (1996) (finding that black and Hispanic mortgage applicants are more likely to be turned down than similarly situated white applicants); see also Marianne Bertrand \& Sendhil Mullainathan, Are Emily and Greg More Employable Than Lakisha and Jamal? A Field Experiment on Labor Market Discrimination, 94 AM. ECON. REV. 991, 991-92 (2004) (reporting that black applicants are less likely to receive interview callbacks for job postings than similarly qualified white applicants); Gopal K. Singh et al., Social Determinants of Health in the United States: Addressing Major Health Inequality Trends for the Nation, 1935-2016, 6 INT’L J. MCH \& AIDS 139, 159-61 (2017); Raj Chetty et al., Race and Economic Opportunity in the United States: An Intergenerational Perspective, 135 Q.J. ECON. 711, 729-30 (2020); Linda Darling-Hammond, Unequal Opportunity: Race and Education, BROOKINGS (Mar. 1, 1998), https://www.brookings.edu/articles/unequal-opportunity-race-and-education; CJ Libassi, The Neglected College Race Gap: Racial Disparities Among College Completers, CTR. FOR AM. PROGRESS (May 23, 2018, 9:39 AM), https://www.americanprogress.org/issues/education-postsecondary/reports/20 18/05/23/451186/neglected-college-race-gap-racial-disparities-among-college-completers.

67. See Anthony G. Greenwald et al., Measuring Individual Differences in Implicit Cognition: The Implicit Association Test, 74 J. PERSONALITY \& SOC. PSYCHOL. 1464, 1465-66 (1998). 
stimuli. ${ }^{68}$ The IAT measures differences in how reflexive it is for people to associate certain social groups (e.g., white versus black, men versus women, old versus young, and so on) with abstract positive or negative evaluations (e.g., good versus bad, pleasant versus unpleasant). ${ }^{69}$ The reasoning behind the IAT is that the quicker people's responses are (in terms of their reaction time), the stronger the implicit association they make between the given group and the given evaluation. ${ }^{70}$ Systematic differences in the ease of association between stereotype-consistent stimuli (e.g., black and unpleasant, white and pleasant) and stereotype-inconsistent stimuli (e.g., young and unpleasant, old and pleasant) indicate the existence of implicit bias. ${ }^{71}$ Such biases are termed "implicit" in the sense that they occur "automatically, effortlessly, and outside of conscious awareness" 72 but nevertheless have been shown to affect actual behavior in significant ways. Importantly, implicit biases often do not correlate with explicit attitudes, so the conscious commitment to egalitarian values does not inoculate someone against the internalization of implicit biases. ${ }^{73}$ Moreover, even an explicit desire to circumvent or control the effects of implicit biases is, by itself, an insufficient means for reducing them. ${ }^{74}$
68. Id.
69. Id.
70. Id. at 1466 .
71. Id. at $1464-65$.

72. John T. Jost et al., The Existence of Implicit Bias Is Beyond Reasonable Doubt: A Refutation of Ideological and Methodological Objections and Executive Summary of Ten Studies that No Manager Should Ignore, 29 RES. ORGANiZATIONAL BeHAV. 39, 43 (2009). Jerry Kang and Mahzarin Banaji describe this process in terms of "racial mechanics": an individual (target) is mapped into a social category in accordance with prevailing legal and cultural mapping rules. Jerry Kang \& Mahzarin R. Banaji, Fair Measures: A Bebavioral Realist Revision of “Affirmative Action," 94 CALIF. L. REV. 1063, 1085 (2006). Once mapped, the category activates various meanings, including cognitive and affective associations that may be partly hardwired but are mostly culturally conditioned. $I d$. These activated meanings then alter the interaction between the perceiver and the target. Id. These processes occur automatically, without effort or conscious awareness on the part of the perceiver. See $i d$. at 1064-67, 1085 (using behavioral realism and the science of implicit social recognition to advocate for the revision of affirmative-action policies).

73. Dovidio \& Gaertner, supra note 61, at 18-19. For a meta-analysis of explicit and implicit attitudes, see Wilhelm Hofmann et al., A Meta-Analysis on the Correlation Between the Implicit Association Test and Explicit Self-Report Measures, 31 PersonAlity \& SOC. PSYCHOL. BulL. 1369 (2005) (finding that correlations between explicit and implicit attitudes are particularly weak in domains where there are strong social desirability concerns such as race- or gender-based biases).

74. Patricia G. Devine et al., The Regulation of Explicit and Implicit Race Bias: The Role of Motivations to Respond Without Prejudice, 82 J. PERSONALITY \& SOC. PSYCHOL. 835, 835 (2002) (“[D] eveloping the personal motivation to overcome prejudice does not guarantee that people will respond without bias .... [D] espite disavowing prejudice consciously and responding without prejudice on easily controllable explicit self-report measures, many people who report being low in prejudice show bias on responses that are less amenable to control. For example, when race-based bias is assessed with implicit measures . . bias is often observed even among those who claim to be nonprejudiced." (citation omitted)). The IAT has been the subject of several critiques of both its role as a measurement tool and its implications. For a critique of the IAT as a measurement tool, see Ralph Richard Banks \& Richard Thompson Ford, (How) Does Unconscious Bias Matter?: Law, Politics, and Racial Inequality, 58 EMORY L.J. 1053, 1064 (2009) ("In the IAT research, levels of implicit bias consistently diverge from levels of conscious bias, but it is difficult to know whether that apparent divergence reflects a real underlying difference or is merely an artifact of the systematic understatement of levels of conscious bias."). See also Philip E. Tetlock \& Gregory Mitchell, Implicit Bias and Accountability Systems: What 
The fact that systematic disparities persist in the legal system even after it became unacceptable to stereotype explicitly in legal proceedings seems to implicate implicit biases in judicial decision-making as a plausible mechanism. ${ }^{75}$ This inference is bolstered by the fact that such disparities occur in cases even when all relevant legal information appears to be identical, implying they should end in identical outcomes. Although there is evidence that implicit biases exist at many stages of the legal process in the criminal justice system-from public perceptions of crime and criminality, ${ }^{76}$ to police encounters, ${ }^{77}$ to prosecutorial decisions ${ }^{78}$ — research has specifically documented implicit, if not explicit, biases in judicial decision-making. For example, data indicate that black defendants receive higher bail amounts when compared with nonblack defendants in similar circumstances, ${ }^{79}$ and convicted black defendants appear to receive harsher sentences than their white counterparts as well. ${ }^{80}$ Implicit biases also seem to be distressingly prominent in the process that determines whether a defendant receives the death penalty: not only are black defendants disproportionately subject to capital punishment, 81 but also a stereotypically black appearance by itself has been linked to a greater relative likelihood of receiving a death sentence, independent of relevant legal considerations such as crime severity and criminal history. ${ }^{82}$ For some black people, racial stereotypes may also be intertwined with and reinforced by stereotypes against the poor. ${ }^{83}$

Must Organizations Do to Prevent Discrimination?, 29 Res. Organizational BeHav. 3, 6 n.2 (2009) (“[T]here is no evidence that the IAT reliably predicts class-wide discrimination on tangible outcomes in any setting ...."). For a refutation of these criticisms, see Jost et al., supra note 72, at 46-64 (discussing the robustness of the accumulated evidence demonstrating the predictive validity of the IAT).

75. E.g., Ian Ayres \& Joel Waldfogel, A Market Test for Race Discrimination in Bail Setting, 46 STAN. L. REV. 987, 991-92 (1994) (finding race-based differences in bail rates disfavoring black defendants after controlling for legally relevant variables); see also Mustard, supra note 44, at 300 (showing that black defendants receive $12 \%$ longer sentences on average than similarly situated white defendants).

76. See Joshua Correll et al., The Influence of Stereotypes on Decisions to Shoot, 37 EuR. J. SOC. PSYCHOL. 1102,1114-15 (2007) (finding that people are quicker to shoot black targets holding a gun and black targets holding innocent objects than identically situated white targets).

77. See, e.g., Joshua Correll et al., Across the Thin Blue Line: Police Officers and Racial Bias in the Decision to Shoot, 92 J. PERSONALiTY \& SOC. PSYCHOL. 1006, 1013-14 (2007) (showing that officers were quicker to identify a black target holding a gun and made more errors in deciding to shoot a black target holding an innocent object than a white target).

78. See Robert J. Smith \& Justin D. Levinson, The Impact of Implicit Racial Bias on the Exercise of Prosecutorial Discretion, 35 SEATTLE U. L. REV. 795, 805 (2012).

79. Ayres \& Waldfogel, supra note 75, at 992.

80. David C. Baldus et al., Racial Discrimination and the Death Penalty in the Post-Furman Era: An Empirical and Legal Overview, with Recent Findings from Philadelphia, 83 CORNELL L. REV. 1638, 1675-722 (1998).

81. Id:; see also DAVID C. BAldus ET AL., EQUAL JustiCE AND THE DEATH PENALtY: A LEGAL AND Empirical ANALysis 142-43 (1990); R.J. Maratea, Overcoming Moral Peril: How Empirical Research Can Affect Death Penalty Debates, in RaCe and THe Death Penalty: The Legacy of MCCLESKEY V. KEMP 51, 63-67 (David P. Keys \& R.J. Maratea eds., 2015).

82. Eberhardt et al., supra note 43, at 384 .

83. See generally Michele Benedetto Neitz, When Myths Become Beliefs: Implicit Socioeconomic Bias in American Courtrooms, in ENHANCING JusticE: REDUCING BiAs 131 (Sarah E. Redfield ed., 2017). 
Many of the studies that document implicit biases among judges do not measure judges' biases directly but instead reason from the existence of inexplicable outcome disparities. ${ }^{84}$ There are, however, at least two studies that examine the prevalence, strength, and implications of implicit biases among judges. This research measures these biases directly using the IAT, 85 which gives us confidence that implicit biases matter in judicial decision-making.

Jeffrey Rachlinski and colleagues recruited several dozen judges who agreed to take the IAT for racial groups (black and white) and then respond to several vignettes simulating judicial decision-making tasks. ${ }^{86}$ The study produced several important results: First, the authors found that judges display implicit biases favoring white litigants over black litigants to the same extent as the wider public. ${ }^{87}$ Thus, judicial professionalism and a commitment to impartiality (even when under the scrutiny of a researcher) do not appear to prevent the internalization of bias-precisely because such processes can be entirely unconscious and occur automatically. Second, white judges exhibited greater prowhite implicit bias than their black peer judges, showing that bias is more pronounced in the context of out-group members. ${ }^{88}$ Third, Rachlinski and his collaborators discovered evidence of judicial implicit bias even though the study's vignettes did not specifically include the race of the defendant (to avoid exposing the goal of the study); instead, they employed the cognitive manipulation technique of racial priming. ${ }^{89}$ Judges were subliminally exposed to words associated with black people, in theory rendering their implicit stereotypes and biases pertaining to black people more salient. ${ }^{90}$ When they were primed to think about black people, judges' implicit biases_ - as measured by their IAT scores_appeared to influence their decision-making processes, ultimately producing harsher sentences. ${ }^{91}$ Taken together, these findings establish that judges, like all people, are

84. See, e.g., supra note 75. But see Rachlinski et al., supra note 40, at 1205, 1221 (finding that judges harbor implicit race-based biases that can influence judicial decision-making through a direct study involving the voluntary participation of 133 judges who took the IAT).

85. Rachlinski et al., supra note 40, at 1209-10; Justin D. Levinson et al., Judging Implicit Bias: A National Empirical Study of Judicial Stereotypes, 69 FLA. L. REV. 63, 97 (2017).

86. Rachlinski et al., supra note 40, at 1208 ("The study included a race IAT; two hypothetical vignettes in which the race of the defendant was not explicitly identified but was subliminally primed; and another hypothetical vignette in which the race of the defendant was made explicit." (footnotes omitted)).

87. Id. at $1208-10$ \& tbl.2 (showing that judges were quicker to respond to stereotype-consistent pairing of white and positive descriptors and black and negative descriptors as compared to stereotype-inconsistent pairings).

88. Id. at 1210 (showing that $87.1 \%$ of white judges and $44.2 \%$ of black judges showed prowhite preference in their responses to the study's vignettes).

89. Id. at 1212. Rachlinski and his colleagues use a task developed in Sandra Graham \& Brian S. Lowery, Priming Unconscious Racial Stereotypes About Adolescent Offenders, 28 LAW \& HUM. BEHAV. 483, 487-88 (2004).

90. Rachlinski et al., supra note 40, at 1213.

91. Id. at 1214-15 ("We found that the judges' scores on the race IAT had a marginally significant influence on how the prime influenced their judgment. Judges who exhibited a white preference on the IAT gave harsher sentences to defendants if they had been primed with black-associated words rather than neutral 
susceptible to implicit biases and that such biases most likely penetrate and unconsciously influence judicial decision-making.

Justin Levinson, Mark Bennett, and Koichi Hioki conducted a similar study with hundreds of participating judges, including 180 from the federal judiciary. ${ }^{92}$ Levinson and his coauthors sought to measure judges' implicit and explicit attitudes toward Jews and Asians and to identify the effect of the judges' attitudes on their decision-making. ${ }^{93}$ The participants were first tasked with completing a sentencing exercise for a defendant with what they defined as a stereotypically white, Asian, Christian, or Jewish name. ${ }^{94}$ The judges then completed a questionnaire measuring their judicial philosophy regarding criminal sentencing and completed an IAT. ${ }^{95}$ Last, the researchers asked each participant questions that explicitly sought to measure their adherence to stereotypes about the subject demographic groups. ${ }^{96}$ The study found that judges harbor implicit biases about both Jews and Asians relative to Christians and whites. ${ }^{97}$ Their evidence also shows that the strength of these biases depends on the judge's group-based identity. ${ }^{98}$ Further, federal district court judges handed down higher sentences to Jewish defendants than they did to their Christian counterparts, though state court judges polled gave higher sentences to white defendants than Asians. ${ }^{99}$ Levinson et al.'s research further confirms the significance of implicit biases on the bench. ${ }^{100}$

Implicit bias presents a possibly useful explanation for why outcome disparities persist in the face of explicit social commitments to judicial impartiality. In today's courtrooms, judges are inevitably exposed to party demographics and identity markers when making decisions, and despite their best intentions, they may fall prey to bias. Focusing on judges when searching for the sources of

words, while judges who exhibited a black preference on the IAT gave less harsh sentences to defendants if they had been primed with black-associated words rather than neutral words." (footnote omitted)).

92. Levinson et al., supra note 85 , at 97 .

93. Id. at 98 .

94. Id. at 100 .

95. Id. at 101. If the sentencing task concerned a white or Asian defendant, the participant's IAT tested only their attitudes toward whites and Asians. If the defendant was Christian or Jewish, the IAT concerned only Christians and Jews. See id.

96. Id. at 101-02 ("For example, participants were asked how much they agreed or disagreed with the following statements: 'Asian Americans are taking more than their fair share of jobs,' and 'Jews are trying to control America."').

97. Id. at 104.

98. Id. at 106-08 (finding that male judges display stronger anti-Jewish implicit biases and that Catholic and Protestant judges have stronger implicit and explicit biases than judges who claim no religion but also finding no evidence that implicit biases vary with the political party of the appointing president).

99. Id. at 104.

100. In more recent work, researchers used a "natural language processing" technique to analyze and uncover gender-based stereotypes in U.S. appellate court decisions. Arianna Ornaghi et al., Stereotypes in HighStakes Decisions: Evidence from U.S. Circuit Courts 2-3 (Ctr. for Law \& Econ., Working Paper No. 02/2019, 2019). They tie their findings on the existence and strength of such stereotypes to legal outcomes. They found that judges who use more stereotype-laden language are more conservative in their rulings regarding women's rights issues (e.g., reproductive rights, sexual harassment, and gender discrimination). Id. at 4-6. 
outcome disparities, however, may blind us to other dynamics also capable of generating disparate outcomes in our legal system. Below, we expand on another likely source of group-based disparities: facially neutral procedures-certain varieties of which can also exacerbate implicit bias.

\section{Structural Biases}

The idea that the underlying structure of legal proceedings can generate disparate outcomes even in the absence of explicit or implicit bias reflects a more general understanding of the connection between legal procedure and legal substance. ${ }^{101}$ Although procedure may be intended to be a collection of technical rules targeting efficiency, simplicity, and clarity ${ }^{102}$ _ separate from the values and trade-offs at the heart of substantive law and aiming only to ease the achievement of substantive arrangements ${ }^{103}$ _ processes can and do shape legal outcomes. In this Subpart, we simply recognize that some of the most basic features of legal proceedings - many of which seem facially neutral and perhaps indispensable, such as face-to-face hearings - may produce systematic disparities across identity groups.

Repeat players who have greater familiarity with the legal system and the ability to pursue long-term goals over many cases benefit from the legal system as it has traditionally functioned. In a seminal article, Marc Galanter uncovered the many ways in which legal procedures and structures are systematically advantageous to the "haves." 104 With the rise of alternative dispute resolution (ADR) in the last quarter of the twentieth century, the significance of procedure

101. Thomas O. Main, Global Issues in Civil Procedure 1 (2006) ("Procedures alter the conduct of groups and individuals, and thus can prefer some over others. And procedures can, in a very practical sense, negate, resuscitate, or generate substantive rights."); Jeremy Lever, Why Procedure Is More Important than Substantive Law, 48 INT'L \& COMP. L.Q. 285, 285 (1999) (“[T] he outcome of cases, whether criminal or civil, is in practice more likely to be affected by procedural rules than by any niceties of substantive law ....."); Jay Tidmarsh, Procedure, Substance, and Erie, 64 VAND. L. REV. 877, 877-78 (2011) ("TThis] Article's point of departure is the one matter on which Justice Scalia, Justice Stevens, and Justice Ginsburg . . . agreed: procedural rules affect the outcomes of lawsuits.").

102. FED. R. CIV. P. 1 ("The[ Rules] should be construed, administered, and employed by the court and the parties to secure the just, speedy, and inexpensive determination of every action and proceeding."); J. A. JolowiCZ, ON Civil Procedure 59 (2000) ("[M]ost people are content to adopt . . procedure as the course taken for the execution of the laws ... '[T]he relation of the rules of practice to the work of justice is intended to be that of handmaid rather than mistress." (footnote omitted) (quoting In re Coles and Ravenshear [1907] 1 K.B. 1, 4 (Collins M.R.))); see also ROBERT M. COVER \& OWEN M. FISS, THE STRUCTURE OF Procedure iii (1979); $i d$. at 6 ("Procedure . . ought to be the means by which correct decisions . . are rendered more probable and more public."); Robert S. Summers, Evaluating and Improving Legal Processes: A Plea for "Process Values," 60 CORNELL L. REV. 1, 4-5 (1974).

103. Under this narrow perspective, value is placed on the formal application of procedural rules, irrespective of the effect such procedures might have on different parties. The specific content of procedural rules is far less important than their simplicity and clarity, which should allow for efficient proceedings, consistent application of procedural law, and, in turn, predictable results. See Summers, supra note 102, at 25-26 (referring to such values under "procedural legality").

104. See generally Marc Galanter, Why the "Haves" Come Out Abead: Speculations on the Limits of Legal Change, 9 LAW \& SOC’Y REV. 95 (1974). 
grew more conspicuous as it became clear that the parties choosing ADR over traditional litigation knew very well that their choice could lead to a different outcome despite the same substantive law governing in the background. ${ }^{105}$ Indeed, mediation has been hailed precisely because of the opportunity it provides to devise creative outcomes that are tailored to the circumstances of the case, as opposed to relying on courts' "limited remedial imagination."106

At the same time, at least one initial perspective on the several disputeresolution processes that have emerged - e.g., litigation, arbitration, and mediation — was that each process had its own "moral integrity," 107 which ultimately shapes the substantive outcome as well as the perceptions of its legitimacy. ${ }^{108}$ This essentialist view has morphed over the years as ADR became institutionalized in courts and variations in both ADR and court processes proliferated. ${ }^{109}$ Examples include the emergence of different mediation models, processes such as early neutral evaluation, judicial settlement conferences, compensation funds, and even specialized courts. ${ }^{110}$ These developments both fed on and further perpetuated the evolution of a new field: dispute systems design. ${ }^{111}$ This field is erected on the fundamental understanding that procedural design in dispute resolution is central to law because of the strong connections among procedural design, substantive outcomes, and legitimacy. ${ }^{112}$

105. See Jean R. Sternlight, Is Alternative Dispute Resolution Consistent with the Rule of Law? Lessons from Abroad, 56 DePAul L. REV. 569, 570-71 (2007) ("The growth of ADR . . sparked a series of significant critiques by people concerned with the privatization and informalization of dispute resolution.... [W] hen private companies ... resolve disputes outside the courtroom, companies have an incentive to skew the processes in their favor." (footnotes omitted)).

106. Carrie Menkel-Meadow, Pursuing Settlement in an Adversary Culture: A Tale of Innovation Co-Opted or "The Law of ADR," 19 FLA. ST. U. L. REV. 1, 7 (1991).

107. Carrie Menkel-Meadow, Lecture, Peace and Justice: Notes on the Evolution and Purposes of Legal Processes, 94 GEO. L.J. 553, 561 (2006).

108. See id. at 576 .

109. See Carrie Menkel-Meadow, Mothers and Fathers of Invention: The Intellectual Founders of ADR, 16 OHIO ST. J. ON DisP. RESOL. 1, 13-14 (2000).

110. See Benjamin F. Tennille et al., Getting to Yes in Specialized Courts: The Unique Role of ADR in Business Court Cases, 11 PEPP. Disp. ReSOL. L.J. 35, 44-54 (2010) (providing an overview of specialized courts and forms of ADR). Examples in courts range from small-claims courts, through class actions, to problem-solving courts. Orna Rabinovich-Einy \& Ethan Katsh, The New New Courts, 67 AM. U. L. Rev. 165, 176-77 (2017) (small-claims courts and class actions); Problem-Solving Courts Guide, NAT'L CTR. FOR ST. CTS, https://www.ncs c.org/Topics/Alternative-Dockets/Problem-Solving-Courts/Home.aspx (last visited May 2, 2020) (problem-solving courts). For the various contexts in which dispute-systems-design principles can be seen and employed, see generally Stephanie Smith \& Janet Martinez, An Analytic Framework for Dispute Systems Design, 14 HARV. NEGOT. L. REV. 123 (2009) (describing the field of dispute systems design).

111. While of course there have been procedural reforms in traditional litigation over the years, systematic thinking about the impact of procedural design began in the area of ADR and only in later years did it expand to include procedure in courts. See generally Menkel-Meadow, supra note 107 (surveying legal process theory from Lon Fuller to the Legal Process School of the 1950s to modern process pluralism).

112. See Orna Rabinovich-Einy, The Legitimacy Crisis and the Future of Courts, 17 CARDOZO J. ConfliCT RESOL. 23, 27 (2015) (“[P]roper design was viewed as a means of ensuring more effective and fair processes in an era of increasing privatization of the dispute resolution realm.”). 
The reality of "process pluralism," 113 which exists across and within individual categories of legal processes, has since generated important questions about the consequences of procedural choice on outcome disparities across social groups. Early on, Richard Delgado and his coauthors explored the implications of informal ADR processes for minorities. ${ }^{114}$ In an article citing socialscience research, they warned that ADR processes may disfavor members of disempowered groups precisely because of ADR's informal structure. ${ }^{115}$ Delgado and his collaborators emphasized the significance of rules and formality for inhibiting prejudice. ${ }^{116}$ Following this article and other critical writing, scholars sought to explore explicitly the connection between procedural choice and outcome disparities across race and gender, 117 but the resulting body of empirical research neither confirmed nor rejected Delgado and his colleagues' informality hypothesis - due, inter alia, to methodological weaknesses, small sample sizes, and missing information in a number of relevant studies. ${ }^{118}$

One important theme of this research has been the ability of structural design to constrain, empower, and guide decision makers. But these studies also implicitly highlight the corresponding relationship between procedure and the behavior of litigants. Process can influence litigant participation and behavior, and the efficacy of both. ${ }^{119}$ For instance, in her writing on structural bias in dispute resolution, Lisa Bingham shifts the focus from decision-maker bias to the impact of "control" in dispute systems design. ${ }^{120}$ We offer a related perspective. Litigation structures - the very physical setting and the most basic

113. Menkel-Meadow, supra note 107, at 555 .

114. See Richard Delgado et al., Fairness and Formality: Minimizing the Risk of Prejudice in Alternative Dispute Resolution, 1985 Wis. L. REV. 1359, 1360-61.

115. Id. at 1361.

116. Id. at $1370-75$.

117. Carrie J. Menkel-Meadow, Dispute Resolution, in The OxFord HANDBOOK OF EMPIRICAL LEGAL Research 597, 610 (Peter Cane \& Herbert M. Kritzer eds., 2010). Most notably, Michele Hermann, Gary LaFree, and Christine Rack compared mediated outcomes with litigated outcomes in a small-claims court in New Mexico across gender and ethnicity, drawing on both objective (amount sought compared with amount ordered) and subjective (party satisfaction) criteria. See MiChele Hermann ET AL., The MetroCourT PROJECT FINAL REPORT xvi-xviii (1993). Their findings showed a complex state of affairs with limited support for the "informality hypothesis" (i.e., that minorities and women fare worse in mediation relative to court-based litigation). See id. at xviii-xxxii; see also LaFree \& Rack, supra note 38, at 780-81, 788-89 (finding the largest disparities under the "informality hypothesis" for minority male claimants, with outcomes correlated with repeat-player effects and other case characteristics).

118. In a recent article, Gilat Bachar and Deborah Hensler compile and study the various empirical analyses that have been conducted on this topic (including HERMANN ET AL., supra note 117). See Gilat J. Bachar \& Deborah R. Hensler, Does Alternative Dispute Resolution Facilitate Prejudice and Bias? We Still Don't Know, 70 SMU L. REV. 817, 829-30 (2017).

119. J.J. Prescott, Assessing Access-to-Justice Outreach Strategies, 174 J. InSTITUTIONAL \& THEORETICAL ECON. 34, 51, 55-56 (2018); Prescott, supra note 15, at 2046-47.

120. Lisa B. Bingham, Control over Dispute-System Design and Mandatory Commercial Arbitration, 67 LAW \& Contemp. Probs. 221, 225 (2004); Lisa Blomgren Bingham et al., Dispute System Design and Justice in Employment Dispute Resolution: Mediation at the Workplace, 14 HaRV. NegOT. L. REV. 1, 4 (2009); Lisa B. Bingham, SelfDetermination in Dispute System Design and Employment Arbitration, 56 U. MiAmI L. REV. 873, 879 (2002). 
processes, those not even considered "law" by most 121 —influence how parties interact with each other and with decision makers en route to substantive legal outcomes. We maintain that the design of litigant procedures, by shaping how individuals can participate successfully in dispute resolution, may affect the outcomes for different social groups differently.

In our context, we hypothesize that a shift from real-time face-to-face legal proceedings to asynchronous, written, online ones could significantly affect a party's ability to convey arguments and narrative effectively. Implicit in this realization is that the status quo arrangement may inherently work to the relative benefit of one social group over another. When parties testify or communicate in person, delivering a coherent and convincing story may be a function of almost anything - specified facts, narrative emphasis, argumentation style, tone of voice, body language, eye contact, dress and appearance, question response style, etc. ${ }^{122}$ On the other hand, in written communication, many of these physical cues disappear; focus must be on the style and content of text. ${ }^{123}$ When communication with a court or another party is asynchronous (i.e., it need not occur in a single session but can be stretched over time, as in an e-mail exchange over a few days), a litigant can devise a strategy at their leisure, taking additional time and accessing resources or the assistance of others whenever helpful. ${ }^{124}$ In

121. Bulinski \& Prescott, supra note 11, at 225-26 (explaining, for example, how a court's hours of operation will affect a litigant's decision to challenge a ticket due to that litigant's work schedule); Prescott, supra note 15, at 2005 ("There is an extensive list of nonlegal costs to using a brick-and-mortar courthouse. ... Employed litigants who must go to court during business hours to meet with a prosecutor or have a hearing before a judge ... often face important economic opportunity costs.”).

122. See, e.g., Robert J. Cramer et al., Expert Witness Confidence and Juror Personality: Their Impact on Credibility and Persuasion in the Courtroom, 37 J. AM. ACAD. PSYCHIATRY \& L. 63, 64 (2009) (noting that an expert witness may be viewed as more credible based on speed of speech, word choice, or cues of nervousness); Elizabeth A. LeVan, Nonverbal Communication in the Courtroom: Attorney Beware, 8 LAW \& PSYCHOL. REV. 83, 94 (1984) (explaining that speaker persuasion is determined at least in part by eye contact, gestures, facial activity, selftouching, relaxation, distance, volume, rate of speech, and whether the speaker faces the audience).

123. See, e.g., Sean Flammer, Persuading Judges: An Empirical Analysis of Writing Style, Persuasion, and the Use of Plain English, 16 J. LEGAL WriTiNG INST. 183, 183-84, 202 fig.4.4 (2010) (noting that the content of a written argument is the key factor in persuading a judge, explaining the importance of clearly communicating that content, and finding judges prefer plain-language explanations of arguments); P. Karen Murphy, What Makes a Text Persuasive? Comparing Students' and Experts' Conceptions of Persuasiveness, 35 INT'L J. EDUC. RES. 675, 679 (2001) ("Along with the content and structure of the argument, . . persuasion is reliant on the comprehensibility and meaningfulness of the base message."); $i d$. at 694 ("Among other things, undergraduates and experts concur that persuasive texts need to be easy to comprehend.”).

124. See Jane Guiller et al., Peer Interaction and Critical Thinking: Face-to-Face or Online Discussion?, 18 LEARNING \& INSTRUCTION 187, 194 (2008) (“[A]synchronous discussion groups do promote the use of formal research evidence to support opinions and arguments, in comparison to face-to-face discussion."); Richard Joiner \& Sarah Jones, The Effects of Communication Medium on Argumentation and the Development of Critical Thinking, 39 INT'L J. EDUC. RES. 861, 862 (2003) ("The first advantage of asynchronous communication is that it allows time for deliberation. Group members can reflect on previous arguments and reply with a thoughtful response.”). 
asynchronous communication, the two-way interaction that occurs in traditional face-to-face settings - i.e., questions and answers, back-and-forth discussions-disappears, and the exchange takes place in parallel. ${ }^{125}$

But more important, for our purposes, than the fact that the particulars of proceedings may randomly make some individuals better and others worse off is the question whether any outcome differences systematically accrue to specific groups. Procedural structures in litigation have the potential to impose what amounts to a disparate impact on litigants from certain identifiable social groups-for example, procedural choices may preclude members of marginalized groups from delivering their "story" as effectively as others to a decision maker. Policymakers, including judges, ought to care about whether procedures result in systematic disadvantages for certain groups and how to identify and remedy such outcome disparities when they exist. ${ }^{126}$

There is good reason to suspect that the structural features of legal proceedings may disparately affect certain groups: traits that seem highly relevant to success in litigation are highly concentrated in certain identifiable groups. Success in face-to-face proceedings that take place in a courthouse, for example, is heavily dependent on: (1) education, experience, and resources that are unequally distributed in society because of socioeconomic and other historical disparities; ${ }^{127}$ (2) cultural expectations of decision makers, which comport with those of certain usually dominant social groups; ${ }^{128}$ and (3) resilience to the anticipated psychological costs of suffering through litigation, ${ }^{129}$ which varies with social status, which itself is correlated with certain identity traits. ${ }^{130}$

125. Joiner \& Jones, supra note 124, at 862 (“[C]omputer-mediated communication ... provides the opportunity for group members to post opinions simultaneously.”).

126. Cf. The Sentencing Project, Report of The Sentencing Project to the United NATIONS SPECIAL RAPPORTEUR ON CONTEMPORARY FORMS OF RACISM, RACIAL DisCRIMINATION, XENOPHOBIA, AND RELATED INTOLERANCE 12 (2018) (discussing racial disparities at each stage within the criminal justice system and advocating that policymakers require, for example, racial impact statements to assess any potential racial effects of proposed legislation); Travis Korte \& Daniel Castro, Disparate Impact Analysis Is Key to Ensuring Fairness in the Age of the Algorithm, CTR. FOR DATA InNOVATION (Jan. 20, 2015), https://www.datainnovation.org/2015/01/disparate-impact-analysis-is-key-to-ensuring-fairness-in-the-ageof-the-algorithm (discussing the importance of disparate impact assessments as a tool for policymakers to prevent discrimination in housing and other areas).

127. See Donald R. Songer et al., Do the "Haves" Come Out Ahead over Time? Applying Galanter's Framework. to Decisions of the U.S. Courts of Appeals, 1925-1988, 33 LAW \& SOC’Y REV. 811, 827 (1999) (“[P]resumed . . repeat players with superior resources consistently fared better than their weaker opponents and the disparity in success rates was greatest when the disparity in strength was greatest.").

128. See Solangel Maldonado, Bias in the Family: Race, Ethnicity, and Culture in Custody Disputes, 55 FAM. CT. REV. 213, 219-26 (2017) (surveying the emergence of implicit biases in family law cases, where judges decide custody disputes according to their own cultural norms); Masua Sagiv, Cultural Bias in Judicial Decision Making, 35 B.C. J.L. \& SOC. JUST. 229, 232-35 (2015) (explaining the inevitable manifestations of cultural biases in the courtroom through case law and literature).

129. See Marc Galanter, The Day After the Litigation Explosion, 46 MD. L. REV. 3, 8-10 (1986) (explaining litigation's significant psychological and social costs).

130. See Am. Psychological Ass'N, Stress \& Health Disparities: ConteXts, Mechanisms, AND INTERVENTIONS AMONG RACIAL/ETHNiC MinORITY AND LOW SOCIOECONOMIC STATUS POPULATIONS 9-11 (2017), https://www.apa.org/pi/health-disparities/resources/stress-report.pdf 
In terms of the necessary skills, knowledge, and resources to access and succeed in a traditional face-to-face legal proceeding, minorities, people with disabilities, the elderly, and immigrants face more difficulty because they are often poor and less legally sophisticated. ${ }^{131}$ These barriers not only affect physical access to courts and legal services but also make it more difficult for members of these groups to maneuver their way through procedural mazes on the fly as well as withstand dilatory tactics and procedural delays. ${ }^{132}$ Members of certain groups, especially if unrepresented, may be less able to devise a convincing story in court if they are regularly interrupted by the judge. ${ }^{133}$ In terms of cultural expectations, the structure of legal proceedings is premised on certain conventions that are more agreeable, all else equal, to members of particular groups. ${ }^{134}$ Legal feminist scholars, for example, have long argued that the inyour-face adversarial nature of proceedings (as well as certain strands of ADR) is a better fit for "male" perceptions of justice. ${ }^{135}$ Finally, in-court processes

(demonstrating through a literature review that stress is inversely correlated with income and is higher in minority populations).

131. E.g., Legal Servs. Corp., Documenting the Justice Gap in America: The Current UNMET CIVIL LEGAL NEEDS OF LOW-INCOME AMERICANS 11 (2009) (“Other barriers, such as geographical distance and isolation, low literacy, physical or mental disability, limited English proficiency, culture and ethnic background, and apprehension about the courts and the legal system, also pose impediments.”); Russell Engler, Reflections on a Civil Right to Counsel and Drawing Lines: When Does Access to Justice Mean Full Representation by Counsel, and When Might Less Assistance Suffice?, 9 SEATTLE J. FOR SOC. JusT. 97, 99 (2010) ("Unrepresented litigants are disproportionately minorities and are typically poor. They often identify an inability to pay for a lawyer as the primary reason for appearing without counsel. Unrepresented litigants often fare poorly in the courts, which can have devastating consequences." (footnotes omitted)); Sara Sternberg Greene, Race, Class, and Access to Civil Justice, 101 IOWA L. REV. 1263, 1288-89 (2016) (finding that poor people and members of minority groups make less use of the civil legal system because they distrust institutions based on past negative experiences and because they are unfamiliar with its procedures); Sagit Mor, With Access and Justice for All, 39 CARDOZO L. REV. 611, 628 (2017) ("People with disabilities] are more likely to be poor, and poor people are more likely to be disabled. In an inaccessible society, the extra costs of disability are higher, and disabled people are prone to poverty and economic marginality." (footnote omitted)).

132. But merely simplifying legal procedures will not necessarily improve pro se litigants' performance. Some of the research on small-claims courts exemplifies this point well. See, e.g., William M. O’Barr \& John M. Conley, Litigant Satisfaction Versus Legal Adequacy in Small Claims Court Narratives, 19 LAw \& SOC’Y REV. 661, 698 (1985) ("[W]itnesses giving testimony . . . often lack any understanding that the law imposes highly specific requirements on narratives.... [T] t is common to find accounts that fail to include a full theory of the case that links an agent with an action that caused harm to the plaintiff. ... [The court] is unable to respond affirmatively when accounts are incomplete. Failure to generate a complete hypothesis for testing against the facts to be presented may result in losing the case.").

133. Ayelet Sela, Streamlining Justice: How Online Courts Can Resolve the Challenges of Pro Se Litigation, 26 CORNELL J.L. \& PUB. POL’Y 331, 359 (2016) (“[T] he structural dynamic of the process results in [self-represented litigants'] accounts being regularly interrupted and dismissed, leading to their effective 'silencing."').

134. Not everyone shares mainstream U.S. values, assumptions, and expectations, and those cultural differences can reinforce other concentrated differences across groups. Thus, American judges may expect an innocent party to speak for themselves and refrain from outbursts, whereas other cultures may view reliance on an elder (e.g., a judge) as a sign of respect and emotional outbreaks as reliable protestations of innocence. Karen Arnold-Burger et al., Hearing All Voices: Challenges of Cultural Competence and Opportunities for Community Outreach, in ENHANCING JustiCE: REDUCING BIAS 197, $203-05$ (Sarah E. Redfield ed., 2017). While judges often interpret eye contact as a sign of truthfulness, in some cultures refraining from eye contact with the judge may actually stem from respect or fear. Id. at 212-13.

135. Carrie Menkel-Meadow, Portia in a Different Voice: Speculations on a Women's Lanyering Process, 1 Berkeley Women's L.J. 39, 50-51 (1985) [hereinafter Menkel-Meadow, Portia in a Different Voice]; Carrie 
necessarily involve a "performance" before a decision maker, often - certainly in low-level offenses and small-scale claims-by the litigants themselves. All may face the same formal process, but experience, skill, and even the psychological implications may vary by group. For instance, awareness of a stereotype of one's group can increase anxiety (i.e., stereotype threat), which can diminish performance, particularly in high-stakes situations. ${ }^{136}$ Stress may manifest in avoiding eye contact, stuttering, and sweating, which a judge might mistakenly interpret as undermining a witness's credibility. ${ }^{137}$

Thus, we have at least two potential mechanisms. First, a focus on human judges as the primary "source" of a judicial system's results links the disparities in litigation outcomes to implicit (or explicit) biases influencing an individual decision maker. Second, the structural view connects the structure and design of court proceedings directly to pervasive and sizable disparities. These two mechanisms are, of course, not mutually exclusive; they presumably often operate in tandem and may mutually reinforce each other in many contexts. For instance, when procedural arrangements allow for more-rather than lessjudicial discretion or independence, the design may also permit greater implicit bias and stereotype-based decision-making. The key point is that, regardless of whether decision-maker biases exist, the characteristics of legal processes and proceedings seem likely_at least in some cases_- to be relatively more advantageous to some groups over others.

Menkel-Meadow, Portia Redux: Another Look at Gender, Feminism, and Legal Ethics, 2 VA. J. SOC. POL’Y \& L. 75, 84-86 (1994) [hereinafter Menkel-Meadow, Portia Redux]. The combative win-lose nature of such procedures is less attractive to women, arguably deterring some of them from accessing or maximizing the opportunities of the justice system. Menkel-Meadow, Portia Redux, supra, at 88-89. Similarly, in our context, one could easily argue that the online nature of more recent process innovations corresponds with younger parties' preferences, presenting a better fit for them relative to older generations, even holding constant income, education, and technological literacy. Carrie Menkel-Meadow, Is ODR ADR?, 3 INT’L J. ON ONLINE DisP. RESOL. 1, 5 (2016) [hereinafter Menkel-Meadow, Is ODR ADR?].

136. See Claude M. Steele, A Threat in the Air: How Stereotypes Shape Intellectual Identity and Performance, 52 AM. Psychologist 613, 619-22 (1997); Claude M. Steele \& Joshua Aronson, Stereotype Threat and the Intellectual Test Performance of African Americans, 69 J. PERSONALiTy \& SOC. PSYCHOL. 797, 805 (1995). For example, black participants appear to perform worse in verbal, SAT-like tests when stereotypes regarding poor academic performance by blacks are more salient. Steele, supra, at 615. These same dynamics seem highly likely to emerge in legal settings, as they have in police encounters. Cf. Cynthia J. Najdowski et al., Stereotype Threat and Racial Differences in Citizens' Experiences of Police Encounters, 39 LAW \& HUM. BEHAV. 463, 471 (2015).

137. Vincent Denault \& Laura Dunbar, Nonverbal Communication in Courtrooms: Scientific Assessments or Modern Trials by Ordeal?, 47 ADvOCATES' Q. 280, 284 (2017); see also Cynthia J. Najdowski, Stereotype Threat in Criminal Interrogations: Why Innocent Black Suspects Are at Risk for Confessing Falsely, 17 PSYCHOL. PUB. POL'Y \& L. 562, 572 (2011) ("[B]ecause threatened Black suspects are more likely than nonthreatened White suspects to experience anxiety and arousal and engage in self-regulatory efforts and, in turn, experience cognitive load, they are more likely to behave, nonverbally, as though they are lying or guilty in interrogations.”). 


\section{Attempts to Reduce Outcome Disparities}

Following our collective awakening to the prevalence of group-aligned disparities in outcomes in judicial decision-making and a growing awareness of the ways in which procedural design can produce (or curb) group-based disparities, many researchers began to explore how we might reduce these disparities, if not eliminate them altogether. ${ }^{138}$ We focus our discussion on attempts to temper implicit biases, but we should be clear: societal understanding of how to address unwarranted disparities is lamentably anemic when compared to our grasp of the existence, prevalence, and impact of such biases. While we are making progress, ${ }^{139}$ researchers have also recognized the many difficult challenges of countering implicit biases in judicial decision-making. ${ }^{140}$

For years now, academics and policymakers have sought to develop practical, real-world strategies and tools to mitigate the impact of judicial biases on litigation outcomes by drawing on research in other decision-making contexts and by leveraging insights gleaned from judicial focus groups and other sources of data. ${ }^{141}$ Reformers have proposed diverse means for reducing judicial biases; they include auditing judges and judicial decision-making, ${ }^{142}$ increasing judicial self-awareness, ${ }^{143}$ educating judges about various biases and their sources, ${ }^{144}$ and monitoring judicial performance ex post. ${ }^{145}$

138. See, e.g., Kang et al., supra note 10, at 1169-86; Traci Schlesinger, Racial Disparities in Pretrial Diversion: An Analysis of Outcomes Among Men Charged with Felonies and Processed in State Courts, 3 RACE \& JusT. 210, 229-30 (2013) (finding disparities in pretrial diversion decisions based on race and recommending the use of racial-impact studies and racial and ethnic task forces for reform); see also Aaron S. Kesselheim \& Christopher T. Robertson, Introduction to BLINDing as a SOlution to BiAS: STRENGTHENING BiomedicAl SCIENCE, ForensiC SCIENCE, AND LAW 3, 3 (Christopher T. Robertson \& Aaron S. Kesselheim eds., 2016) ("The classic icon of Lady Justice wearing a blindfold symbolizes the paradoxical insight that less information can sometimes produce better decisions. Should we encourage more opportunities for professionals to be blinded to potentially biasing influences?”).

139. See Pamela M. Casey et al., Addressing Implicit Bias in the Courts, 49 CT. REV. 64, 64-65 (2013).

140. See, e.g., Lindsay M. Perez et al., Assessing Interventions to Reduce Judicial Bias: Fighting Implicit BiasWhat Judges and Lamyers Can Do, in ENHANCING JusTiCE: REDUCING BIAS 317 (Sarah E. Redfield ed., 2017) (emphasizing why policymakers and others need to regularly reassess the effectiveness of interventions that seek to reduce judicial implicit bias).

141. NAT'L CTR. FOR St. Courts, Helping Courts AdDress Implicit Bias: Strategies to REDUCE THE INFLUENCE OF IMPLiCIT BiAS 2-5 (2012), https://horsley.yale.edu/sites/default/files/files/I B_Strategies_033012.pdf [hereinafter STRATEGIES] (borrowing from bias research to make recommendations to courts).

142. Rachlinski et al., supra note 40, at 1230 (arguing that such a measure would both "increase the available data regarding the extent to which bias affects judicial decisionmaking" as well as "enhance the accountability of judicial decisionmaking").

143. Strategies, supra note 141 , at 7.

144. Id. at 5-6.

145. Rachlinski et al., supra note 40, at 1231 (suggesting that appeals be conducted by a panel of three diverse judges and that clear error scrutiny be replaced with de novo review, which together would uncover any missteps caused by biases and reduce the likelihood of a biased decision by the higher court). Obviously, monitoring judicial performance also requires that judicial decision-making data be collected and analyzed on a regular and ongoing basis. Cf. Kang et al., supra note 10, at 1178 ("If judges do not seek out the information that could help them see their own potential biases, those biases become more difficult to correct.”). 
Early innovators in debiasing were optimistic that explicit awareness of the existence of implicit biases - combined with a judge's commitment to reduce them-would largely alleviate their impact on judicial decision-making. Studies have shown that when decision makers are made aware of the existence of implicit biases in human thinking, are motivated to be unbiased, and have cognitive resources to compensate for such inclinations, bias in decision-making diminishes (although eliminating it altogether proved unattainable). ${ }^{146}$ With respect to judicial decision-making, for example, "when judges are [made] aware of a need to monitor their own responses for the influence of implicit racial biases, and are motivated to suppress that bias, they appear able to do so."147 According to this debiasing approach, awareness of implicit biases is a critically necessary, albeit insufficient, step toward reducing their impact. ${ }^{148}$

Yet self-audit as a practical debiasing strategy met with skepticism in light of judges' lack of resources and even the skills necessary to regularly perform such auditing tasks. ${ }^{149}$ Perhaps just as important is the fact that such measures seem to run "counter to overwhelming evidence of how habits are formed." 150 Judges must be motivated to avoid bias, which reformers merely assume to be true in view of their public commitment to impartiality and rule of law. ${ }^{151}$ But probably the most severe obstacle to this approach to debiasing is that awareness of biases and motivation to reduce them must be accompanied with deliberate decision-making, which in turn demands significant individual and institutional resources, both scarce in real-world judicial settings. ${ }^{152}$ Indeed, this is where

146. Cynthia Lee, Awareness as a First Step Toward Overcoming Implicit Bias, in ENHANCING JustiCE: REDUCING BIAS 289, 295 (Sarah E. Redfield ed., 2017).

147. Rachlinski et al., supra note 40, at 1221; see also Andrew J. Wistrich \& Jeffrey J. Rachlinski, Implicit Bias in Judicial Decision Making: How It Affects Judgment and What Judges Can Do About It, in ENHANCING JuSTICE: REDUCING BiAs 87, 109 (Sarah E. Redfield ed., 2017) ("[]ndividual judges could self-audit by recording data such as sentence length, defendant's race, victim's race, and so on and periodically reviewing it for consistency.").

148. Recommended actions include reading about implicit biases, taking the IAT, and participating in educational sessions facilitated by judges, which demonstrate the impact of judicial biases in legal and other professional contexts. See Kang et al., supra note 10, at 1176-77. Another technique is "consider-the-opposite" or "consider-the-alternative," which works by asking judges to imagine coming to a conclusion that is the opposite of the opinion they currently hold and then to generate explanations that would justify holding such an alternative view of events. See Wistrich \& Rachlinski, supra note 147, at 112-13.

149. Indeed, scholar-critics have shown that long-term eradication of biases is difficult. Stanley P. Williams Jr., Double-Blind Justice: A Scientific Solution to Criminal Bias in the Courtroom, 6 IND. J.L. \& SOC. EQUALITY 48, 63 (2018).

150. Id. at 64 .

151. Kang et al., supra note 10, at 1174-76 (examining a California-based study that found that education assists judges in becoming aware of their biases); $i d$. at 1174 ("A powerful way to increase judicial motivation is for judges to gain actual scientific knowledge about implicit social cognitions.").

152. Raising awareness has been described as “an important first step." Lee, supra note 146, at 291. To successfully minimize bias in this fashion, one must have a high degree of self-awareness and focus on not only the outcome but also the entire decision-making process to reduce opportunities for schemata, stereotypes, and intuitions to color parties' interactions, the weighing of evidence, and the determination of facts. See Kang et al., supra note 10, at 1177-78. Such deliberate decision-making requires alleviating personal and institutional sources of stress. $I d$. 
biases in human decision-making and structural biases coalesce, and therefore, efforts to mitigate biases must operate in both spheres simultaneously.

Others have recommended thwarting implicit biases harbored by judges (and jurors) by exposing them to counterstereotypical portrayals of members of stigmatized groups. ${ }^{153}$ Apparently useful in pursuing this strategy is the removal of any verbal or visual materials or other cues in a court, say, that might contain or display information that could increase the weight of any stereotypebased thinking or otherwise activate implicit biases. ${ }^{154}$ Beyond cleansing a court of physical triggers, research suggests that active engagement with individuals who controvert group-based stereotypes-ideally, individuals of equal statuscan be effective at reducing the general level of implicit bias toward members of a particular group. ${ }^{155}$ But the potential upside of counterstereotypical exposure is inherently limited when decision makers frequently encounter "stereotype-consistent" group members who reinforce implicit biases. ${ }^{156}$

Research has also pointed to judicial training as a potentially scalable means of debiasing the judicial system. These calls for education emphasize the necessity of implementing training regimens on a voluntary basis and in a nonthreatening manner by focusing on certain biases rather than others and by refraining from asking judges to disclose or publicly acknowledge their IAT scores. ${ }^{157}$ Recommendations include institution-wide, diversity-oriented training programs with a multicultural perspective that recognizes individual and group differences. ${ }^{158}$ More generally, ongoing, transparent, and nonthreatening feedback

153. One avenue for such exposure is through the types of pictures, posters, and pamphlets courts display in judges' offices and their surrounding areas — and even in judges' immediate work environment, through displays of atypical roles for minorities and women on judges' screensavers. Kang et al., supra note 10, at 1171 ("In chambers and the courtroom buildings, photographs, posters, screen savers, pamphlets, and decorations ought to be used that bring to mind countertypical exemplars or associations for participants in the trial process."); STRATEGIES, supra note 141, at 19-21 (promoting the exposure of judges to counterstereotypical information and exercises that promote such associations); Wistrich \& Rachlinski, supra note 147, at 115 (suggesting creating a "[c]onstructive [c]ourtroom [e]nvironment" and fostering diversity in judges' personal lives). This idea is based on the contact hypothesis. See Yehuda Amir, Contact Hypothesis in Ethnic Relations, 71 PSyCHOL. Bull. 319, 319 (1969) (predicting that more contact enables individuals "to know each other better and that this close contact will reduce ethnic prejudice and intergroup tension and improve relations").

154. Casey et al., supra note 139, at 69.

155. Id.

156. Michael Gross, Can We Change Our Biased Minds?, 27 Current Biology R1089, R1091 (2017).

157. Kang et al., supra note 10, at 1176-77 ("First, training should commence early, starting with newjudge orientation when individuals are likely to be most receptive. Second, training should not immediately put judges on the defensive, for instance, by accusing them of concealing explicit bias.... Third, judges should be encouraged to take the IAT or other measures of implicit bias. ... That said, we do not recommend that such tests be mandatory .... Moreover, judges should never be expected to disclose their personal results."); see also STRATEGIES, supra note 141, at 6-7. Such training is meant to reduce biases, not to make judges "color-blind," which could actually increase discrimination. See id. But see Wistrich \& Rachlinski, supra note 147, at 107 (warning that although training could promote conscious self-correction, it might make judges more prone to other types of bias by depleting their cognitive resources).

158. Casey et al., supra note 139, at 66. This approach highlights individual differences rather than a color-blind approach. $I d$. Promoting such training on a court-wide basis with appropriate institutional and 
that relates to the decision-making process, and not only to court outcomes, may allow judges to learn from their past experiences and reduce biases. ${ }^{159}$ Here again, reality presents hurdles to these strategies, both in terms of the resources required to collect relevant data and in terms of delivering feedback in an effective manner. ${ }^{160}$ Calls for augmenting judicial appellate review have been met with similar reservations - it may be too costly and inefficient to justify as an ongoing solution-but also with concerns that it may backfire: "Substitution of one bias for another is no remedy."161

Another more structural recommendation in the campaign to curtail implicit biases in judicial decision-making is to reduce legal ambiguity and, thus, the ambit of judicial discretion. Judges can use ambiguity to account for disparate outcomes, and it creates fertile ground for using stereotype-based evidence or facts. ${ }^{162}$ One way to counter these tendencies is to establish concrete standards and criteria before any decision-making phase. ${ }^{163}$ This limits the human tendency to rely on schemas and stereotypes to simplify a situation and reduce ambiguity. ${ }^{164}$ Increasing structure and limiting discretion may inoculate judges from stereotypical thinking and make it easier to detect variation in outcomes. But, as we stress, process changes can generate pernicious disparities in their own right, and there has recently been, if anything, greater reliance on informal, flexible processes (with a high degree of ambiguity) and managerial judging practices in the name of judicial efficiency. ${ }^{165}$ The fact that many, if not most, judges - especially in state courts_-face incessant pressure to streamline their case processing in the face of an ever-growing docket seems to be driving courts

financial resources should minimize bias given that research has demonstrated that egalitarian workplace norms reduce levels of individual implicit bias. Id.

159. Id. at 68 . In this vein, scholars and others have recommended that courts monitor judicial decisions and provide feedback by reviewing court data and organizing sentencing roundtables in which judges can discuss and reflect on real and simulated cases. $I d$.

160. The prospect of reducing bias under conditions of a heavy caseload, a constant reality for many overworked judges in the United States, may be far-fetched. See Williams, supra note 149, at 64. Moreover, critics fear that even if such training efforts do affect judges, the overall effect could be negative if judges overcorrect for their biases. See id. at 62.

161. Id. at 65 .

162. See M. Bertrand \& E. Duflo, Field Experiments on Discrimination, in 1 HANDBOOK OF FIELD EXPERIMENTS 309, 313 (Abhijit Vinayak Banerjee \& Esther Duflo eds., 2017) ("Implicit biases are more likely to drive behavior under conditions of ambiguity, high time pressures and cognitive loads, or inattentiveness to the task.").

163. Casey et al., supra note 139 , at 68 .

164. Id.

165. See, e.g., Judith Resnik, Managerial Judges, 96 HARV. L. REv. 374, 395 (1982) ("Since the early 1900's, judges have attempted to respond to criticism of their efficiency by experimenting with increasingly more managerial techniques."); $i d$. at 405 (“'Once brought into the enforcement process, however, the judge often uses informal management techniques in an effort to save time and avoid the pressures of public controversy."); see also id. at 429-30 (contrasting traditional judging activities with judges as "pretrial case managers" who "operate in the freewheeling arena of informal dispute resolution"). 
in the exact opposite direction, thereby encouraging judges to rely more on intuition, schemas, and stereotypes. ${ }^{166}$

We would be remiss to ignore judicial diversification as a strategy to address implicit bias, ${ }^{167}$ although this approach operates not by debiasing existing judges but by selecting judges so as to reduce any systematic group disparities that biases may produce. Various critical movements have revealed the ways in which legal norms and judicial decision-making have been skewed in favor of white males relative to disempowered groups_racial and ethnic minorities, ${ }^{168}$ women, ${ }^{169}$ and people with disabilities. ${ }^{170}$ While rulings by white male judges once stood as the benchmark of impartiality, ${ }^{171}$ these critical studies detail the prevalence of dominant but often inaccurate narratives in judicial decision-making - a consequence that many (at least partially) attribute to a nondiverse bench. ${ }^{172}$ For diversification proponents, identity is an inherent lens through

166. See Chris Guthrie et al., Blinking on the Bench: How Judges Decide Cases, 93 CoRnELL L. REv. 1, 29 (2007) ("The intuitive approach to decision making is quick, effortless, and simple .... The obvious advantage of [the intuitive approach] is its speed; judges with heavy dockets can rely on intuition to make judgments quickly.”).

167. Melissa L. Breger, Making the Invisible Visible: Exploring Implicit Bias, Judicial Diversity, and the Bench Trial, 53 U. RiCH. L. REV. 1039, 1072 (2019) ("A diversified bench might lead to better and informed decision making as well as reducing bias."). Of course, judicial diversification has been a goal for many in and of itself, and the case for such diversification extends beyond benefits relating to the implicit-bias phenomenon.

168. Kimberlé Williams Crenshaw, Race, Reform, and Retrenchment: Transformation and Legitimation in Antidiscrimination Law, 101 HARV. L. REV. 1331, 1369 (1988); Cheryl I. Harris, Equal Treatment and the Reproduction of Inequality, 69 FORDHAM L. REV. 1753, 1757-58 (2001).

169. Catharine A. Mackinnon, Toward a Feminist Theory of the State 237-49 (1989) ("From a feminist perspective, male supremacist jurisprudence erects qualities valued from the male point of view as standards for the proper and actual relation between life and law. Examples include standards for scope of judicial review, norms of judicial restraint, reliance on precedent, separation of powers, and the division between public and private law.").

170. Martha Minow, Making All the Difference: InClusion, Exclusion, And American LAW 51 (1990) (“[W]e typically adopt an unstated point of reference when assessing others. It is from the point of reference of this norm that we determine who is different and who is normal.... Handicapped persons are different in relation to the unstated norm of able-bodiedness ... . The unstated point of comparison is not general but particular, and not inevitable but only seemingly so when left unstated." (footnote omitted)).

171. Sherrilyn A. Ifill, Racial Diversity on the Bench: Beyond Role Models and Public Confidence, 57 WASH. \& LEE L. REV. 405, 459-61 (2000) (" [I]f black and female judges are suspected of bringing racialized or genderized perspectives to bear on issues of discrimination, then we must assume that white and male judges also bring race and gender perspectives to their decision-making. ... [C]ases suggest that white judges may be enjoying a perception of built-in racial impartiality that parties deny to black judges.”).

172. Id. at 440 ("Often masquerading as 'neutral principles,' racial and gender narratives have informed and shaped the construction and interpretation of legal principles such as merit, discrimination, colorblindness, property, parental autonomy, individual rights, and reasonableness." (footnotes omitted)). Given the "inevitability of the existence of a perspective" in judicial decision-making, many believe the diversification of the bench is essential to including the unique perspectives and experiences of nondominant groups. Id. at 461 ("Seeking a form of impartiality that is neither 'raced' nor 'gendered' is both impractical and impossible. As Martha Minow cautioned some time ago, " $\mathrm{t}$ ] his aspiration of impartiality . . . is just that —an aspiration rather than a description- because it may suppress the inevitability of the existence of a perspective."' (alterations in original) (quoting Martha Minow, Foreword: Justice Engendered, 101 HARV. L. REV. 10, 45 (1987))); see also id. at 451 ("Minority judges' ability to bring to the bench particular perspectives to help understand racial bias and discrimination should be conceived of as a valuable asset to judicial decision-making."); id. at 45354 (describing a study of federal judges' decisions in race discrimination cases and observing that "the lack of 
which judges view and weigh the facts and interpret and apply the law. ${ }^{173}$ But so far, diversification has proven difficult, ${ }^{174}$ and research indicating that judicial identity may be less important to most litigation outcomes than many initially expected reinforces worries that such steps would constitute tokenism. ${ }^{175}$

\section{E. Reducing Disparities Through Online Proceedings?}

The legitimacy of our legal system is premised on impartiality, and yet "justice" in the U.S. somehow seems to walk hand in hand with large and persistent group-based outcome disparities. ${ }^{176}$ We seek in Part I to identify reasons for this strange discrepancy, arguing that the arrangement of traditional legal proceedings - including the prominence of in-person hearings in front of judgesmay be a key source of disparities in legal outcomes. Specifically, legal proceedings like hearings seem inevitably to involve face-to-face encounters, which automatically expose judges to many irrelevant, identifying characteristics of parties. It is this physical exposure to identity features that can routinely trigger implicit schemas, biases, and stereotypes and thus produce disparities. ${ }^{177}$ But customary hearings also rely on oral, real-time presentations of parties' stories, arguments, and evidence before a judge-who has considerable discretion over how the proceeding unfolds, ${ }^{178}$ especially when ambiguity reigns, as is the rule

full racial diversity on federal appellate courts determines the outcome of discrimination cases at the appellate level ... [and] may be shaping the development of federal anti-discrimination law" (footnote omitted)); Menkel-Meadow, supra note 59, at 202 ("[W]omen may not only arrive at different outcomes in some kinds of cases, but they are likely to 'reason' differently, or consider different facts, circumstances, and conditions as they consider what to decide in granting asylum or not ....”).

173. Indeed, research even hints that diversification serves the instrumental goal of reducing bias, particularly when decisions are made in diverse judicial panels. See Grossman et al., supra note 43, at 45-46.

174. Ifill, supra note 171, at 434; see also TRACEY E. GEORGE \& ALBERT H. YOON, AM. CONST. SOC'Y FOR L. \& POL'Y, THE GAVEL GAP: WhO SiTS IN JudgMENT IN STATE COURTS? 1, 13, http:/ /gavelgap.org/ pdf/gavel-gap-report.pdf (last visited Aug. 2, 2018) (demonstrating that women and minority judges are underrepresented in state courts). Some worry that such steps serve symbolic ends rather than substantives ones. See Barbara L. Graham, Toward an Understanding of Judicial Diversity in American Courts, 10 MICH. J. RACE \& L. 153, 179-80 (2004); Ifill, supra note 171, at 409, 481; id. at 487 ("The goal is to increase not just cosmetic diversity, but to increase the number of judges who can authentically articulate and legitimate the perspectives and values of 'outsider voices' in judicial decision-making.").

175. See Orley Ashenfelter et al., Politics and the Judiciary: The Influence of Judicial Background on Case Outcomes, 24 J. LEGAL STUD. 257, 281 (1995) (finding that judge identities influence procedures but do not influence outcomes in a study of 2,258 federal civil rights and prisoner cases filed in three district courts). Cf. Ifill, supra note 171, at 487-88 (arguing that "diversity candidates" for the judiciary should not come only from racial minority groups, because white judges who represent marginalized voices may be better able to legitimate these voices' values in the application of the law). But see text accompanying notes 47-54.

176. See supra notes 36-41 and accompanying text.

177. Casey et al., supra note 139, at 69.

178. Cf. Stephen B. Burbank, Procedure and Power, 46 J. Legal Educ. 513, 514 (1996) ("Many if not most Federal Rules make no policy choices. Rather, they confer discretion on the trial judge, thereby insulating the Rules from effective challenges ...."). 
with respect to minor legal issues. ${ }^{179}$ Every aspect of the process-who speaks, when, about what, to whom, under what conditions and restrictions - can benefit certain parties and disadvantage others. Whenever these benefits or disadvantages become concentrated in groups, "normal" court proceedings result in structure-driven outcome disparities.

And yet the essence of legal proceedings - the physical, in-person nature of which has always seemed fundamental to the adversarial process underpinning our legal system ${ }^{180}$ - is in a state of flux. Court processes of all kinds are confronting transformation by online communications technology, which may offer new avenues for curbing the judicial and structural biases that may be entrenched in face-to-face proceedings. ${ }^{181} \mathrm{~A}$ shift to online hearings could reduce disparities in outcomes for (at least) two main reasons.

The first reason online procedures might reduce unwarranted outcome disparities is that online interactions mechanically reduce the salience of identity features-especially of the parties. ${ }^{182}$ A "blinding" measure of this sort has always been thought impossible to implement in courts due to the nature of legal adjudication. People have understandably assumed that litigation must occur in a courtroom, making parties' and judges' identity features salient, allowing for unstructured interaction, and relying on face-to-face oral communication. ${ }^{183}$ Unlike most of the debiasing approaches we discuss in Part I.D, which seek to cure implicit biases that follow judicial exposure to activating stimuli, online proceedings remove the face-to-face element of dispute resolution altogether. By eliminating bias preexposure, they effectively shield judges.

Obscuring group-identity features from decision makers has been a successful strategy for reducing biases and attaining greater impartiality in other domains. ${ }^{184}$ Today, a few institutions use anonymous hiring practices to remedy

179. See supra notes 162-66 and accompanying text (advocating for standards as a means of imposing structure and abating ambiguity).

180. E.g., Amendments to Rule 26(b) of the Fed. Rules of Criminal Procedure, 207 F.R.D. 89, 93-94 (2002) (argument by Justice Scalia that reciprocal video transmission is an insufficient replacement for incourt, in-person confrontation in a criminal trial).

181. See, e.g., Brian A. JaCkSON ET AL., Fostering InNOvation IN the U.S. Court System: IDENTIFYING HIGH-PRIORITY TECHNOLOGY AND OTHER NEEDS FOR IMPROVING COURT OPERATIONS AND OUTCOMES ix (2016) ("Use of new technologies could result in better data management and sharing across the criminal justice system. Changes in policy could enable new approaches to address disparities or assist individuals who choose to represent themselves in court proceedings.").

182. Bulinski \& Prescott, supra note 11, at 209; Kesselheim \& Robertson, supra note 138, at 4; Meghan M. O'Neil \& J.J. Prescott, Targeting Poverty in the Courts: Improving the Measurement of Ability to Pay, 82 LAW \& CONTEMP. PROBS. 199, 220-21 (2019); Christopher T. Robertson, Why Blinding? How Blinding? A Theory of Blinding and Its Application to Institutional Corruption, in BLINDING AS A SOLUTION TO BIAS: STRENGTHENING BIOMEDICAL SCIENCE, FORENSIC SCIENCE, AND LAW, supra note 138, at 25, 36.

183. See supra note 14 and accompanying text.

184. Lawrence Lessig, Foreword, in BLINDING AS A SOLUTION TO BIAS: STRENGTHENING BIOMEDICAL SCIENCE, FORENSIC SCIENCE, AND LAw, supra note 138, at xv, xv-xvi ("If you are skeptical that the best violinists are only men, then conduct the auditions behind a screen. If you are worried that the vote of employees against a union was affected by their fear of retaliation by the employer, make the ballot secret.”). 
persistent outcome gaps in hiring decisions involving women and minorities. ${ }^{185}$ A number of orchestras, institutions that are infamous for being male-dominated, have implemented one of the most literal methods one can imagine for ensuring anonymity in hiring - conducting auditions behind a screen (and explicitly instructing women not to wear heels). ${ }^{186}$ Blinding measures like these have proven quite effective at diversifying orchestras. ${ }^{187}$ Similarly, anonymization via double-blind peer-review procedures in academic publishing has, at least in some cases, succeeded in reducing bias toward women and academics from lower-ranked institutions. ${ }^{188}$

The second reason that shifting to an online medium for hearings might lead to fewer outcome disparities has to do with everything else that changesand perhaps especially the enhanced structure and limited judicial discretion associated with the introduction of software-driven communication. Online proceedings invariably differ in ways beyond simply "blinding" a judge from a litigant's group-identity traits. The precise structure of the process (i.e., software's programmed workflow) limits judicial "process discretion,"189 similar in spirit to how guidelines can constrain sentencing practices. ${ }^{190}$ Other differences, however, may not alleviate disparities. In theory, they may even exacerbate them or offset one another. If, instead of appearing and arguing in person, parties use online tools to participate asynchronously in their hearings through writing, this

185. David Hausman, Note, How Congress Could Reduce Job Discrimination by Promoting Anonymous Hiring, 64 STAN. L. REV. 1343, 1352-53 (2012).

186. Kesselheim \& Robertson, supra note 138, at 3.

187. Id.; see also Claudia Goldin \& Cecilia Rouse, Orchestrating Impartiality: The Impact of "Blind" Auditions on Female Musicians, 90 AM. ECON. REV. 715, 737-38 (2000) (showing that these measures significantly reduce gender-biased hiring and employment disparities in symphony orchestras). Unfortunately, while effective in expanding the number of female orchestra players, these measures have not necessarily eradicated discrimination between male and female players once hired. See Jennifer Schuessler, Star Flutist Sues Boston Symphony over Pay Equity, N.Y. TiMES (July 6, 2018), https://www.nytimes.com/2018/07/06/arts/music/boston-sym phony-orchestra-equal-pay-massachusetts.html.

188. Emily A. Largent \& Richard T. Snodgrass, Blind Peer Review by Academic Journals, in BLINDING AS A SOlution to BIAS: STRENGTHENING BIOMEDiCAL SCIENCE, FORENSIC SCIENCE, AND LAW, supra note 138, at 75, 83; Andrew Tomkins et al., Reviewer Bias in Single-Versus Double-Blind Peer Review, 114 PROC. NAT'L ACAD. SCI. 12708, 12708 (2017) (demonstrating that single-blind review benefits well-known authors and those belonging to prestigious institutions). But see Christopher T. Robertson, Disclosure Discretion and Selection Bias in Blinding of Experts, in Blinding AS A SOLUTION TO BIAS: STRENGTHENING BIOMEDiCAL SCIENCE, FORENSIC SCIENCE, AND LAW, supra note 138, at 211, 211 ("Blinding is not ideal. It is a second-best solution.”); Julian Kolev et al., Is Blinded Review Enough? How Gendered Outcomes Arise Even Under Anonymous Evaluation 25 (Nat'l Bureau of Econ. Research, Working Paper No. 25759, 2019).

189. More precisely, a software-driven process will follow fixed, predesigned steps in a rigid and transparent way. O’Neil \& Prescott, supra note 182, at 214 (“'T] he process is fixed in advance and therefore applied equally to everyone, regardless of race, gender, or class, and the entire exchange between the litigant and the court can be recorded for later audit." (footnote omitted)). For better or worse, software does not "freewheel," so all parties in all groups (with similar cases) should expect to go through the same stages.

190. U.S. Sentencing Comm’n, Federal Sentencing: The Basics 1-2 (2018) (explaining that the federal sentencing guidelines were created to address the "unlimited discretion" of judges, to reduce sentencing disparities, and to limit "the broad discretion of sentencing courts and parole [officials]" by mandating steps that judges had to follow to impose a sentence (alteration in original) (quoting Peugh v. United States, 569 U.S. 530, 535 (2013))). 
switch in process may benefit some groups more than others, and if the groups that benefit most are already "haves," then disparities will grow, not shrink. ${ }^{191}$ However, many of the differences between online and offline settings do not generate obvious predictions for group-based disparities, making data-driven research to explore the possibilities all the more important. ${ }^{192}$

Investigating whether and how conducting court proceedings online has consequences for existing group-based disparities in legal outcomes is essential as more and more courts move toward providing remote online services for more and more legal matters. How any encouraging effects might compare to the potential benefits of alternative reforms targeting disparities, like many of the debiasing strategies we discuss above, is just as important. In the next Part, we empirically explore the impact of technology and online tools in courts (which we sometimes denote as "online courts") on the existence of disparate outcomes, both those that might originate in judicial decision-making (implicit bias) and those that might be attributable to the procedural features of face-toface hearings that are missing in online hearings (structural bias), such as oral, real-time communication between the judge and the parties.

\section{EMPIRICAL STUDY OF LEGAL OUTCOMES ONLINE AND OFFLINE: DISPARITIES AND POTENTIAL BIASES}

\section{A. Background: Online Court Proceedings}

Identifying sources and solutions for group-based outcome disparities in litigation has taken on greater urgency as courts across the world encounter a sea change-one that may carry an opportunity to make the U.S. legal system more impartial. This evolution is the shift from traditional face-to-face court proceedings to those that can occur remotely through technology. ${ }^{193}$ Remote proceedings operate through online platforms that connect judges, parties, and court personnel to each other virtually; they permit negotiation, mediation, and even adjudication over the Internet. ${ }^{194}$ This development blossomed from two independent advances: the rise of first-generation ODR technology as a way to resolve private (usually) consumer disputes remotely and the diffusion of digital

191. See Kentaro Toyama, Geek Heresy: Rescuing Social Change from the Cult of TECHNOLOGY 49 (2015) (explaining that the haves are better positioned than the have-nots to take advantage of technologies where access is not assured for all).

192. Online proceedings and procedural tools are surely susceptible to new forms of bias stemming from the qualities of the online medium, and they may generate other benefits (e.g., efficiency) or costs (e.g., less legitimacy) that affect the overall appeal of online solutions to dispute resolution. See id.

193. Keith B. Kaplan, Will Virtual Courts Create Courthouse Relics?, AM. B. Ass’N (May 1, 2013), https://www.americanbar.org/groups/judicial/publications/judges_journal/2013/spring/will_virtual_cou rts_create_courthouse_relics/.

194. Prescott, supra note 15, at 2020. 
technology into courts. ${ }^{195}$ Concern over eliminating group-based outcome disparities has not been a driving factor in these two trends, but improved impartiality may be an important and long-lasting unintended consequence. ${ }^{196}$

At its inception, ODR was not meant for the courts. It arose in the mid1990 s as a subfield of ADR to fill a dispute-resolution vacuum. ${ }^{197}$ As e-commerce began to flourish, new disputes also cropped up, frequently between distant strangers who could not resolve their differences face-to-face. ${ }^{198}$ Traveling any distance to resolve quarrels over relatively small sums of money was unlikely in practice and, in any event, inefficient. This friction threatened the new form of commerce; therefore, a real need for effective mechanisms of redress surfaced in the new online commercial arena. ${ }^{199}$ But, much like ADR processes and courts, attractive ODR processes had to be efficient, accessible, flexible, and fair ${ }^{200}$ —or commercial actors had to perceive them as such. Consequently,

195. Id. at 2010; see also Orna Rabinovich-Einy \& Ethan Katsh, Lessons from Online Dispute Resolution for Dispute Systems Design, in Online DisPuTE Resolution: THEOrY AND PraCtiCE 51, 52-54 (Mohamed S. Abdel Wahab et al. eds., 2012) (discussing the origins of ODR as a consumer dispute-resolution platform for websites like eBay and Wikipedia and its eventual use in resolving legal disputes).

196. See infra Part III.A; see also William E. Crozier \& Brandon L. Garrett, Driven to Failure: An Empirical Analysis of Driver's License Suspension in North Carolina, 69 DUKE L.J. 1585, 1621-25 (2020) (observing that members of disempowered groups are less likely to appear in court, potentially because of economic hardship or the absence of notice to appear, and further finding these individuals suffer disproportionately from the consequence of failing to appear: the suspension of their driver's licenses).

197. Rabinovich-Einy \& Katsh, supra note 195, at 51-52 ("In the late 1990s . . . [t] [the unique features of online communication made traditional, face-to-face dispute resolution processes irrelevant. ... The realization that the very features that have contributed to the emergence of disputes online-mainly the communication over geographical, cultural and linguistic differences-have also served to make traditional dispute resolution avenues ineffective, has given rise to the development of what has been termed 'online dispute resolution,' or ODR. Originally, the term referred to processes for dispute resolution that relied on ICT or were being offered through the internet for addressing conflicts that arose online (namely in the e-commerce setting or on online social forums) or were related to the digital environment (such as copyright abuse). Over time, use of such processes has expanded, and these mechanisms are increasingly being offered for the resolution of offline disputes (although interestingly some of the very early ideas for using ODR targeted offline conflicts, offering online processes for addressing family disputes).”).

198. ETHAN Katsh \& ORNA RABinovich-Einy, Digital Justice: TeChNOlogy and The INTERNET OF DISPUTES 9-10, 29-33 (2017).

199. Rabinovich-Einy \& Katsh, supra note 195, at 51-52.

200. See Amy J. Schmitz \& Colin Rule, The New Handshake: Where We Are Now, 2 InT'L J. ON OnLINE Disp. RESOL. 84, 93-94, 96-98 (2016). The eBay ODR system developed by Colin Rule and his team provided "proof of concept" as it grew to handle 60 million disputes per year, primarily through automated means (alongside human intervention), and received high levels of trust from eBay users. See Prescott, supra note 15, at 2017 ("[T]o succeed, technology that enhances access to justice must ensure fair process and proper procedural protections through the right balance of automation and human involvement and oversight.....”); Colin Rule, Quantifying the Economic Benefits of Effective Redress: Large E-Commerce Data Sets and the Cost-Benefit Case for Investing in Dispute Resolution, 34 U. ARK. LiTTLE ROCK L. REV. 767, 772-74 (2012) (measuring satisfaction by user loyalty and showing that eBay users who went through ODR, whether they "won" or "lost" their case, increased their website activity by greater rates than those who did not experience a dispute or did not go through ODR). 
the growing sophistication in the design of ODR processes and systems-together with changing habits in the daily use of online communication ${ }^{201}$ —eventually rendered ODR processes a potentially valuable new option outside of the e-commerce setting, with applications extending to traditional consumer, neighbor, and family legal disputes. ${ }^{202}$ Indeed, over the last few years, ODR has evolved from fairly simple software capable of providing online redress for consumers to an important general dispute-resolution tool for enhancing access to justice, particularly through its adoption by courts. ${ }^{203}$

While online court proceedings are still a novel approach to dispute resolution, they build on a solid (if imperfect and uncoordinated) foundation of technology adoption by courts. ${ }^{204}$ Implementing online court proceedings has only been possible because of previous eras of technology acceptance for data collection, case management, process modernization, and internal court communication. ${ }^{205}$ While these advances began toward the end of the twentieth century, they gained real significance in the last two decades as courts digitized their historical files and work processes, with a large number of courts now offering online filing services, opportunities for digital display of evidence in court, and state-of-the-art videoconferencing facilities. ${ }^{206}$ These early efforts to deploy digital technology were primarily about efficiency: streamlining the administration of cases by allowing access from afar to lawyers and judges, automating some of the workflow functions, and allowing for court decisions to be published online. ${ }^{207}$ Over time, it became clear that digital technology would

201. Bulinski \& Prescott, supra note 11, at 206-07 ("Starting and managing bank accounts, initiating stock sales, filing mortgage applications, applying for student loans, and purchasing insurance, both auto and property, are just a few of the areas in which technology has saved time and expense on all sides of the market." (footnotes omitted)). The distinction between online and offline disputes itself became elusive with the spread of smartphones and the rise of social media. Smartphones made online interaction pervasive and freed online access from being tied to personal computers that were located in homes, offices, or libraries. See Aaron Smith, Chapter One: A Portrait of Smartphone Ownership, PEW RES. CTR. (Apr. 1, 2015), https://www. pewresearch.org/internet/2015/04/01/chapter-one-a-portrait-of-smartphone-ownership/ (noting that 15\% of Americans reported that they had a "limited number of options" to access the Internet and 10\% had no other form of Internet access beyond their smartphone). Social media changed our habits and preferences, making online interaction with those closest to us as prevalent as, and perhaps more prevalent than, communication with distant strangers. See KATSH \& RABINOVICH-EINY, supra note 198, at 33.

202. Rabinovich-Einy \& Katsh, supra note 110, at 187. See also O’Neil \& Prescott, supra note 182, at 211-12 (explaining the benefits of online courts in ability-to-pay hearings).

203. Rabinovich-Einy \& Katsh, supra note 110, at 203-12; see also J.J. Prescott \& Alexander Sanchez, Platform Procedure: Using Technology to Facilitate (Efficient) Civil Settlement, in SELECTION AND DECISION IN Judicial Process Around THE World 30, 38 (Yun-chien Chang ed., 2020) ("Over the last few years, advances in platform technology have made it possible for courts to offer new dispute resolution services to litigants."). But see Menkel-Meadow, Is ODR ADR?, supra note 135, for critiques of ODR and a discussion of its limitations.

204. See supra notes 194-95 and accompanying text.

205. KATSH \& RABINOVICH-EINY, supra note 198, at 154-56. In many respects, these developments in the courts are no different than those that took place in workplaces more generally, replacing paper with digital files and archives with digital backups. $I d$. at $155-56$.

206. Id. at 154-56.

207. Id. at 155 . 
not merely amplify the effectiveness of existing processes but would also cultivate opportunities for reimagining what court processes could be. ${ }^{208}$

In the course of the last decade, several innovative court systems in the U.S. have instituted ODR and online court proceedings, a choice that is quickly gaining momentum and inspiring courts worldwide. ${ }^{209}$ The platform we use in our study, Matterhorn, has been operating in courts since 2014;210 Matterhorn now operates in more than one hundred state courts and agencies and has contracts in at least thirteen states. ${ }^{211}$ Courts currently use Matterhorn to facilitate the online resolution of a range of legal disputes, including minor arrest warrants, civil infractions, minor misdemeanors, ability-to-pay determinations, foreclosures, family issues, and small claims. ${ }^{212}$ Matterhorn is not alone in the ODR space, however. ${ }^{213}$ For example, Tyler Technologies—one of the largest technology service providers for local governments in the U.S.-merged with Modria, a start-up that designed online proceedings and other dispute-resolution solutions, in 2017 and offers ODR in county courts. ${ }^{214}$

And the world is taking notice. For example, in 2016, an online tribunal began operating in British Columbia, addressing small claims and certain disputes between neighbors. 215 As part of a large reform effort of its court system, the U.K. government is designing and implementing an online-solutions court to address disputes of up to $£ 25,000$, which accounts for a significant share of the civil caseload in that country. ${ }^{216}$ Developed by local legal-aid providers, an online process in the Netherlands for a time offered new opportunities for reaching consensual divorces and addressing neighbor disputes. ${ }^{217}$ Another

208. See Rabinovich-Einy \& Katsh, supra note 110, at 169-70.

209. Kaplan, supra note 193; Kieren McCarthy, China's Cyber Court Opens for Business; A Gavel-Free Zone?, REGISTER (Aug. 21, 2017, 7:39 PM), http://theregister.co.uk/2017/08/21/chinas_cyber_court_opens _for_business (discussing online tribunals in China, Canada, and the U.K.).

210. Anna Stolley Persky, Michigan Program Allows People to Resolve Legal Issues Online, ABA J. (Dec. 1, 2016, 3:10 AM), http://www.abajournal.com/magazine/article/home_court_advantage (stating that Michigan courts started using Matterhorn in 2014).

211. E-mail from M.J. Cartwright, Chief Exec. Officer of Matterhorn Inc., to J.J. Prescott, Professor of Law, Univ. of Mich. Law Sch. (Apr. 27, 2020) (on file with authors); see also MATTERHORN, https://getmatterhorn.com (last visited Apr. 27, 2020) ("Matterhorn online dispute resolution (ODR) is trusted by over 70 courts, resolution centers, and municipalities . . ..”).

212. Civil Case Online Resolution, MATTERHORN, https://getmatterhorn.com/odr-solutions/civil/ (last visited May 15, 2020); ODR Solutions, MATTERHORN, https://getmatterhorn.com/odr-solutions/ (last visited May 15, 2020); see also Rabinovich-Einy \& Katsh, supra note 110, at 197-98.

213. See Provider List, NAT’L CTR. FOR TECH. \& DISP. RESOL., http://odr.info/provider-list (last visited Jan. 14, 2020) (listing over ninety known ODR providers).

214. Rabinovich-Einy \& Katsh, supra note 110, at 201-03. Hawaii recently selected TurboCourt to implement ODR in its courts. Press Release, TurboCourt, Hawaii Judiciary Selects TurboCourt to Activate ODR (Sept. 3, 2019), https://turbocourt.com/go.jsp?act=actShowScreen\&source=scrShowNews \&scr=sc rShowNews\&srcde $=$ dteNews\&dstde $=$ dteNews\&form $=$ frmNews\&id $=514847496$.

215. Id. at $190-92$.

216. Id. at 194-96.

217. Id. at 193-94. Although this platform was eventually discontinued, it may yet be resurrected and has served as an inspiration for other online court initiatives. Id. at 194. 
court, in the District of Hangzhou, China, is already handling e-commerce, copyright, and financial-services-related claims online. ${ }^{218}$ More recently, Singapore incorporated ODR into its court system for two claim types: motor-accident claims and spousal- and child-support actions. ${ }^{219}$

As courts acclimate to these advances in communications technologymorphing from being a "place" to a group of "services" 220 — the role of policymakers and academics is to understand the consequences, intended or otherwise, that may follow this type of transformation. We must appreciate how online courts will shape the values, processes, and outcomes of the legal system; the roles played by judges and lawyers; and the perceptions of individuals using online court proceedings. ${ }^{221}$ One particularly important dimension, we believe, is how online proceedings will affect the ability of courts to deliver on their institutional commitment to impartiality.

We exploit this setting - and the variation in the availability of online proceedings over time and across courts - to better understand the origins of outcome disparities between members of different social groups and how we might use technology as a way to combat them. We postulate that online proceedings may improve matters. We expect that the reduced salience of identity traits during online hearings, coupled with the additional structure such procedures afford, will make social-group membership affect litigation outcomes less than it would in traditional face-to-face proceedings. 222 But there may be countervailing forces at work: online court proceedings differ from in-person proceedings

218. HANGZHOU INTERNET COURT, https://netcourt.yuncourt.com/portal/main/en/index.htm (last visited July 8, 2018); see also Hangzhou Internet Court, NAT’L CTR. FOR TECH. \& DiSP. RESOL. (Aug. 18, 2017), http://odr.info/hangzhou-internet-court.

219. 2019 ODR International Forum: 'Online Dispute Resolution Is Here to Stay,' NAT’L CTR. ST. CTS., https://www.ncsc.org/Newsroom/at-the-center/november-2019/ODR-Forum.aspx (last visited Feb. 6, 2020); Theresa Tan, Family Justice Courts Launch Cheaper and Faster Way for Users to File Applications, STRAITS TiMES (Oct. 2, 2019, 1:44 PM), https://www.straitstimes.com/singapore/family-justice-court-launchescheaper-and-faster-way-for-users-to-file-applications.

220. RiCHARD SUSSKIND, TOMORROW'S LAWYERS: AN INTRODUCTION TO YOUR Future 109 (2d ed. 2017).

221. Compare Richard Atkinson, Opinion, Virtual Courts: More Speed, Less Justice?, GuARDIAN (July 18, 2012), https://www.theguardian.com/commentisfree/2012/jul/18/virtual-courts-speed-justice ("Little consideration seems to have been given to the need to balance speed with justice-justice being about convicting the guilty and acquitting the innocent, rather than focusing on the desire for retribution."), with O'Neil \& Prescott, supra note 182, at 220 ("Most respondents contend that the tool is easier to use and less biased than in-person ability-to-pay determinations. Specifically, judges feel that minorities, the elderly, the disabled, and non-English speakers obtain better access to justice using the assessment tool.”).

222. In an early study of online court proceedings, one of us analyzed data from both online and faceto-face proceedings in courts employing the Matterhorn platform. Prescott, supra note 15, at 1993. The study focused on court ODR's effect on access to justice; it examined case duration, payment, and default rates in civil-infraction cases, finding that ODR had a dramatic impact on these outcomes, enhancing access to justice both on and off the platform. Id. at 2026-50. See also id. at 2050 (finding that adopting court ODR can reduce case duration, improve satisfaction, and reduce default rates, all indicators of enhanced access to justice). To date and to our knowledge, there has been no study of how the shift from face-to-face to online proceedings affects outcome disparities by litigant-identity characteristics. 
in ways other than simply reducing the salience of group identity (e.g., by substituting asynchronous, text-based communication for oral, real-time exchanges). These changes in process may influence outcomes differently for different identity-based groups, and these differences may magnify, offset, or overwhelm any reduction in implicit bias-based disparities.

In our work, we statistically compare the outcomes of online and face-toface proceedings for resolving civil-infraction cases (specifically, traffic violations), which constitute much more than $50 \%$ of cases in state courts, 223 touching most of the population and rendering them important determinants of the legal system's reputation for legitimacy. We analyze litigation outcome disparities across three different types of litigant-identity traits: age, gender, and race. The existing literature on party-identity characteristics and their effects on legal outcomes is compelling but does not encompass all types of cases or courts. For example, while there is substantial research on the impact of party race on judicial outcomes in the criminal justice arena broadly, 224 and in some civil contexts, 225 there is significantly less research on judicial biases and systematic disparities in the context of civil infractions and minor legal matters. ${ }^{226}$

This is a significant gap, especially given that most cases in U.S. courts involve relatively minor matters. ${ }^{227}$ Americans are far more likely to interact with courts, judges, and other parties like law enforcement over minor legal issues (as opposed to more complicated and weighty legal problems), and the collateral effects of even minor civil infractions can be surprisingly serious, particularly for the poor. ${ }^{228}$ The associated fines disproportionately affect people of

223. More than half of cases in state courts fall into the traffic category. See ROBERT C. LAFOUNTAIN ET AL., NAT’L CTR. For STATE COURTS, EXAMINING THE WORK OF STATE COURTS: AN ANALYSiS OF 2010 STATE COURT CASELOADS 3 (2012), http://www.courtstatistics.org/ /media/Microsites/Files/CSP/DA TA\%20PDF/CSP_DEC.ashx.

224. See, e.g., Berdejó, supra note 4; Johnson, supra note 4; Mustard, supra note 44; see also supra note 38 and accompanying text.

225. See, e.g., Audrey Chin \& Mark A. Peterson, Deep Pockets, Empty Pockets: Who Wins IN COOK COUNTY JURY TRIALS 37-46 (1985) (concluding, after analyzing 9,000 jury trials, that black plaintiffs are less likely than white plaintiffs to prevail in similar cases and that plaintiffs between ages forty and fifty-nine win more in damages than those in other age brackets); Eric Helland \& Alexander Tabarrok, Race, Poverty, and American Tort Awards: Evidence from Three Data Sets, 32 J. LEGAL STUD. 27, 51-52 (2003) (finding that tort awards by county are negatively correlated with white poverty rates but positively correlated with poverty among minorities).

226. See, e.g., Kang et al., supra note 10, at 1164 ("In the criminal trajectory, we already learned of juror bias via meta-analyses as well as correlations with implicit biases. Unfortunately, we lack comparable studies in the civil context."); Megan Stevenson \& Sandra Mayson, The Scale of Misdemeanor Justice, 98 B.U. L. REV. 731, 737 (2018) (finding "profound racial disparity" in arrest rates for most kinds of misdemeanors, with "variation in racial disparity across offense types" remaining "remarkably constant over the past thirty-seven years").

227. See LAFOUNTAIN ET AL., supra note 223, at 3.

228. See, e.g., Alexandra Natapoff, Misdemeanor Decriminalization, 68 VAND. L. REV. 1055, 1081-82, 1084-86 (2015) (discussing the risk of incarceration for failure to pay civil fines and fees); see also Bulinski \& Prescott, supra note 11, at 224 (noting the lost wages workers experience when they are required to go to court during business hours). See generally Crozier \& Garrett, supra note 196 (considering the far-reaching consequences of relatively minor infractions when they result in license suspension). 
color and often lead to more frequent (and more disruptive) interactions with courts. ${ }^{229}$ If citizens form conclusions about the impartiality of courts, law enforcement, and government in general, at least in part, from their experiences with courts, then addressing disparities in resolving civil infractions in state courts is vital to the overall success of the U.S. legal system.

Finally, and importantly, minor civil cases appear especially subject to implicit biases in judicial decision-making because judges face more serious constraints on time and other resources in this domain. Caseload pressures are likely to exacerbate any bias by making the use of heuristics and rules of thumb more attractive and therefore more frequent. ${ }^{230}$ Moreover, when courts resolve disputes over civil infractions, they commonly use more informal processes, allowing for greater discretion and potentially aggravating any unwarranted outcome variation. ${ }^{231}$ In this vein, research has documented that identity traitsage, gender, and race-affect traffic-related policing decisions, ${ }^{232}$ which share many features with traffic-related judicial decisions. For example, female drivers are more likely to be warned but less likely to be cited by police relative to similarly situated male drivers. ${ }^{233}$ And older drivers are more likely to be warned but less likely to be cited compared to their younger counterparts. ${ }^{234}$ Our data allow us to examine whether similar dynamics and resulting disparities exist after law enforcement has already issued a citation at the level of judicial outcomes along the axes of age, gender, and race.

229. Alexes Harris, A Pound of Flesh: Monetary SAnCtions as Punishment For the PoOr 156 (2016) ("Existing racial and ethnic disparities in criminal justice contact and its consequences are exacerbated by the imposition of monetary sanctions. African Americans, Native Americans, and Latinos are disproportionately convicted and incarcerated, and the burden of monetary sanctions is disproportionately borne by people of color.").

230. See supra note 166 and accompanying text.

231. See Daniel Klerman \& Holger Spamann, Law Matters_Less Than We Thought 20 (USC Gould Sch. of Law Ctr. for Law \& Soc. Sci., Legal Studies Research Paper Series No. 19-25, 2019), https://papers.ssrn. com/sol3/papers.cfm?abstract_id=3439526 ("The experiment provides some support for the idea that application of a rule is more predictable than application of a standard and that judges under a rule feel more bound to reach the correct results.").

232. Rob Tillyer \& Robin S. Engel, The Impact of Drivers' Race, Gender, and Age During Traffic Stops: Assessing Interaction Terms and the Social Conditioning Model, 59 CrIME \& DELINQ. 369, 381-85 (2013). Stevenson and Mayson "estimate[ that there are 13.2 million misdemeanor cases filed each year and that such cases disproportionately affect poor people and people of color." Crozier \& Garrett, supra note 196, at 1597 (citing Stevenson \& Mayson, supra note 226, at 731). But "studies of misdemeanor outcomes often exclude data from traffic cases-or at least non-DWI traffic cases" because traffic-court dockets are too large, outcomes are inconsistently reported, and data are difficult to obtain in traffic cases. Id. (citing Stevenson \& Mayson, supra note 226, at 773-75).

233. Tillyer \& Engel, supra note 232, at 318.

234. Id. 


\section{B. Online and Offline Legal Proceedings}

We study case outcomes in state courts that implemented online proceedings to resolve disputes over alleged traffic-related civil infractions. These courts offered offline, face-to-face proceedings throughout the period we study but made online proceedings available to litigants partway through the sample period, ${ }^{235}$ meaning that remote options were unavailable at the outset of our quasi-experiment. We leverage the midstream adoption of online proceedings to evaluate their effects on group-based outcome disparities. The courts we study administered the Matterhorn ODR platform, ${ }^{236}$ which was designed to mimic, as closely as possible, the basic workflow of face-to-face hearings in the courts that use it. ${ }^{237}$ Matterhorn operated during the period we observe in a similar way across our sample courts, simplifying our comparison of online hearings and traditional face-to-face proceedings.

The courts we study only offer online hearing opportunities to litigants with eligible cases, ${ }^{238}$ and litigants must choose to use the online platform in lieu of the physical in-court process (or in lieu of accepting responsibility and paying their ticket). Thus, the online proceedings operate in the courts we investigate as a substitute for traditional "informal" face-to-face hearings, which occur in a brick-and-mortar courtroom. These in-court hearings are similar in important ways to the thousands that occur in state courts throughout the country every day: they bring together, in the same room, the litigant and an officer or prosecutor before a judge. The litigant seeks a reduced charge or fine or some other relief. The magistrate or judge invites the parties to recount their version of events, make their arguments, and answer any questions. ${ }^{239}$

The court's online hearing platform similarly solicits input from the parties (in writing) through a process in which the litigant assumes responsibility for

235. Our sample period runs from approximately 2012 to 2019, with courts adopting their online platforms at least a couple of years after the beginning of our sample period. We discuss the details of the sample period and cases in the data section below. See infra Part II.C.

236. Matterhorn was developed in 2013 to enhance access to justice by connecting litigants directly to decision makers through online technology. Several Michigan state courts piloted the platform, and its developer, Court Innovations Inc., initially targeted the resolution of civil infractions and outstanding minor warrants. Matterhorn later expanded to other jurisdictions and was reconfigured to handle additional case types. Andrew Mohr, The University of Michigan-Making the Justice System More Accessible, MATTERHORN (Mar. 1, 2015), https://getmatterhorn.com/the-university-of-michigan-making-the-justice-system-more-accessible; Persky, supra note 210.

237. E-mail from M.J. Cartwright, Chief Exec. Officer of Matterhorn Inc., to J.J. Prescott, Professor of Law, Univ. of Mich. Law Sch. (Apr. 26, 2020) (on file with authors).

238. By "litigants with eligible cases," we mean individuals who have been charged with civil infractions that the courts determine can be resolved through the online platform. These infractions include most, but not all, traffic offenses. Prescott, supra note 15, at 2022 n.156 ("Eligibility criteria typically relate to the nature of the offense and the litigant's criminal history or driving record.").

239. Inevitably, and as labeled, this is an informal setting with significant discretion. Judges do not follow a script, can ask any question they deem relevant (in any fashion they choose), and can make a decision whenever they wish. See Bulinski \& Prescott, supra note 11, at 242. 
the incident but the particular outcome (i.e., the charge and/or the monetary fine) is contested. ${ }^{240}$ At least in the online proceedings we observe, the content, presentation, and order of the judge's questions are identical in every case, determined by the court in advance as the "right" questions to assemble the information necessary to resolve the case. Litigants answer questions and provide their story, and law enforcement can respond. All parties can participate at any time of day. After digesting the written arguments and case documents, the judge issues a decision along with a sanction-usually a conviction on a specific charge and the final fine amount-if appropriate. ${ }^{241}$

Despite their formal similarities, online proceedings differ from face-toface hearings in several respects. First, as we note above, all parties are able to access the platform at any time on any day of the week, meaning that arguments and decisions are often made when the courts are physically inaccessible. ${ }^{242} \mathrm{Sec}-$ ond, communication and argumentation take place asynchronously, ${ }^{243}$ operating like instant messaging, e-mail, and court briefs. Communication between parties and judges can stretch over days, giving parties more time to consider and craft their submissions. ${ }^{244}$ Indeed, litigants may even ask someone to draft a statement on their behalf. In general, communication on the platform between the party and the judge is one-sided and occurs in parallel, in contrast to an in-court interaction that occurs in real time and involves a two-way exchange. Third, and critically, parties interact through the Internet entirely via text-based writing and the submission and exchange of electronic text, documents, and other electronic files. ${ }^{245}$ The parties and judges do not see each other's faces or bodies, hear each other's voices, or see each other's clothes (unless a party uploads an image or audio file with this content as evidence; we are unaware of this ever having happened through the Matterhorn platform). ${ }^{246}$ Judges, however, are exposed to party names, which can carry information about gender

240. Because online litigants are a self-selected sample, any inferences we draw must take into account the possibility of selection bias. For instance, people who wish to contest their ticket will not choose the online platform. The possibility of the ticketing officer's age-, gender-, or race-related bias also comes into play-these biases will influence whether an officer lets a driver leave with a warning. And face-to-face hearings may have higher numbers of young, male, or black litigants because they might be more likely to receive a ticket under perceived "unfair" circumstances and attempt to contest the charges.

241. See Prescott, supra note 15, at 2022-25.

242. Bulinski \& Prescott, supra note 11, at 226. In theory, although this $24 / 7$ access factor might change a proceeding's outcome, it seems unlikely to do so because of a judge's partiality to one group over another, unless a judge draws inferences based on communication time stamps. However, it does seem plausible that greater access to dispute-resolution opportunities may benefit some groups over others.

243. Id.

244. Id.; see also Guiller et al., supra note 124, at 193-94 ("[Evidence] suggests that asynchronous discussion groups do promote the use of formal research evidence to support opinions and arguments, in comparison to face-to-face discussion.").

245. Prescott, supra note 15, at 2022 ("Matterhorn asks litigants to explain in writing their reasons for using the platform ... and to defend their request with valid reasons and evidence.").

246. Admittedly, judges do read litigants' writings and see their answers to questions. With respect to the former (the latter can be regulated), a judge might be able to assess someone's facility with English, 
and national origin (and perhaps age), and they can locate a party's gender and date of birth when looking at the party's driving history. ${ }^{247}$

Operationally, litigants initiate their online judicial proceeding on the court's website. ${ }^{248}$ Individuals search for their case using their identifying information-for example, their name, birthdate, or driver's license number-and provide contact information for subsequent communication between the parties and the court. ${ }^{249}$ The system reviews dockets for cases involving the individual and, if the search is successful, ${ }^{250}$ it runs each case through eligibility filters to determine whether the case qualifies for ODR procedures. ${ }^{251}$ For eligible cases, litigants have the option to proceed by engaging with a prosecutor and a judge online to resolve their case-with the same outcomes possible that a litigant would face at an in-person informal hearing in the courthouse. ${ }^{252}$ If a litigant decides to continue with an online hearing, the court gives the litigant instructions and asks questions through the platform. ${ }^{253}$ The litigant can choose whether and how to respond, just as in real court. ${ }^{254}$ The system is configured by each court to collect the kind of information judges assert is relevant in faceto-face proceedings. ${ }^{255}$ Just as a judge would do in a face-to-face hearing, the

educational level, and perhaps wealth or socioeconomic background. In the future, one can imagine technology that could automatically dampen or obscure revealing features of language usage without compromising substantive effectiveness, or optional functions like spell-checking or grammar-checking, or the use of templates for standard filings or communications.

247. See Andy Mohr, ODR Video: College Town Court Connects with the Public Online, MATTERHORN (May 9, 2019), https://getmatterhorn.com/odr-video-college-town-court-connects-with-the-public-online; see also Bulinski \& Prescott, supra note 11, at 248 ("Some litigants may be concerned, of course, that even though the judge cannot see them, the judge (or a clerk) might still discern information like race, gender, or nationality from other information like names on files or forms.").

248. See How It Works, MATTERHORN, https://getmatterhorn.com/how-it-works/ (last visited May 15, 2020) [hereinafter How It Works]; Plea Online, MATTERHORN, https://getmatterhorn.com/matterhorn-platform/plea-online/ (last visited May 15, 2020).

249. See, e.g., Alex Tekip, Online Ticket Review System Streamlines Process of Resolving Traffic Citations, C \& G NEWSPAPERS (June 24, 2016), https://www.candgnews.com/news/online-ticket-review-system-streamlinesprocess-resolving-traffic-citations-93940 ("Before a driver can have his or her ticket reviewed online [in the particular district court], he or she must input his or her driver's license number and date of birth ....").

250. Accept Uploads for Waivable and Correctable Traffic Offenses Online, MATTERHORN, https://getmatterho rn.com/odr-solutions/traffic/accept-uploads-for-waivable-traffic-offenses-online/ (last visited Apr. 12, 2020). If a docket search is unsuccessful, Matterhorn encourages litigants to provide contact information and to allow Matterhorn to continue to search for a ticket in the days ahead.

251. Courts develop eligibility criteria in order to limit the platform's availability to only those kinds of cases that they deem appropriate for resolution in an online setting. Eligibility criteria typically relate to the nature of the offense and the litigant's criminal history or driving record. See supra note 238.

252. Even after fully exhausting their options through Matterhorn, litigants retain the option of going to the courthouse in person. Prescott, supra note 15, at 2022 n.158. Using Matterhorn results in no prejudice; thus, there is no significant risk to litigants in accessing a court's procedures using Matterhorn.

253. "At the outset, Matterhorn requests contact information (e.g., e-mail address and mobile number) from litigants so the court or other parties can impart information, requests, and/or any decisions to them during the remainder of the process." Id. at $2022 \mathrm{n} .159$ (citing How It Works, supra note 248).

254. Id. at $2022 \mathrm{n} .160$ (explaining that citizens can tell the court about their case-if it is eligible-and answer questions from the court on the platform).

255. The set of questions that courts ask litigants is adjusted to take account of case and litigant information of which the court is already aware, and the ordering of questions is designed to take advantage of 
court always entreats litigants (via a prompt presented by the platform) to explain and justify their requests, although in writing.

Matterhorn directs the litigant's submissions and all other information in the case (charge, etc.) to a prosecutor or a police officer for online review and a text-based recommendation, which is logged on the platform. The judge then reviews the case- the charges, the arguments, the evidence, and the prosecutor's input-and makes a determination about how to proceed, ${ }^{256}$ which almost always means resolving the case, but a judge may request additional information. While the range of possible outcomes is the same in both mediums, the online platform presents the judge with a menu of preconfigured punishment options, combining fine amounts with final charges. A reduced charge counts as relief independent of a reduced fine because it translates into fewer driver's license "points" relative to the original charge. When hearing a case online, judges select from a set of preconfigured choices; although they can deviate from these options in some cases, judges rarely do so. ${ }^{257}$ After a judge decides the case, the system informs the litigant of the outcome.

The simultaneous availability of online proceedings and in-person informal hearings in the civil-infraction context presents a unique opportunity to contrast the outcomes of these two procedural approaches. Our empirical analysis amounts to a statistical comparison of group-based outcome disparities in cases resolved in a face-to-face court setting and those resolved via the online court platform. ${ }^{258}$ We focus on in-person "informal" hearings and alternative online hearings because, in both, litigants overwhelmingly seek a reduction in punishment, rather than contest their responsibility. ${ }^{259}$ Judges act as the ultimate decision makers in both types of processes for equivalent types of cases, but the two processes differ in adjudication structure, in the level of decision-maker discretion, and in the visibility to the judge of a litigant's group-defining physical

"smart" online-survey technology (for example, questions that become irrelevant based on previous answers are not presented) to reduce the burden on litigants.

256. See Bulinski \& Prescott, supra note 11, at 243. Typical decision-relevant data include the type of infraction, the circumstances of the incident, the specific relief requested, the litigant's criminal and traffic history, and the litigant's communication with and submissions to the court. See id.

257. See id. at 213-14; E-mail from M.J. Cartwright, supra note 237.

258. The cases resolved through the different mediums should be substantively the same or similar (once we control for observables; we discuss potential omitted variable bias and selection concerns below), but as we make clear in Part I, supra, decision makers inevitably consider extraneous factors in their deliberations. See Timothy D. Wilson \& Nancy Brekke, Mental Contamination and Mental Correction: Unwanted Influences on Judgments and Evaluations, 116 PSYCHOL. BULL. 117, 119-30 (1994) (discussing the causes and implications of what the authors term "mental contamination"). Altering the means of communication affects the salience of these irrelevant factors and can change decision-making-in our terminology, a structural bias. See, e.g., Holly K. Orcutt et al., Detecting Deception in Children's Testimony: Factfinders' Abilities to Reach the Truth in Open Court and Closed-Circuit Trials, 25 LAW \& HuM. BEHAV. 339, 358 (2001) (finding, in a mock-trial experiment, that jurors are less likely to convict a defendant when intentionally deceptive accusers testify using closedcircuit television as opposed to when they testify in person).

259. E-mail from M.J. Cartwright, supra note 237; Telephone Interview with Manager, Mich. Dist. Court (June 21, 2019) [hereinafter June Telephone Interview]; Telephone Interview with Manager, Mich. Dist. Court (July 3, 2019) [hereinafter July Telephone Interview]. 
traits. ${ }^{260}$ We turn now to describing our data and explaining the methods we employ for comparing online and offline proceedings.

\section{Data and Methodology}

Our analysis is based on comprehensive data of similar online and face-toface traffic violation cases that were resolved in multiple courthouses that make up two district courts in Michigan. These data come directly from each court's case-management system and include descriptive details of the litigant, ${ }^{261}$ the

260. We take measures to overcome the "baseline problem" that plagues analyses of dispute-resolution systems. See Menkel-Meadow, supra note 117, at 4. The term refers to the difficulty of establishing valid comparisons between traditional court procedures and novel alternatives. Carrie Menkel-Meadow has elaborated on this issue in the ADR context, where attempts to derive evaluative conclusions about ADR procedures raise the question of "compared to what?" Id. ADR procedures are invoked by parties with distinctive interests in a unique pool of cases; random assignment is virtually impossible. Id. Likewise, in our work, it is important to identify the right set of face-to-face proceedings to contrast with online hearings.

In our traffic-case context, our sample courts provide multiple options for face-to-face dispute resolution: prehearing conferences, informal hearings, and formal hearings. June Telephone Interview, supra note 259. During prehearing conferences, litigants speak with police officers in a once-a-week, no-appointments setting and negotiate fines and charges (essentially, a plea deal) without magistrate or judge supervision. Id. By contrast, informal hearings are judge centered - although often presided over by magistrates — and usually do not involve legal representation. Id. Litigants in informal hearings are almost always found guilty-the rare exceptions include case dismissals if the ticketing police officer fails to appear or nonguilty dispositions if strong evidence contradicts the police officer's claims. Id.; see also E-mail from M.J. Cartwright, supra note 237. The aim of informal hearings is often to determine appropriate punishment. June Telephone Interview, supra note 259. During (rare) formal hearings, litigants experience a full-fledged trial, usually with legal representation and a district judge presiding. Id. In formal hearings, litigants typically contest the charges outright, and the government seldom alters the original charges along the way. Id.

Prehearing conferences and informal hearings are the most similar to online hearings in terms of their structure and likely outcomes. June Telephone Interview, supra note 259; July Telephone Interview, supra note 259. The parties assume the litigant's guilt in prehearing conferences, and guilty pleas and judgments are overwhelmingly common in informal hearings. June Telephone Interview, supra note 259. Litigants arrive at these hearings seeking to improve on the default outcome of simply accepting full responsibility, usually angling for less serious charges associated with fewer license penalty points, but fine amounts matter to litigants as well. June Telephone interview, supra note 259; July Telephone Interview, supra note 259.

A key difference between prehearing conferences and informal hearings ultimately led us to eliminate the former from our control group of in-person cases: Cases disposed via prehearing conferences resolve through negotiated agreements between litigants and police officers; these agreements are ultimately approved later by a magistrate or judge but inevitably without alteration of the negotiated terms. June Telephone Interview, supra note 259; July Telephone Interview, supra note 259. Even if we were to treat police officers as "decision makers" in such cases, our data for these cases do not list the officer involved, leaving us unable to control for the identity of the presiding individual (which, in our primary analysis of judges in informal hearings, turns out to be important). More important is that police officers involved in preconference hearings are both parties and judges; it is unclear what we can learn about litigation disparities from such proceedings. In the end, we believe the baseline problem is less acute when comparing only informal hearings to online proceedings. The two pools are of course not perfectly equivalent, so in unreported work we perform our main analysis on multiple combinations of in-person hearing types and conclude that our findings are qualitatively unaffected (robust). These results are available upon request.

261. In particular, litigant data in our sample include gender, date of birth, and driver's license state and zip code from driving records as well as race from the traffic ticket. The litigant's race is entered as perceived by the ticketing police officer at the time the ticket is written; to our knowledge, the litigant is not asked to acknowledge, verify, or correct this race information at any stage in the legal process. Although it appears to be a standard practice for police to record the perceived race of a litigant at the time of ticketing, 
traffic incident, ${ }^{262}$ and the court processes that led to the final disposition. ${ }^{263}$ The court records are largely complete, though we limit our analysis to the sample of cases with no missing details. ${ }^{264}$ All of the cases in our data meet the requirements for online eligibility as established by the courts. ${ }^{265}$ To ensure that our comparisons of outcomes across groups in face-to-face and online hearings are informative, we take several measures in how we define our sample and in our modeling assumptions to maximize the chances that we are analyzing what are effectively similar cases.

To begin with, because we focus on disparities in severity of punishment that result from a judge's exercise of discretion in a procedurally structured environment, we restrict our analysis to cases that allow for this discretion-i.e., where a judge makes a decision. We exclude cases never subject to dispute resolution, either because the individual paid the ticket at the outset or because they never paid the ticket or responded to court inquiries, sending the case into

officer identification is less than perfect. See Rhonda Fanning, Why Are Texas Officers Misidentifying Race During Traffic Stops?, TEX. STANDARD (Nov. 6, 2015, 10:00 AM), https://www.texasstandard.org/stories/why-aretexas-cops-misidentifying-race-during-traffic-stops (reporting that investigators found "lots and lots of examples" of "people that were clearly Hispanic" recorded as white on traffic citations). Such misreporting may be explained by officers attempting to avoid detection for engaging in racially biased traffic stops. Elizabeth Luh, Not So Black and White: Uncovering Racial Bias from Systematically Misreported Trooper Reports 31 (Mar. 20, 2020) (unpublished manuscript), https://elizluh.github.io/files/highwaybias.pdf (finding "evidence that misreporting allows biased officers to evade punishment for bias").

262. In particular, traffic-incident data in our sample include the traffic-case type (i.e., state-statute violation or local-ordinance violation), the original charge code and description, and the incident date-all of which are found on the traffic ticket.

263. The court-processing data in our sample include a unique case number for each incident, the name of the presiding judge or magistrate, the case-filing date, the hearing type, the final charge code and description, the final disposition, the case-closing date, and the dollar amount of court fines ordered at the conclusion of the final court hearing.

264. Our analysis aims to understand the role of litigant age, gender, and race in outcome disparities across hearing mediums (face-to-face versus online), so we exclude cases that are missing any of the following: judge name, litigant date of birth, litigant gender, litigant race, and litigant zip code-since we use these data to create various control variables in our analysis. Because litigant date of birth and gender come from driving records, this information is only missing for a handful of cases. Unsurprisingly, the judge name, which relies on the court clerk's diligence during the creation of the court record, and litigant race, which relies on the ticketing police officer's perception and care during the traffic-ticketing process, are missing more frequently. In unreported analysis, we find that the qualitative conclusions of our empirical work are unaffected (robust) when we include the observations with missing judge and race information using a variety of assumptions. Notably, we arrive at similar results if we define all cases with missing race information (that are otherwise complete) as all black and as all nonblack-two configurations that serve as upper and lower bounds for the actual race distribution of this sample.

265. In general, courts using Matterhorn's ODR platform limit eligibility for the online hearing process to particular case types even within the traffic category of cases. But eligibility varies some from court to court and depends on the extent of the court's experience with resolving cases online (as a court becomes more experienced, the scope of online eligibility tends to grow). The district courts in our sample determine online eligibility using original charges. Though all original charge types in our sample are eligible for the online platform, not all of them are equally populated. We test to see if this phenomenon biases our results in any way, in unreported analysis, by limiting the sample to only those cases with the most common original charges and find no substantive difference in our main results. 
default. ${ }^{266}$ We then exclude any cases with not-guilty dispositions, ${ }^{267}$ cases with guilty dispositions that were not ordered to pay any fines, ${ }^{268}$ and cases in which charges were dismissed on technical grounds. ${ }^{269}$ These cases are rare and unusual or the circumstances compelled the case's outcome, leaving the judge with minimal discretion. Further, in order to compare cases across relatively similar circumstances, we also omit very old cases, ${ }^{270}$ and we exclude any cases with litigants younger than age eighteen. ${ }^{271}$ In terms of case types, we restrict our analysis to cases that were or would have been eligible for online resolution, again in hopes of comparing apples to apples.

We use court data that begin a few years before online proceedings become available (pre-data), and we have at least two years of online hearing and contemporaneous in-person hearing data for each court (post-data). ${ }^{272}$ The final data set includes 5,232 cases, of which 2,713 are face-to-face and 2,519 are online. 273 Of the cases in our sample that use face-to-face informal hearings in

266. There is evidence that better access to the court through ODR leads relatively more litigants to invoke dispute resolution. Prescott, supra note 15, at 2047-48 (finding that litigants using ODR had an 18.6 to 23 percentage-point reduction in their likelihood of defaulting). So there is an extensive margin-selection issue, which we believe our control variables address. We are also able to test for various forms of selection by studying the evolution of the face-to-face docket before and after ODR implementation.

267. In a sense, a ruling of no responsibility in the traffic-court context is the ultimate display of potential bias (toward leniency), given the generally very low probability of successfully challenging traffic charges. We exclude these cases because our main interest lies in punishment disparities among similarly situated guilty parties. However, in unreported work, we find that adding these cases into our analysis does not alter the essence of our results, although some relationships are less precisely estimated: we see the same patterns of disparity by litigant characteristics in the face-to-face setting and similar disparity alleviation in the online setting when we include these outlier cases in our analysis.

268. According to conversations with court staff, any cases displaying guilty dispositions and no fines are likely erroneously entered because no zero-dollar court fines are ordered for cases with guilty dispositions. June Telephone Interview, supra note 259; July Telephone Interview, supra note 259. The total number of cases with these circumstances is very small (thirty-nine). In unreported analysis, we include these cases and find no substantive difference in our main conclusions.

269. Our data include information on whether the court dismissed a case. We assume that all dismissed cases in our sample are dismissed on technical grounds.

270. One district court only shared detailed case data from 2012 to 2019 with us. While the other court's records we obtained go as far back as 2000, they are not consistent until 2012. In unreported analysis, we include the cases filed before 2012 and find no substantive changes to our main conclusions.

271. According to conversations with court staff, judges and magistrates may openly display bias while dealing with teenage drivers, as they see traffic tickets as opportunities to shape future driving behavior. June Telephone Interview, supra note 259; July Telephone Interview, supra note 259. In unreported analysis, our main conclusions are robust to including the subsample of minor drivers. This is no surprise, as restricting our analysis to adult litigants excludes a population that is explicitly (and, in the court's view, lawfully) treated more harshly, whereas differential treatment is more difficult in online proceedings.

272. The exact number of years before and after the online platform implementation depends on the court. One district court launched the Matterhorn platform in 2014 and the other in 2016.

273. A total of twenty-three judges preside over all cases in our sample, but only six preside over more than fifty cases in total. In unreported analysis, we limit the sample to only those six judges who preside over fifty or more cases and find no substantive difference in our results. Eight judges preside over cases in the online pool, but two judges handle the vast majority of these cases $(97 \%)$, and three resolve almost all of them $(99.7 \%)$. While we conjecture that the reduction of group-based disparities is a result of the online platform, it is possible that the effect might be the result of two especially fair-minded judges self-selecting into presiding over online cases. We test for this, in unreported results, by isolating the face-to-face and online 
a physical courthouse, courts disposed of approximately $32 \%$ before and $68 \%$ after Matterhorn's installation. This quasi-experiment in implementation timing allows us to assess differences in group-based outcome disparities across mediums. ${ }^{274}$ Again, we assess group disparities along three identity markers: age, gender, and race. We select these three traits because they are relevant to bias, discrimination, and disparities in other domains; they are observable in our data; and they are visible in face-to-face court proceedings but are significantly less salient on the Matterhorn platform. ${ }^{275}$

Table 1-which we display in the Appendix, along with all other tablespresents the details of the cases we examine in greater depth, including the demographic characteristics of the litigants using each medium. Face-to-face and online cases look surprisingly similar in terms of litigant age, with a median age

cases presided over by these same two judges and analyzing the differences in age-, gender-, and race-based disparities across the two hearing types. The results of this test mirror our main results, suggesting that judge self-selection does not drive our findings.

274. Because we have data from cases that closed before the implementation of the online platform, we can explore whether our findings result from selection. See generally RONET BACHMAN \& RUSSELL K.

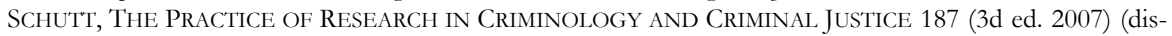
cussing selection bias and differential attrition) ("Subjects who receive some advantageous program benefit are more likely to stay in the experiment ... ; subjects who do no[t] receive program benefits are more likely to drop out."). Specifically, our concern is that only or mostly litigants who would have received fair court fines or charge adjustments, regardless of their demographic characteristics, choose to use the online platform-in that scenario, the online platform would not be the reason for their improved relative outcomes. Instead, the platform would have merely "skimmed" cases that, for whatever reason, are less disparity prone. This hypothesis has a testable implication, however: group-based disparities in face-to-face hearings should increase as less disparity-prone cases depart to online proceedings. In unreported results (available upon request), we test for such selection bias by checking for changes in group-based disparities in face-to-face hearings before and after the launch of the online platform. A growth in group-based disparities in face-to-face hearings in the post-Matterhorn period would imply selection bias in our main results. In this scenario, disparities across all modes of resolution would likely remain constant. We find no statistically significant increase in group-based disparities post-Matterhorn for offline cases, suggesting selection plays at most a limited role in explaining our main results.

275. Many empirical studies have found that exposure to a name is enough to produce biased outcomes from decision makers. Résumé audit studies, in which résumés that are substantively identical but vary in terms of identity markers are sent to employers, have found age-, gender-, and race-based discrimination. See Bertrand \& Mullainathan, supra note 66, at 997-1003 (finding race-based labor-market discrimination based solely on an applicant's name); Eva Derous \& Jeroen Decoster, Implicit Age Cues in Resumes: Subtle Effects on Hiring Discrimination, 8 FRONTIERS PSYCHOL. 1, 7-9 (2017) (demonstrating age-based discrimination in the labor market, where younger applicants are preferred); Rhea E. Steinpreis et al., The Impact of Gender on the Review of the Curricula Vitae of Job Applicants and Tenure Candidates: A National Empirical Study, 41 SEX RoLES 509, 516-22 (1999) (showing gender-based labor-market discrimination favoring male applicants in the higher education context). Relatedly, exposure to names alone has also been shown to affect educators' decisions. See Meike Bonefeld \& Oliver Dickhäuser, (Biased) Grading of Students' Performance: Students' Names, Performance Level, and Implicit Attitudes, 9 FrONTIERS PSYCHOL. 1, 5-8 (2018) (finding that educators give higher marks to those with stereotypically German names compared to those with names stereotypically associated with Turkish migrants). See generally Rachel Baker et al., Bias in Online Classes: Evidence from a Field Experiment (Ctr. for Educ. Policy Analysis, Working Paper No. 18-03, 2018), https://cepa.stanford.edu/sites/default/files/wp 18-03-201803.pdf (finding that educators in online courses are more likely to respond to questions and comments from white and male students than their nonwhite and female peers). Identity salience in writing may be most clear in terms of gender. See, e.g., Rob Thomson \& Tamar Murachver, Predicting Gender from Electronic Discourse, 40 BRIT. J. SOC. PSYCHOL. 193, 201 (2001) (finding, experimentally, that most informal communication reveals an author's gender). Even so, the online court context is more formal and structured than the online-chat and e-mail contexts used in Thomson \& Murachver's study. 
of thirty-three and thirty-five years, respectively. Interestingly, the online sample includes a larger share of women than the face-to-face sample does-in fact, $62 \%$ of women opt for online hearings, compared to $57 \%$ of men, in cases filed after Matterhorn adoption. ${ }^{276}$ Racial demographics also differ across the two dispute-resolution mediums. The proportion of litigants who are white shifts from roughly $73 \%$ in face-to-face hearings to $83 \%$ in online proceedings, whereas the proportion of litigants who are black decreases from $25 \%$ in the face-to-face setting to $15 \%$ in the online setting. ${ }^{277}$ The socioeconomic status of litigants (based on mean household income for their driving-record zip code) $)^{278}$ is similar across the two dispute-resolution mediums, with the vast majority of litigants originating from middle-class zip codes. ${ }^{279}$ The share of litigants from high-income zip codes increases by almost six percentage points in online hearings, but representation of litigants from low-income zip codes only decreases by one percentage point. ${ }^{280}$

276. Women may be overall more comfortable using online applications for government paperwork. Lee Rainie \& Elena Larsen, The Rise of the E-Citizen: How People Use Government Agencies'Web Sites, PEW RES. CTR. (Apr. 3, 2002), https://www.pewresearch.org/internet/2002/04/03/the-rise-of-the-e-citizen-howpeople-use-government-agencies-web-sites (finding that a larger share of women $(73 \%)$ than men $(66 \%)$ use government websites to accomplish work-related tasks).

277. We admit that these differences further emphasize the important concerns we describe above about within-group selection-perhaps the particular black litigants choosing to use the online platform are less likely to be subject to discrimination in any situation. As we note, supra note 274 , one implication of this story is that disparities in the offline setting should increase if online dispute resolution is attracting black litigants who are systematically less likely to suffer disparate outcomes relative to others. In unreported work, we see no significant evidence of this selection dynamic. See $i d$.

278. In unreported analysis, we instead use median household income by zip code and find that our findings are robust to this change.

279. Zip-code mean household incomes come from the 2013-2017 American Community Survey fiveyear estimates by the U.S. Census Bureau. 2013-2017 ACS 5-year Estimates, U.S. CENSUS BurEAU, https://www.census.gov/programs-surveys/acs/technical-documentation/table-and-geography-changes/2 017/5-year.html\#par_textimage (last visited Feb. 9, 2020). The zip-code socioeconomic-status thresholds are defined by the minimum wage in Michigan (in annual income terms, just under $\$ 20,000$ per person, assuming a forty-hour workweek). Because our income measure by zip code is mean bousehold income (including the income of all work-eligible residents), we doubled this minimum-income amount to create the low-income threshold. Thus, we consider any zip codes with mean household incomes below $\$ 40,000$ to be low-income zip codes. In comparison, the high-income zip-code threshold is three times the low-income threshold: any zip codes with mean household incomes above $\$ 120,000$ are high-income zip codes (notably, this household income is above the ninety-fifth percentile for the areas under the jurisdiction of these district courts). We consider all zip codes with mean household incomes above $\$ 40,000$ but below $\$ 120,000$ to be middle-class zip codes. For lack of any alternative, we assume zip codes are economically homogeneous.

280. If we are to believe that mean household income by zip code is an accurate representation of inhabitants' economic resources, the consistent representation across mediums may indicate that low-income litigants are not necessarily precluded from participating in online courts by the "digital divide." Accord Bulinski \& Prescott, supra note 11, at 236 ("In 2013, the U.S. Department of Commerce reported that 80 percent of Whites in the United States had home computers, but that for Blacks that number was only 62 percent. Individuals with disabilities owned home computers at even lower rates (53 percent), as did individuals with a lower income ( 52 percent of households with less than $\$ 25,000$ annual income). These racial and economic disparities raise significant concerns. However, the main disparity seems to be in home computer ownership rates and not actually in Internet access." (footnotes omitted)). 
We assess group disparities in two distinct outcomes. First, we use the total dollar amount of the fine ordered by the judge at the conclusion of the hearing. Second, we analyze whether the judge reduced the charges at the conclusion of the hearing, which typically signifies a reduction in points allocated to the litigant's driving record. ${ }^{281}$ In our view, the latter helps us understand the likelihood that the judge or the process favors certain groups over others in more high-stakes ways, whereas the former may help us assess whether certain groups disproportionately benefit in smaller, potentially more pervasive ways. These variables are linked, of course, as a judge must decide each outcome simultaneously. ${ }^{282}$ But they are conceptually and methodologically distinct, with distinct consequences for litigants in these cases, and so we analyze each outcome separately. ${ }^{283}$ Our empirical approach is straightforward. We use a standard OLSregression framework to study the relationship between litigant-group demographics (i.e., age, gender, and race) and the dollar amount of court-ordered fines, and we use a dichotomous outcome logit analysis to examine the relationship of these same litigant demographics to the likelihood that a judge reduced the litigant's charges. ${ }^{284}$

Our main hypothesis is that the shift from a face-to-face medium to an online approach will reduce outcome disparities that are correlated with litigants' identity characteristics. We reason that a traditional hearing with a judge increases the salience of the litigant's identity-related features, such as age, gender, and race, because a physical encounter necessarily takes place. Although proceedings conducted over an online platform do allow judges to see a litigant's name and date of birth fairly easily (and with a bit of work, whether the litigant is listed as male or female), we anticipate that this text-based, asynchronous process reduces their salience; it makes ascertaining identity information more costly or at least not instantaneous.

281. To be precise, the data only tell us whether the final charges are different-not that they were necessarily reduced-from the original charges. But conversations with court staff indicate that charges are never increased following either online or informal hearings. June Telephone Interview, supra note 259; July Telephone Interview, supra note 259. Accordingly, we assume "altered" translates as "reduced." Police officers tend to begin by recommending the highest possible charges for each incident (in this context, the "highest possible" charges are those associated with the greatest fines or number of license points).

282. They may be substitutes or complements from a judge's perspective. Either way, focusing on just one outcome would ignore a potentially important facet of outcome disparities in civil-infraction cases and would result in either an underestimate or an overestimate of the overall extent of any disparities. In unreported robustness work, we analyze these two outcomes together-specifically, in our analysis of fines, we control for the initial charge, the final charge, and whether the charge changes. The substance of our findings with respect to fines is largely unaffected by this different approach.

283. In terms of methodology, these are two very different types of variables and, consequently, are subject to different types of analysis. The amount ordered is a continuous variable, and the reduction in charge is a binary variable. At a conceptual level, these variables represent different elements of the punishment and may weigh differently in judges' preferences.

284. Scholars employ similar modeling techniques in other studies examining the explanatory role of demographics in traffic court. See generally, e.g., Richard G. Greenleaf et al., Race-Based Decisions: Traffic Citations and Municipal Court Dispositions, 8 JUST. POL’Y J., Spring 2001. 
Beyond defining our sample as a set of similar cases, we control for various observable case-level characteristics in our analysis to better isolate the impact of online court hearings and, in particular, their effect on age-, gender-, and race-based disparities in litigation outcomes. Importantly, we control for the category of the initial charge in our models so that any differences we observe are not simply the consequence of differences in the kinds of cases being handled in the face-to-face versus online hearing settings. ${ }^{285}$ We implicitly assume (soundly, in our view) that law-enforcement practices with respect to charging did not change with the arrival of online hearing options. Conversations with courts and law enforcement support this assumption, and we have seen no evidence in this or other contexts to suggest changing police practices in ticketing or citation enforcement. ${ }^{286}$

We also control for the identity of the specific judge in each case so that any differences in case outcomes derive from differences in the medium and not from the fixed practices or preferences of individual judges, some of whom are more likely to preside over some types of hearing than others. ${ }^{287}$ To this end, we only consider cases that contain information about the identity of the judge. 288 Our data also contain zip codes corresponding to the driver's license records of litigants in these cases, so we use this information to generate proxy measures for out-of-state drivers, local residents, and household incomes. ${ }^{289}$

285. We control for the original charge when we analyze the effect of litigant-identity traits on the probability that a charge reduction occurs. We also control for the final charge when we analyze the effects of litigant characteristics on the fine ordered after a hearing. This latter step is important because different charges have drastically different average fines. In our data, for example, the difference in average court fines between charge code 2740 — improper use of lights — and charge code 1810 — careless driving — is more than $\$ 90$. Because litigant-identity traits may be correlated with certain charges, we must include charge controls to isolate the effects of age, gender, and race identity traits on court-ordered punishments. In our analysis of court-ordered fines, we also control for whether the litigant's charges were reduced in order to remove the influence of "package punishment deals." See supra note 282 and surrounding text. Because more serious charges are associated with more license penalty points (resulting in higher car-insurance premiums and perhaps putting the driver's license at risk of revocation), litigants may ask to pay higher court fines in exchange for a charge reduction. Although certainly an interesting phenomenon, we seek to control for these dynamics in our analysis in case they are correlated in some way with certain social groups, which would affect the interpretation of our within-medium results.

286. In fact, the use of online courts for traffic cases is not universal in neighboring districts, so it is especially unlikely that state, county, or city law enforcement would alter their charging behaviors.

287. For example, in one court, two magistrates preside over $99.6 \%$ of online proceedings; in the other court, the chief judge presides over $99.9 \%$ of online cases. See supra note 273.

288. Of the 6,115 cases that are otherwise complete, 883 or $14 \%$ were missing judge information. The sets of cases including and excluding judge information are similar in terms of their distribution of litigant demographic characteristics, original charges, and use of the Matterhorn platform. In unreported results, we perform equivalent analyses on the two data sets (excepting the judge controls), and these lead to the same statistical conclusions. Our results are robust to including all 6,115 cases in our main analysis, but given that the cases with judge information appear to be representative of the whole sample, we restrict our main analysis to cases with judge information so that we are able to control for fixed judge differences across mediums. See also supra notes 264 and 273 (discussing judge data).

289. The out-of-state control is a binary variable equal to one if the litigant's zip code is not from Michigan and zero otherwise. The local-resident control is a binary variable equal to one if the litigant's zip code is within close proximity to the district court's jurisdiction and zero otherwise. For the suburban district court, this area includes 
Speeding is the most common charge in this sample, so we anticipate that judges may be either more or less lenient in their treatment of local residents (and, to some extent, state residents generally) relative to outsiders. Though outsiders can reasonably claim to be ignorant of the exact speed limits on every road within the court's jurisdiction, they have no political power and are "easy targets" in the sense that they are unlikely to challenge their citations — at least via in-person hearings in a courthouse. ${ }^{290}$

For our analysis, we calculate household income as a continuous variable equal to the mean household income for each driver's zip code. ${ }^{291}$ To be sure, this proxy is an exceedingly rough measure of income (and, arguably, educational attainment), but there is evidence of spatial segregation by wealth at the zip-code level. ${ }^{292}$ The lowest mean household income by zip code in our sample is $\$ 30,200$, and the highest is $\$ 218,801$, so variation in income may help explain case outcomes. If household income is correlated with certain identity groups, controlling for it can help us be more confident we are identifying group-based disparities and not, in truth, disparities related to income differences (although such disparities themselves would be interesting and worthy of study). It seems reasonable to assume that most litigants' incomes fall within a standard deviation of their residential area's mean income, which would make our income proxy a useful, if rough, control in our analysis. ${ }^{293}$

\section{Findings}

Fundamentally, our analysis tests for differences in litigation outcomes (specifically, the court-ordered fine amount and any reduction in charges) between the face-to-face and online samples along the axes of age, gender, and race of litigants. Table 2 in the Appendix presents our results for fines-specifically, it reports the relationship between litigant demographic characteristics and the dollar amount of court-ordered fines across face-to-face informal hearings and online proceedings, controlling for case characteristics, litigant income,

all zip codes within the county. For the urban district court, this area includes all zip codes that make up the city and directly adjacent zip codes. In two unreported analyses, we include only those cases with litigants who have Michigan zip codes and who have local-resident zip codes (as defined above), respectively. We find no substantive differences from our main analysis — that is, we detect no reliable evidence of bias in favor of locals over passersby.

290. Out-of-state drivers account for $2.3 \%$ of the total sample, $1.8 \%$ of the face-to-face sample, and $2.7 \%$ of the online sample. Excluding these litigants from our analysis-i.e., studying only in-state litigantsdoes not materially change our results.

291. See supra note 279.

292. See, e.g., Douglas S. Massey et al., The Changing Bases of Segregation in the United States, 626 ANNALS AM. ACAD. POL. \& SOC. SCI. 74, 81-85 (2009) (documenting the shift in spatial segregation from being primarily racially or ethnically motivated at the macro level in the beginning of the twentieth century to being primarily socioeconomically motivated at the micro level (i.e., by county and census tract) at the end of the last century).

293. We also take account of time effects and time trends, as we describe in greater detail below, that might otherwise correlate with the adoption of online proceedings. See, e.g., infra note 305. 
and residency information. Table 3 in the Appendix shows the role of litigant age, gender, and race in the likelihood that a judge reduced a litigant's original charges after a hearing. ${ }^{294}$ The estimates we report in Table 2 can be interpreted as dollars, while those in Table 3 are odds ratios. ${ }^{295}$ In this Part, we address both sets of results simultaneously, and we discuss the differences in disparities across mediums for all three group-identity traits.

Before we elaborate on what we find, however, it is important to be very clear on how we are using the word "disparity" in this Article. We use the word disparity to mean only that, having controlled for observables, individuals from one group end up with different outcomes on average than individuals from another group. ${ }^{296}$ This difference in outcomes may be either due directly to the group-identity trait (e.g., differential treatment by a judge or law enforcement on the basis of that trait) or due to various unobservables that are correlated with that group-identity trait. ${ }^{297}$ In our context, for example, unobservables that may be correlated with age, gender, or race include group differences in driving behavior that are not fully taken into account by our charge controls as well as average group differences in income, education, or priorities that influence litigation success. ${ }^{298}$ Therefore, when we report age-, gender-, or race-based disparities, we are only asserting that members of a particular group appear to wind up with systematically different outcomes on average. Such differences may have a fairly benign explanation, ${ }^{299}$ but, of course, they may not. ${ }^{300}$

294. The number of observations for the logit analysis of charge reductions is smaller than the sample for the OLS analysis of court-ordered fines. We drop a total of seventy-seven observations-twelve because they were presided over by judges who never varied in whether they reduced charges and sixty-five because certain initial charge codes were either always reduced or never reduced by judges.

295. Odds ratios can be interpreted as relative changes in likelihood. When a particular independent variable has an odds ratio coefficient estimated to be greater than one, it indicates that the relative likelihood of an event depicted by the dependent variable (in this Article, whether a charge reduction occurs) increases with an increase in the independent variable. Similarly, an estimated odds ratio coefficient of less than one indicates that an increase in the independent variable is associated with a decrease in the relative likelihood of the event-i.e., a charge reduction. These odds ratios can be used to calculate changes in the predicted probabilities of receiving a charge reduction; we depict these probabilities in Figures 1(b), 2(b), and 3(b).

296. See Roland G. Fryer, Jr. et al., Racial Disparities in Job Finding and Offered Wages, 56 J.L. \& ECON. 633, 648-50 (2013) (proposing a similar model of disparity).

297. Hence, disparities may be attributable to the judge's consideration of inappropriate information (such as a litigant's race or gender) or to the judge's consideration of legitimate, but unobserved, variables that happen to correlate with litigant race or gender. See Aidan R. Vining, Developing Aggregate Measures of Disparity, 21 CRIMINOLOGY 233, 240 (1983) (describing disparity as a function of inappropriate considerations and unobserved characteristics).

298. See, e.g., Shima Baradaran \& Frank L. McIntyre, Predicting Violence, 90 TEx. L. REv. 497, 538-42 (2012) (exploring the possibility that judges have access to information that they weigh when making their decisions but that is not captured in the authors' data or by their statistical model).

299. For example, within any particular offense category, young people may tend to commit more serious infractions on average, which the police and judges may observe but which are not visible in the available data. See $i d$. at 541 (finding that judges successfully take into account information-that researchers do not observe-in deciding whether to detain individuals).

300. Many existing studies find similar patterns of differential treatment on the basis of age, gender, race, or some combination with strong identification strategies. See, e.g., Bertrand \& Mullainathan, supra note 
Instead, what we care about for our purposes is whether there is a difference in any particular disparity between the two types of proceedings. ${ }^{301}$ If we assume that groups do not sort differently into face-to-face and online proceedings in a way that biases our results - that is, hearing type is effectively random, an assumption we address in our work 302 - then we can expect unobservable differences between groups to be the same on average across the sample. Consequently, we ought to observe similar group-based outcome disparities in both face-to-face and online settings. In our analysis below, we emphasize differences in disparities because they demonstrate that procedural choices matter differently for different groups, perhaps because they are more or less affected by judicial implicit bias. ${ }^{303}$ Put another way, we take the initial disparity in face-toface hearings to be a baseline, and we ask whether moving to an online hearing format changes this preexisting disparity, which we assume would not occur if civil procedure generally - and in particular, the use of asynchronous, remote hearings - were irrelevant to group-based disparities.

\section{Age-Based Disparities}

We begin by investigating whether, after controlling for observables, any age-based disparities in legal outcomes-i.e., the court-ordered fine amount and whether the judge reduced the original charge-differ between face-to-face and online proceedings. We treat litigant age as a binary variable, split by the median age (i.e., litigants thirty-five and younger versus those older than thirty-five), although our conclusions are not sensitive to this choice. ${ }^{304}$ We separately regress our two litigation outcomes on our age variable, the type of proceeding

66, at 994-97 (employing a résumé audit study to capture pernicious differential treatment on the basis of race); Fryer et al., supra note 296, at 648-50 (incorporating previous wage information to capture unobserved characteristics in a study concerning job-market discrimination); Darrell Steffensmeier et al., The Interaction of Race, Gender, and Age in Criminal Sentencing: The Punishment Cost of Being Young, Black, and Male, 36 CRIMINOLOGY $763,773-75$ (1998) (accounting for differences in crime circumstances not captured by charge codes by using an offense-severity scale created by the Pennsylvania Commission on Sentencing and detailed criminal history data as controls).

301. This difference-in-differences approach is often used in empirical studies to mimic a natural experiment. See, e.g., Sarah Marx Quintanar, Man vs. Macbine: An Investigation of Speeding Ticket Disparities Based on Gender and Race, 20 J. APPLIED ECON. 1, 2 (2017).

302. See supra Part II.C and notes 266, 274, and 277 (discussing selection issues)

303. Chloë FitzGerald et al., Interventions Designed to Reduce Implicit Prejudices and Implicit Stereotypes in Real World Contexts: A Systematic Review, 7 BMC PSYCHOL. 1, 10 (2019) (" $] \mathrm{f}$ intervention X reduces the bias in group $\mathrm{Y}$, it is by no means certain that same intervention is efficient to reduce bias against group Z.").

304. The age variable is a binary variable equal to one if the litigant's age is greater than thirty-five and zero otherwise. Our findings are robust to this particular characterization of age. Had we treated age as a continuous variable, we would have estimated instead the change associated with an additional year of age for our outcomes. We structure the age variable in this alternative way in unreported analysis and find the same substantive results. But we hypothesize that the impact of age is determined not by the number of years separating two particular litigants' ages but rather by the perception that the two litigants are in separate age “categories" (i.e., young versus old). See Darrell Steffensmeier et al., Age Differences in Sentencing, 12 JuST. Q. 583, 592 (1995) (finding that the effect of age on sentencing decisions is "curvilinear or U-shaped," with defendants in the twenty to twenty-nine age group facing the most severe punishments compared to similarly 
indicator (i.e., face-to-face versus online), and their interaction, in addition to a wide range of control variables.

We find strong evidence that younger drivers pay higher fines than their older peers in face-to-face courts but that this disparity evaporates in cases resolved through online hearings. ${ }^{305}$ Column (1) of Table 2 depicts the average difference in the court-ordered fine amount for those over thirty-five years old across both types of hearings. Controlling for case details and hearing type, older litigants are ordered to pay lower fines than their younger counterpartsa highly statistically significant difference on the order of $\$ 3$ per case (or roughly $2 \%$ of the average fine). ${ }^{306}$ In Column (2) of Table 2 , we compare the relationship of age to fine amount separately by hearing type: the estimated coefficient on the "Age Above 35 Years" indicator variable tells us that, on average and independent of case facts, older litigants receive lower court fines in face-toface proceedings - a difference on the order of more than $\$ 5$ (or 3\% of the average fine). Conversely, our interaction-coefficient estimate in Column (2) implies that this difference is absent in the online setting: younger litigants, on average, receive only slightly higher fines relative to their older counterparts-

situated younger and older defendants (emphasis omitted)); see also John Y. Campbell \& João F. Cocco, How Do House Prices Affect Consumption? Evidence from Micro Data, 54 J. Monetary Econ. 591, 603 (2007) (constructing a dummy variable to represent whether a homeowner is above or below forty years old); David Neumark et al., Do State Laws Protecting Older Workers from Discrimination Reduce Age Discrimination in Hiring? Evidence from a Field Experiment, 62 J.L. \& ECON. 373, 379 (2019) (constructing a dummy variable to represent how senior job seekers' outcomes are dependent on state antidiscrimination laws). We use the median age to define the two age categories, but, in unreported results, we experiment with defining age using three categories instead of just two: ages eighteen to thirty-five, ages thirty-six to sixty-five, and ages greater than sixtyfive. With that coding scheme, we find that the benefits of increasing age in traffic courts diminish after retirement age but that the divide between those younger than thirty-five and those older persists. To further investigate the validity of these choices, in unreported analysis, we create eight age categories containing mostly ten-year age cohorts (e.g., ages eighteen to twenty-five, ages twenty-six to thirty-five, etc.). In this more complex age-category model, we learn that litigants appear to begin to benefit from their age in face-to-face hearings at age thirty-six; these effects seem to disappear in the online setting. Therefore, we believe our treatment of age as a binary variable split at age thirty-five appropriately captures the basic idea of "litigant age" for purposes of understanding court-outcome disparities in our context.

305. The court-ordered fine amount (in dollars) serves as our outcome variable. We control for the identity of the judge, the offense type, and other factors that might add noise or otherwise confound our analysis (such as time trends in litigation outcomes). These additional controls include linear and squared time trends, indicator variables for the year and the month of the year in which a case is filed, and an indicator variable for whether the litigant has an out-of-state driver's license. Because the courts we study increased fines across the board at the time of the online platform's installation, we also include an indicator variable for cases that closed after the implementation of the Matterhorn online platform to separately capture this unrelated increase in fine amounts. Our results are robust to excluding these time-related controls. And since we examine the impact of online proceedings on age-, gender-, and race-based disparities in hearing outcomes (rather than the overall impact of online proceedings), we also include an indicator variable to capture the main effect of litigants' use of the online platform beyond the disparate effects of age, gender, and race. We also control for litigant gender and race to isolate the differences attributable to age. When we study the role of gender, we likewise control for age and race, and so on.

306. Darrell Steffensmeier, John Kramer, and Jeffery Ulmer show in their study that a relatively small but persistent difference in court outcomes by age group can manifest as additional incarceration time; relatively small outcome differences can be insidious if they are systematic and repeated. Steffensmeier et al., supra note 304, at 591-99. 
the remaining disparity is statistically insignificant. Figure 1(a) illustrates the presence of this disparity in face-to-face hearings as well as its apparent reduction when the dispute is resolved in an online proceeding. ${ }^{307}$

Figure 1(a). Age, Hearing Type, and Court-Ordered Fines

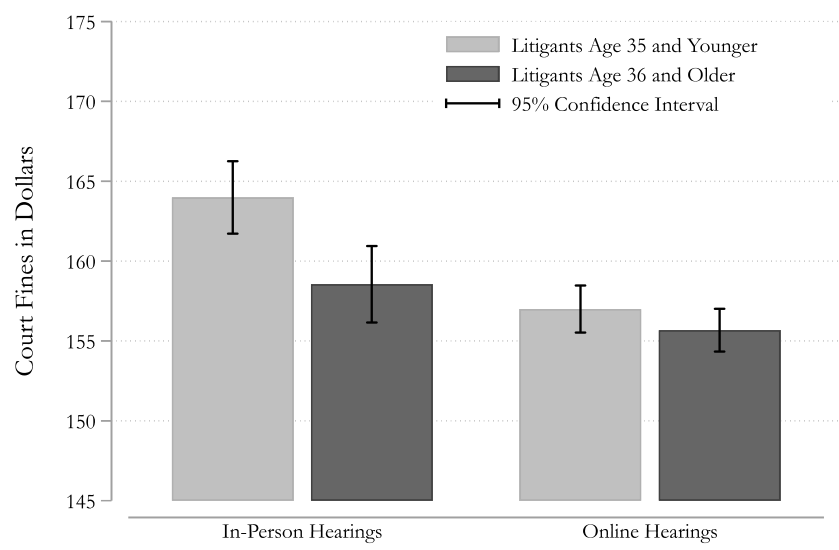

Notes: The figure displays predicted court-ordered fines by age group and hearing type with 95\% confidence intervals calculated using residuals from the regression reported in Column (2) of Table 2.

By contrast, we find no age-based disparities in charge reductions in either face-to-face or online courts. ${ }^{308}$ Column (1) of Table 3 reports that, on average, independent of the type of hearing and controlling for other potential confounders, older litigants are more likely to receive a charge reduction than their younger counterparts - but this estimated difference is only marginally statistically significant. More important for our hypothesis, when our analysis takes into account the type of proceeding in Column (2), the coefficients we estimate on both age-related terms lack any statistical significance and are very close to one. These numbers imply that older litigants are neither more nor less likely to receive charge reductions online versus face-to-face proceedings. ${ }^{309}$ Figure 1(b) illustrates our charge-reduction findings graphically.

307. Figure 1(a) depicts a prediction of the total average court-ordered fine, calculated using residuals from our regression analysis. The total fine amount appears to decrease for both young and old litigants using the online platform, but our study's interest lies in the disparity between the two age categories. The disparity is notably lower in the online setting.

308. Our dependent variable is whether the judge decided to reduce the charge (a binary outcome). For this reason, we estimate a logit regression and report odds ratios. In our analysis, the charge-reduction variable is equal to one if the judge reduced the original charges after the hearing and zero otherwise. (Charges never become more serious. See supra note 281.)

309. We recognize that interpreting coefficients on interaction terms raises significant issues in nonlinear models like logits. See generally Chunrong Ai \& Edward C. Norton, Interaction Terms in Logit and Probit Models, 80 ECON. LETTERS 123 (2003). In part for this reason, along with reporting odds ratio-style results in Table 
Figure 1(b). Age, Hearing Type, and Charge-Reduction Probability

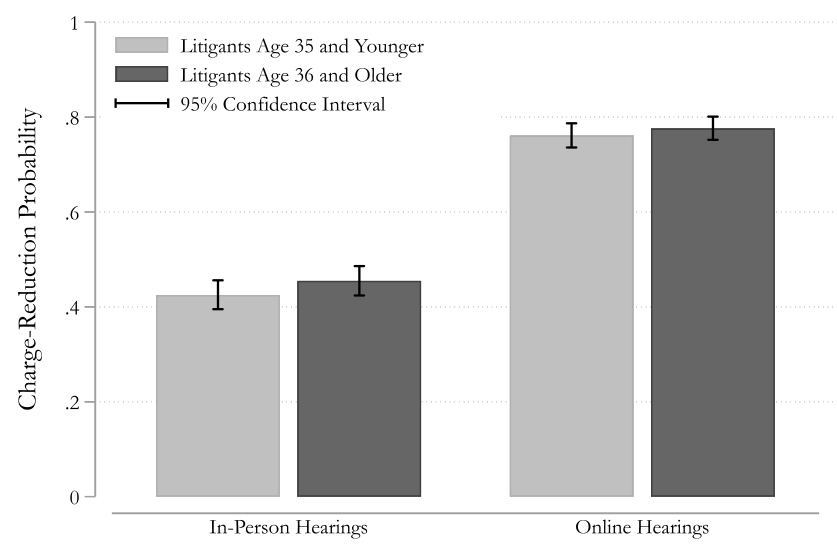

Notes: The figure displays the predicted probability of a charge reduction by age group and bearing type with 95\% confidence intervals calculated using residuals from the regression described by Column (2) of Table 3.

All in all, we find no evidence to suggest that there are age-related disparities growing out of a judge's decision whether to reduce charges in either the face-to-face or the online medium, but we do find evidence that litigant age operates in some fashion to influence the total fine amount, with older individuals paying relatively less in face-to-face settings. An implicit-bias interpretation might conclude that any bias is somewhat modest, resulting in a nontrivial change in the fine amount but not one sufficiently potent to tip a judge toward a charge reduction. ${ }^{310}$ Other interpretations might point to invidious explicit bias or even purposes of punishment that incorporate age directly-i.e., judges who feel it is proper to teach "young people" a lesson by giving them higher fines but not upsetting their future insurance costs by withholding a charge reduction. ${ }^{311}$ At the same time, our difference-in-disparity result for court-ordered

3, we also appropriately transform the coefficients to calculate predicted probabilities by group, which we present in Figures 1(b), 2(b), and 3(b).

310. Judges may differ in whether they view reductions in charges and court fines as equivalent in punishment terms, making it important to analyze how both outcomes change in response to technological innovations. Cf. Jeffrey J. Rachlinski et al., Can Judges Make Reliable Numeric Judgments? Distorted Damages and Skewed Sentences, 90 IND. L.J. 695 (2015) (arguing that judges can be influenced by the units of punishment in their sentencing deliberations). See also supra note 282.

311. See supra note 271. It may be conventional wisdom that younger drivers are more likely than older drivers to engage in risky driving, but studies evaluating whether younger drivers actually present a greater risk of committing driving offenses or accidents return mixed results based on a variety of factors, including gender, length of licensure, and the seriousness of the offense. See generally Patricia F. Waller et al., Changes in Young Adult Offense and Crash Patterns Over Time, 33 ACCIDENT ANALYSIS \& PreVENTION 117 (2001); A. F. Williams, Young Driver Risk. Factors: Successful and Unsuccessful Approaches for Dealing with Them and an Agenda for the Future, 12 INJURY PREVENTION i4 (2006). 
fines may indicate that age groups vary in how procedural conventions affect them. Young people may be better able to communicate using text over an online platform than their older counterparts; 312 or, put another way, young people may fare poorly in court, at least with respect to court-ordered fines, because they do not perform or communicate well in face-to-face proceedings with visibly older judges. 313

\section{Gender-Based Disparities}

Next, we analyze whether the differences in the two mediums (face-to-face versus online court proceedings) influence any outcome disparities associated with a party's gender. ${ }^{314}$ First, we examine the role of gender, hearing type, and their interaction in explaining court-ordered fine amounts. Column (1) in Table 2 tells us that, on average and independent of the kind of hearing and case facts, women tend to receive slightly lower fines than men. ${ }^{315}$ This difference, however, is not statistically significant. Column (3) in Table 2 displays the disparities between male and female litigants across both types of proceedings. When we analyze the data by hearing type, the relative outcomes are not necessarily identical: women who use face-to-face hearings receive slightly lower fine amounts than men, and women who use the online platform receive fines that are almost identical to men. However, none of these differences is statistically significant, so we cannot claim — at least with our sample and in our setting - that evidence of gender-based disparities exists with respect to fines ordered by judges either in general, or in face-to-face or online court settings separately. Likewise, we find little evidence that gender and medium are related to the probability of receiving reduced charges. As can be seen in Column (3) of Table 3, women are slightly more likely than their male counterparts to receive a charge reduction in the face-to-face setting, though not with statistical significance. There is no sign of a different tendency in an online court. Thus, we find no evidence of gender playing an explanatory role in outcome disparities in civil-infraction lit-

312. See Eszter Hargittai \& Amanda Hinnant, Digital Inequality: Differences in Young Adults' Use of the Internet, 35 COMM. RES. 602, 603-04 (2008).

313. See, e.g., Thomas Grisso et al., Juveniles' Competence to Stand Trial: A Comparison of Adolescents' and Adults' Capacities as Trial Defendants, 27 LAW \& HuM. BEHAv. 333, 343-56 (2003) (finding that young adults aged eighteen to twenty-four are similar to sixteen- and seventeen-year-old juvenile defendants across a variety of trial readiness and performance metrics, including compliance with authority).

314. With the exception that, in our gender analysis, we control for litigant age rather than litigant gender, we pursue precisely the same approach as we do in Part II.D.1. See supra notes 305 and 308. When we turn to analyzing the role of race, we control correspondingly for litigant age and litigant gender.

315. It is worth reiterating here that this very slight disparity is what remains after we control for those observables for which we have data; however, if women tend to commit infractions in different, slightly less serious ways, perhaps because of gender differences in driving patterns, the "disparity" we observe could simply be the result of some underlying (but unobserved) difference in case facts. See supra notes 296-303 and accompanying text. 
igation on average, but we cannot rule it out, either; a larger sample or a different context might tell a very different story. ${ }^{316}$ Figures $2(\mathrm{a})$ and $2(\mathrm{~b})$ show our results.

Figure 2(a). Gender, Hearing Type, and Court-Ordered Fines

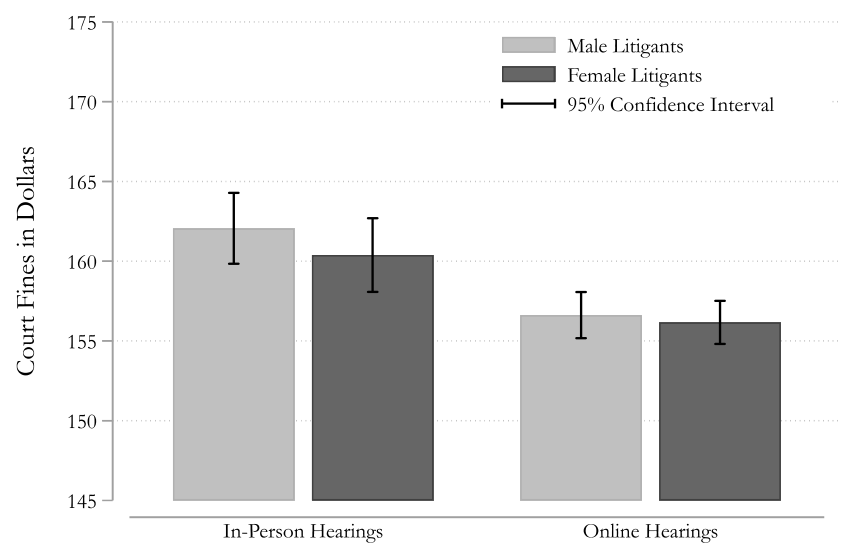

Notes: The figure displays predicted court-ordered fines by gender and hearing type with $95 \%$ confidence intervals calculated using residuals from the regression reported in Column (3) of Table 2.

Figure 2(b). Gender, Hearing Type, and Charge-Reduction Probability

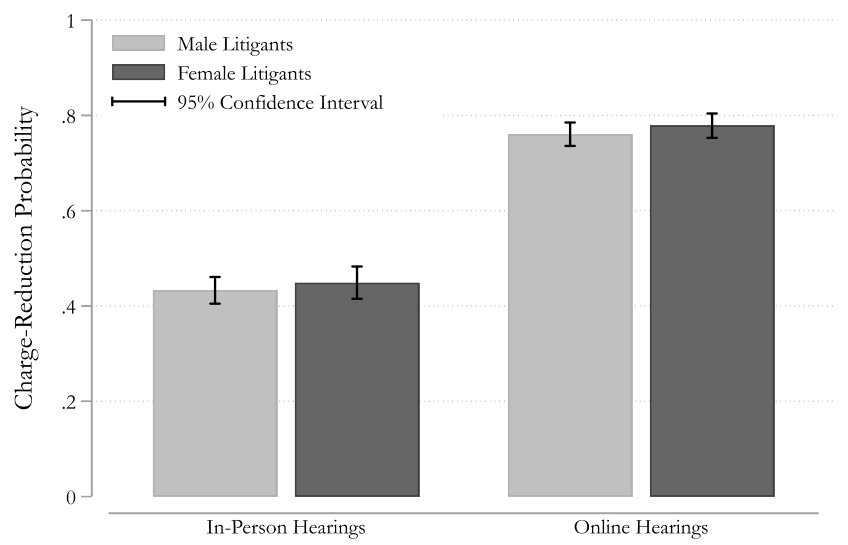

Notes: The figure displays the predicted probability of a charge reduction by gender and hearing type with $95 \%$ confidence intervals calculated using residuals from the regression described by Column (3) of Table 3.

316. See, e.g., Darrell Steffensmeier et al., Gender and Imprisonment Decisions, 31 CRIMINOLOGY 411, 435 (1993) (finding that gender has a small-to-moderate effect on the likelihood of incarceration-with women being less likely to be imprisoned-but has no noticeable effect on incarceration length). 


\section{Race-Based Disparities}

Finally, we investigate race-based disparities in litigation outcomes, ${ }^{317}$ examining whether any apparent outcome disparity in the face-to-face court setting is reproduced in the online hearing setting or, alternatively, whether disparity levels shift with the change in medium. First, we find substantial evidence that black litigants receive higher court fines and are less likely to receive charge reductions in face-to-face settings than similarly situated nonblack litigants. ${ }^{318}$ Second, our analysis of the data indicates that these outcome disparities vanish or are at least significantly smaller in online proceedings, suggesting that online proceedings may have some ability to reduce the role of implicit bias or tweak the structural distortions of traditional procedure so that black litigants experience better litigation outcomes on average.

Sticking with our empirical approach from above, we begin by examining the relationship of race, medium, and their interaction with the total amount of court-ordered fines. ${ }^{319}$ Column (1) of Table 2 shows that, on average and independent of hearing type and case facts, black litigants receive higher fines than nonblack litigants - on the order of over $\$ 6$ (or roughly $4 \%$ of the average fine). This estimated disparity is highly statistically significant. When we assess this disparity in court-ordered fine amounts separately by hearing type, the results of which we present in Column (4) of Table 2, we observe an important and sizable shift. Black litigants using the online platform see a much lower relative fine, all else equal, relative to black litigants engaging with the court in person; race-based disparities associated with traditional procedures disappear in the online setting, and in fact, we estimate that black litigants receive slightly lower fines than their nonblack counterparts. Figure 3(a) illustrates these relationships.

317. The race variable in our analyses is a binary variable equal to one if the litigant's race is black and zero otherwise. We compare black to nonblack litigants instead of comparing black, Asian, Native-American, and white litigants. White and black litigants make up the vast majority of litigants in our sample; Asian and Native-American litigants are not sufficiently common in our data to make reliable inferences about their groups' average litigation experience. In unreported results, we test the impact of including all individual races in our analysis and find the same relationships that we report in our main results between both white and black litigants and Asian and black litigants. Asian litigants in our sample fared significantly better than white litigants in the face-to-face setting, but our sample of Asian litigants is too small to make inferences about any population-level effects.

318. Again, these disparities may exist because of omitted variable bias and so they should not be interpreted as the causal result of litigant race. See supra notes 296-303 and 315. For a thorough discussion of the effects and limitations of omitted variable bias in empirical work using (often incomplete) law-enforcement and court data, see generally David B. Mustard, Reexamining Criminal Behavior: The Importance of Omitted Variable Bias, 85 REV. ECON. \& STAT. 205 (2003).

319. Except that we control for litigant age and gender in this case. 
Figure 3(a). Race, Hearing Type, and Court-Ordered Fines

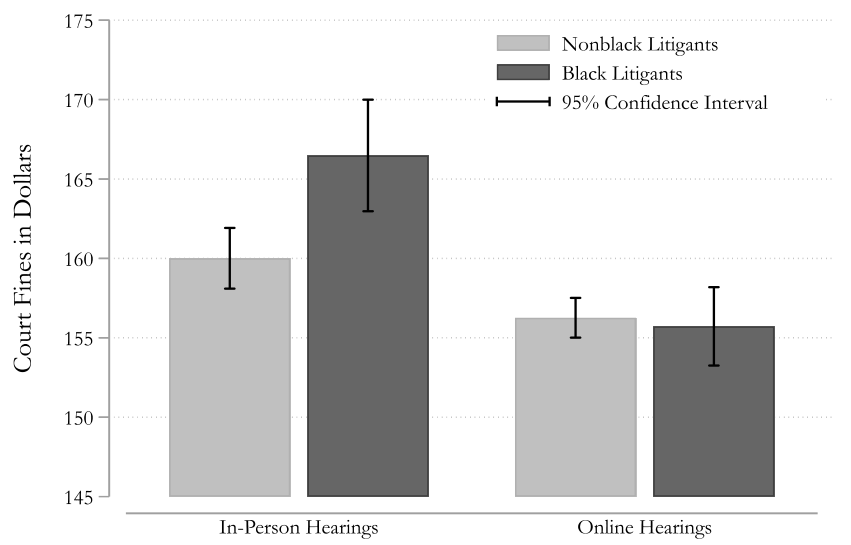

Notes: The figure displays predicted court-ordered fines by race and hearing type with 95\% confidence intervals calculated using residuals from the regression reported in Column (4) of Table 2.

A similar phenomenon emerges with respect to charge-reduction probability: Column (1) of Table 3 shows strong statistical evidence that, on average and independent of hearing type and observable case facts, black litigants are significantly less likely to receive reduced charges from a judge than are their nonblack counterparts. 320 As Column (4) of Table 3 shows, however, the difference between black and nonblack litigants evaporates in the online setting, according to our estimates. ${ }^{321}$ Figure 3(b) illustrates the difference in the likelihood of a charge reduction between black and nonblack litigants across the two types of hearings. Even if the likelihood of a charge reduction for black litigants in online proceedings is at the lower bound of the $95 \%$ confidence interval, it would remain a marked improvement over their expected face-to-face outcome. These effects are consistent across courts, as well. ${ }^{322}$

320. The coefficient on the race variable in Column (1) of Table 3 is 0.729 . This means that the odds a black litigant's charges will be reduced are roughly $73 \%$ of the odds a nonblack litigant's charges will be reduced, all other factors equal (and without taking into account the differences in hearing medium). This result is statistically significant at the $1 \%$ level.

321. The coefficient on the race variable in Column (4) of Table 3 is 0.637 , meaning that the average black litigant is even less likely to receive a charge reduction than their nonblack peers once we account for the hearing medium. However, the coefficient on the race-and-medium interaction variable is 1.646 — a highly significant result. Since the effect in logit models is multiplicative, the difference between a black litigant and an otherwise equal nonblack litigant using the online platform is 1.05 . Therefore, black litigants actually appear to be slightly more likely to receive a charge reduction when their cases are heard through the online platform relative to an otherwise equivalent nonblack litigant.

322. Two distinct district courts constitute our complete analysis sample—one situated in a suburban area and the other in a population-dense city. While we believe the similarities between these courts outweigh the differences in any statistical sense, both courts define face-to-face hearings and process traffic cases in slightly different ways. Consequently, in unreported work, we repeat our analysis on the two district-court 
Figure 3(b). Race, Hearing Type, and Charge-Reduction Probability

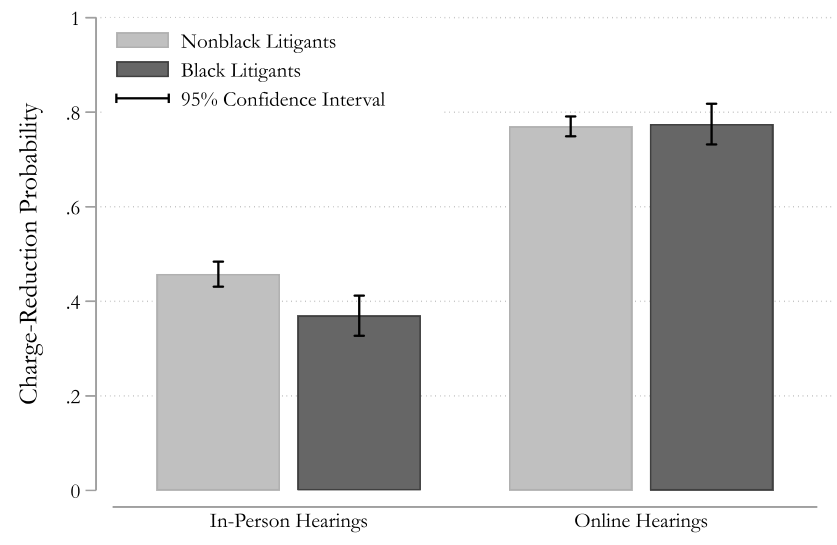

Notes: The figure displays the predicted probability of a charge reduction by race and hearing type with 95\% confidence intervals calculated using residuals from the regression described by Column (4) of Table 3.

\section{Intersectional Identity Biases}

By design, our three analyses control for "other" observable identity traits when we identify changes in disparities across mediums. ${ }^{323}$ However, the empirical legal literature on intersectionality highlights the potential for additional variation in litigation outcome disparities along shared axes of age, gender, and

samples separately. Tables are available from the authors upon request. The suburban-court results approximate the main results fairly closely. Older litigants receive significantly lower court-ordered fines than younger litigants in face-to-face hearings and equal fines online. Older litigants are also more likely to receive charge reductions than younger litigants in face-to-face settings_- a disparity that decreases in magnitude online. The disparity in court-ordered fines across genders is not significant, though it gestures in the same direction as our aggregate analysis. However, unlike our main analysis, female litigants are significantly more likely to have their charges reduced than male litigants in face-to-face hearings - a disparity that fades online. Black litigants receive significantly higher court-ordered fines than nonblack litigants do in face-to-face hearings and nearequal court fines online. Black litigants are also significantly less likely to receive reduced charges than their nonblack counterparts in face-to-face hearings; online courts nearly eliminate this disparity as well (though, notably, the change is not statistically significant). The urban-court results are also close to the main results, with one key distinction. In analyzing this court's data alone, we note that women litigants are somewhat less likely to receive charge reductions in face-to-face hearings. This is in direct contradiction with our gender results from the suburban court. Since women are nearly evenly distributed across the courts, this may explain the lack of significant gender-based disparities for the entire sample. Age-based disparities are also much larger in the urban court: older litigants receive significantly lower court fines than younger litigants in faceto-face hearings; the online platform greatly (and statistically significantly) reduces this difference, though disparities favoring older litigants are still present.

323. Specifically, we control for gender and race when examining age, we control for age and race when examining gender, and we control for age and gender when examining race. 
race. ${ }^{324}$ Our data and setting provide an opportunity to extend the study of intersectionality into the civil-infraction context and to draw conclusions about the role of procedural design and/or implicit bias - and of online hearings generally - in understanding intersectional disparities. We test for the intersectional group-identity disparities by comparing predicted outcomes on various identity subgroups using the estimates from our main analysis. Not surprisingly, certain groups experience larger disparities in court outcomes in the face-to-face traffic-court context. In particular, our data show that younger black male litigants fare worse than younger litigants, black litigants, and male litigants as groups. Likewise, we find that younger black female litigants do poorly relative to younger litigants, black litigants, and female litigants as groups. ${ }^{325}$ As in our main analysis, in general, the apparent disparities that appear in our data in faceto-face proceedings are much less pronounced online, although our estimates of these changes are often imprecise in these small-sample analyses. 326

\section{Limitations, Caveats, and Extensions}

Although the evidence we present provides encouraging support for our hypothesis regarding the potential of online proceedings to reduce group-based outcome disparities, our analysis is limited in several respects. Our single most important assumption is that the litigants using (and the cases being resolved

324. A common focus of intersectionality analysis in the empirical legal literature is minority women as plaintiffs in civil lawsuits or as judges. See, e.g., Rachel Kahn Best et al., Multiple Disadvantages: An Empirical Test of Intersectionality Theory in EEO Litigation, 45 LAW \& SOC'Y REV. 991 (2011) (discussing the relatively low success rate for black women making intersectional employment discrimination claims); Todd Collins \& Laura Moyer, Gender, Race, and Intersectionality on the Federal Appellate Bench, 61 POL. RES. Q. 219, 225 (2008) (finding that minority women judges are more likely than their minority male and nonminority female peers to support claims of criminal defendants). Fewer studies focus on intersectionality in the criminal context, in which minority men suffer severe disparities. See, e.g., Steffensmeier et al., supra note 300.

325. Younger black male litigants fare worse than any other intersectional identity group in our data. This finding is consistent with intersectionality research in the law-enforcement and criminal-adjudication contexts. See Steffensmeier et al., supra note 300. See generally Andrea L. Dottolo \& Abigail J. Stewart, 'Don't Ever Forget Now, You're a Black. Man in America": Intersections of Race, Class and Gender in Encounters with the Police, 59 SEX ROLES 350 (2008). For women, race-based disparities are larger in magnitude than they are in our full sample: black women receive significantly higher court fines than nonblack women in person but slightly lower court fines online. This finding aligns with empirical intersectionality research generally. See Stephanie A. Shields, Gender: An Intersectionality Perspective, 59 SEX ROLES 301, 302-04 (2008).

326. We forgo an extended discussion of the details of our intersectionality findings, but our results are available upon request. To summarize other patterns we observe in the data: older nonblack male litigants do relatively well in face-to-face hearings, meaning that older nonblack male litigants receive lower fines and exhibit higher charge-reduction probabilities than older litigants, nonblack litigants, and male litigants as groups, and older nonblack female litigants receive lower fines and higher charge-reduction probabilities than older litigants, nonblack litigants, and female litigants as groups. In both cases, these intersectional disparities are much smaller in online proceedings. Older black litigants experience better outcomes than black litigants overall in face-to-face hearings but do significantly worse than older litigants overall and male/female litigants as groups. These disparities also dissolve online. Younger nonblack litigants suffer worse outcomes in faceto-face hearings than nonblack litigants overall but do significantly better than all younger litigants. These disparities also exist in the online setting. 
through) traditional proceedings are comparable to the litigants opting for online hearings. ${ }^{327}$ Litigants and cases are not allocated randomly; rather, litigants actively choose whether to pursue a traditional face-to-face proceeding, an online hearing, or nothing at all. ${ }^{328}$ It is possible that the patterns we document are not attributable to the change in medium but rather to the characteristics of the parties who choose to access courts online versus offline. For example, online users may have greater access to the Internet, may be more technologically savvy, and could be busier, so age- and race-based disparities may be less likely to manifest within this narrower group. Unfortunately, we cannot eliminate the possibility that selection explains our results to some extent. Mindful of the confounding effect of selection bias, we took measures to test for its presence and correct for it whenever possible. ${ }^{329}$

Also, in a similar vein, it is worth reiterating that our within-medium disparity findings should not be interpreted causally. ${ }^{330}$ Our results show statistically significant disparities in litigation outcomes between younger and older and between black and nonblack litigants in face-to-face proceedings after we control for observable case and demographic information. Unfortunately, we do not observe-and therefore cannot control for-many details of these disputes that might matter to explaining outcomes. One important example is an individual's infraction history, which most view as a legitimate consideration for a judge deciding whether to grant a litigant relief, 331 and yet infraction history may be correlated with race or age. 332 We were not able to obtain these data for

327. See supra notes 240,274 and accompanying text.

328. See Lee Epstein \& Gary King, The Rules of Inference, 69 U. CHI. L. REV. 1, 99-114 (2002) (explaining the importance of random sample selection to avoid selection bias in empirical studies).

329. Although selection bias may affect our difference-in-disparities findings, we know it cannot explain our results entirely. In unreported analysis, we compare the group of face-to-face cases litigated prior to the implementation of the online platform with the face-to-face cases litigated after implementation and find no statistically significant differences in the group-based disparities of the two face-to-face samples. See supra note 274 . After accounting for all quantifiable variables available, we find no statistical difference between older, female, or black litigants who chose to litigate their alleged traffic offense in a courtroom across the two time periods. Had we found that the post-implementation face-to-face cases exhibited significantly higher disparities than the pre-implementation sample, a selection story would have been very plausible. But our unreported robustness analysis shows that it is unlikely that litigants who would have received favorable outcomes regardless of the hearing medium (for whatever reason not strictly and causally related to age, gender, or race-including legal awareness, social connections, wealth, or education) are the main driving force behind the reduction in group-based disparities we document in online hearing outcomes. Moreover, because we care about disparities between younger and older litigants, male and female litigants, and black and nonblack litigants and not the average level of court outcomes across hearing types, we also know that our results are not driven by above-average online platform use by older litigants, female litigants, or nonblack litigants, respectively, who happen to receive more lenient court outcomes in face-to-face proceedings.

330. See supra notes 296-303 and accompanying text.

331. E.g., Mich. COMP. LAWs ANN. \ 257.907(2) (West 2015) ("[F]or a violation of section 602b, the person shall be ordered to pay . . a civil fine of $\$ 100.00$ for a first offense and $\$ 200.00$ for a second or subsequent offense."); June Telephone Interview, supra note 259; July Telephone Interview, supra note 259.

332. See Travis Hirschi \& Michael Gottfredson, Age and the Explanation of Crime, 89 AM. J. SoC. 552, 581 (1983) ("Age is everywhere correlated with crime. Its effects on crime do not depend on other demographic correlates of crime. ... Although correlated with crime, age is not useful in predicting involvement 
litigants in our analysis; however, our cases were selected by eligibility criteria that ensure that litigants in our sample are similar in terms of their driving history. Future research on civil infractions and misdemeanor decision-making ought, whenever possible, to include a measure to control for litigant driving histories — or perhaps a measure to control for whether judges consider driving histories in their deliberations. ${ }^{333}$

Although we do not discuss it above, we also uncover a provocative relationship between average neighborhood income and litigation outcomes in our data. Our analysis suggests that more work is necessary to understand groupbased disparities and how they arise in our justice system. ${ }^{334}$ We find that litigants from zip codes with higher mean household incomes receive lower fines and are more likely to receive a charge reduction in face-to-face hearings. The sizes of these effects are not large, and the interpretation of disparities based on zip-code household income is unclear, 335 but both relationships are statistically significant. The roles of income and wealth in explaining litigation outcomes have obvious policy implications. Future work may also involve an in-depth analysis of the actual interactions between parties and judges in both face-toface hearings and online courts. ${ }^{336}$ Our results indicate that online courts affect the extent of group-based outcome disparities, but we know far too little about the reasons for this shift. One conjecture, of course, is that reduced identity salience plays an outsized role in the benefits of online proceedings, but the many procedural tweaks that accompany online proceedings may also coalesce in a way that benefits some groups more than others.

in crime over the life cycle of offenders."); Alex R. Piquero \& Robert W. Brame, Assessing the Race-Crime and Ethnicity-Crime Relationship in a Sample of Serious Adolescent Delinquents, 54 CRIME \& DELINQ. 390, 395-96 (2008) ("Generally speaking, both police records and self-report surveys show disproportionate involvement in serious violence among Blacks with somewhat less Hispanic involvement. This is significant, because research also indicates that crimes involving serious violence are more likely to be reported to the police, more likely to result in apprehension of the offender, and more likely to trigger more severe criminal justice sanctions. In addition, researchers have also examined racial disproportionality in prisons. This research generally suggests that much of the minority overrepresentation in prisons can be attributed to race group differences in arrests for crimes that are most likely to lead to imprisonment. But this research also indicates that it is unlikely that behavioral differences can account for all minority overrepresentation." (citations and footnotes omitted)). See generally Gary Sweeten et al., Age and the Explanation of Crime, Revisited, 42 J. YOUTH \& ADOLESCENCE 921 (2013) (examining developmental reasons for why crime varies with age).

333. Incorporating criminal-history data into analyses can dramatically change statistical inferences. See, e.g., Steffensmeier et al., supra note 300.

334. Tables containing these results are available from the authors upon request.

335. This is especially true for data from the suburban court. Zip codes in this relatively low-density area are larger than those surrounding the urban court; any zip-code-level income data from the suburbancourt zip codes describes the average income of each neighborhood less accurately due to the relative size difference of the zip codes across district courts.

336. Court interactions and other unquantifiable factors are especially important to review, given their frequent presence in judicial deliberations. See, e.g., Baradaran \& McIntyre, supra note 298, at 541. 


\section{E. Discussion on Disparities}

Taken together, our findings carry several implications for scholarship on disparities both in general and in the legal arena specifically. First, our analysis highlights the importance of age-based disparities in legal outcomes. Age, as an identity trait, receives much less attention than race and gender do in the study of legal institutions. ${ }^{337}$ This relative neglect is surprising given that ageism is an extensively studied topic in the social-science literature on implicit bias. ${ }^{338}$ Indeed, research that uses the IAT typically finds that age-based implicit bias is among the strongest categories of bias, ${ }^{339}$ overshadowing both gender-based and race-based biases. ${ }^{340}$ Research on age-based implicit bias and procedurebased structural biases in the justice system may be limited because age is assumed either to be a formal legal factor properly affecting outcomes ${ }^{341}$ (e.g., eligibility for juvenile delinquency proceedings) ${ }^{342}$ or substantively unimportant. ${ }^{343}$ But age as a factor can be relevant within the adult population, in particular in the traffic context where deterring young drivers may be seen as an appropriate consideration in judicial decisions. ${ }^{344}$ Thus, when it comes to age-based disparities in litigation outcomes, we do not know whether explicit, implicit, or structural biases_or all of the above-explain the disparities we observe.

We confirm that age may indeed shape legal outcomes. Older litigants appear to receive lower court-ordered fines compared with their younger counterparts in face-to-face proceedings but pay similar fines to those imposed on younger drivers in online proceedings. There are various explanations for the difference across mediums in the disparities we observe.

337. See Becca R. Levy \& Mahzarin R. Banaji, Implicit Ageism, in AgEISM: STEREOTYPING AND Prejudice Against Older Persons 49, 52 (Todd D. Nelson ed., 2002).

338. See, e.g., id. at 49-53.

339. Id. at 53-56. The IAT is the most popular test to assess implicit biases, taken by millions of respondents across the globe. See supra Part I.B.

340. Brian A. Nosek et al., Harvesting Implicit Group Attitudes and Beliefs from a Demonstration Web Site, 6 GROUP DYNAMICS 101, 107 (2002) ("Negative implicit attitudes toward old relative to young were, on average, the strongest of any obtained at the [IAT] demonstration Web site.").

341. See, e.g., J.D.B. v. North Carolina, 564 U.S. 261, 271-75 (2011) (finding age is a relevant factor in determining whether a person is in custody).

342. Anne Teigen, Juvenile Age of Jurisdiction and Transfer to Adult Court Laws, NCSL (Apr. 7, 2020), https://www.ncsl.org/research/civil-and-criminal-justice/juvenile-age-of-jurisdiction-and-transfer-to-adultcourt-laws.aspx (breaking down by state the age at which juveniles are transferred to adult court); Legal Ages Laws, LAW LiBR. - AM. L. \& LEGAL INFO., https://law.jrank.org/pages/11848/Legal-Ages.html (last visited May 3, 2020) (charting various "legal ages" by state).

343. See William J. Chopik \& Hannah L. Giasson, Age Differences in Explicit and Implicit Age Attitudes Across the Life Span, 57 GERONTOLOGIST S169, S169-70 (2017) (noting that "little attention has been paid to how implicit and explicit attitudes differ across [one's] life span” and finding various implicit preferences based on age).

344. See Roger C. Cramton, Driver Behavior and Legal Sanctions: A Study of Deterrence, 67 MiCH. L. REV. 421, 426 (1969); Barry M. Sweedler, Strategies to Reduce Youth Drinking and Driving, 14 AlCoHol HeALTH \& RES. WORLD 76 (1990). 
One possibility is that the age-based implicit stereotypes in this setting serve to improve the condition of older litigants who enjoy lower fines for similar offenses. This dynamic can be a manifestation of "benevolent ageism": older people may appear to benefit from ageist stereotypes when, in fact, these "benefits" simply reinforce these biases. ${ }^{345}$ Under this interpretation, online proceedings disrupt the stereotyping process by making it more difficult for judges to discern a litigant's age. Another possibility is that the disparate outcomes in face-to-face proceedings reflect a conscious attempt (explicit bias) to deter young drivers. Yet even in that context, our finding that disparate treatment persists with statistical significance between ages twenty-six and thirty-five-a point in a typical driver's life when they have between one and two decades of driving experience_-blunts any "shaping young minds" argument for conscious bias. According to this view, online proceedings as currently deployed simply make it harder for judges to punish younger litigants. Finally, our traditional processes may work to the benefit — at least with respect to fines — of older litigants, perhaps because they are experienced and less intimidated by judges; by contrast, online proceedings may empower younger people.

With respect to gender, we do not observe outcome disparities under traditional proceedings_-nor in online proceedings. While much attention has been dedicated to examining the impact of judge gender on legal outcomes, there is less research studying the role, if any, of party gender. ${ }^{346}$ Existing research provides inconclusive findings, possibly because it is very difficult to find a pool of cases that are equivalent in the type of legal matter, the size of the stakes, and the surrounding context across genders, ${ }^{347}$ particularly in the criminal domain. ${ }^{348}$ Here, we locate a class of disputes - civil traffic violations-in which we can more easily assemble equivalent pools.

Although our research does not find gender-based disparities in legal outcomes in face-to-face proceedings, we cannot claim that there are no implicit or structural biases in traditional hearings. ${ }^{349}$ But the fact that a shift in medium and with it the change from oral to written communication does not seem to produce a change of some sort suggests that 1) little or no implicit bias exists, 2) implicit bias continues apace online because it is — currently_-somewhat easy

345. Cf. Peter Glick \& Susan T. Fiske, An Ambivalent Alliance: Hostile and Benevolent Sexism as Complementary Justifications for Gender Inequality, 56 AM. PSYCHOLOGIST 109, 110 (2001) (stating that "[b]enevolent sexism is a subtle form of prejudice, yet the ideology it represents may be far from trivial in promoting gender inequality").

346. With respect to the impact of judge gender on outcomes, evidence is also inconsistent. See Boyd et al., supra note 56 , at 392.

347. The difficulty of creating equivalent or comparable case pools is due in part to the fact that women and men have different criminological landscapes, both in terms of the crimes they commit as well as the circumstances surrounding those crimes. See, e.g., Darrell Steffensmeier \& Emilie Allan, Gender and Crime: Toward a Gendered Theory of Female Offending, 22 ANN. REV. SoC. 459, 460-64 (1996).

348. See Sonja B. Starr, Estimating Gender Disparities in Federal Criminal Cases, 17 AM. L. \& ECON. REV. 127, 128-29 (2015).

349. See supra notes $296-303$ and accompanying text. 
to discover a person's gender in online proceedings (through a litigant's name), or 3) there is no gender-group comparative advantage to using online hearings versus traditional hearings. This last possibility seems at odds with research indicating that differences between women's and men's writing styles lead to outcome disparities in other contexts, ${ }^{350}$ but it may still make sense in light of the brief and straightforward nature of written statements in the traffic violation context, a question that is the subject of our future research.

Finally, our study also contributes to the research on race-based disparities in the justice system by showing that black litigants experience worse outcomes than (observably) similarly situated nonblack litigants in terms of both courtordered fine amounts and the likelihood of receiving a charge reduction. In line with the large literature showing that racial identity is a common source of bias and disparity in the criminal justice system, ${ }^{351}$ we calculate large disparities for black traffic-court litigants in face-to-face courts, but these race-based outcome disparities appear to evaporate in online proceedings. Barring a selection story, the dramatic disappearance of these disparities seems very likely to result from a reduction of implicit bias and/or the influence of the online medium's distinctive procedural attributes-for example, the shift to written form, the removal of potentially stressful face-to-face encounters, and the additional procedural structure, which may put groups on more equal footing. Unlike with gender, ascertaining the race of a litigant is difficult in the online proceedings we study unless the litigant has a name that makes drawing an accurate inference about race easy for a judge. ${ }^{352}$ We hope to better understand the exact reason for this reduction in outcome disparities through future research.

\section{IMPARTIALITY IN THE AGE OF DIGITAL COURTS}

\section{A. Toward a New Impartiality Equilibrium?}

Online courts have been gaining traction in recent years. ${ }^{353}$ This advance is due to two principal developments. The first is the growth of ODR - in particular, its evolution from resolving consumer controversies to addressing a

350. Kolev et al., supra note 188.

351. See generally Radley Balko, 21 More Studies Showing Racial Disparities in the Criminal Justice System, WASH. POST (Apr. 9, 2019), https://www.washingtonpost.com/opinions/2019/04/09/more-studies-show ing-racial-disparities-criminal-justice-system/ (summarizing results from multiple studies showing racial bias in the criminal justice system).

352. See, e.g., Bertrand \& Mullainathan, supra note 66, at 992 (finding that résumés with African-American-sounding names are $50 \%$ less likely to receive callbacks than résumés of similar quality with whitesounding names).

353. See Part II.B; supra note 15 and accompanying text. 
broader class of legal disputes. ${ }^{354}$ The second development is the maturing of court technology, especially record-keeping software. Pressure to enhance court efficiency and accessibility prompted this change, and improvements include allowing judges and lawyers remote access to court information, digitized case management, automatization of workflow functions, online filing of claims, and online publication of judicial rulings. 355 The next natural step was to move beyond mere digitization and piecemeal communication to carrying out entire judicial processes online-a metamorphosis we are now observing with the expansion of ODR into public courts. 356

Alongside enhanced efficiency and access, the diffusion of technology in courts over the last decade has, inadvertently, opened the door to other potential advantages. As we argue in this Article, the shift from in-person to online proceedings changes the nature of litigation. These "technical" improvements may seem minor, but they have important implications for group-based disparities in litigation outcomes. The introduction of remote, text-based, asynchronous judicial proceedings has, at a minimum, the potential to allay unwarranted disparities due to implicit biases by limiting a judge's exposure to a party's identity information. In our work, we find that despite judges having some identityrelevant information available to them in text format, the elimination of physical encounters appears to reduce or eliminate disparate outcomes correlated with certain identity characteristics. 357

Addressing litigation disparities through the use of online court technology does not involve the tools and approaches that underlie more traditional interventions to reduce bias (i.e., developing awareness and motivation to counter the automatic tendencies toward and triggers of implicit bias). ${ }^{358}$ These conventional efforts demand substantial resources as well as a strong and consistent commitment from individual judges, court personnel, and courts as institutions. But such resources are often difficult to collect and maintain because the legal system is under constant pressure to cut costs and improve efficiency. Plus, judges and court administrators may find it psychologically difficult to commit those resources when reducing implicit bias seems elusive-despite judges being fiercely devoted to impartial decision-making in the abstract. ${ }^{359}$

Online proceedings can make ex post debiasing unnecessary, obviating the need for an enduring and systemic commitment by courts to costly debiasing

354. The spread of smartphones and social media induced dramatic changes in Internet-use patterns, blurring pure online and offline activities and transforming what individuals view as an appropriate domain for online solutions. See supra note 201 and accompanying text.

355. See supra notes $205-07$ and accompanying text.

356. See supra notes 209-14 and accompanying text. For a list of courts throughout the United States and worldwide using ODR, see Courts Using ODR, NAT'L CTR. FOR TECH. \& DiSP. ReSOL., http://odr.info/courts-using-odr/ (last visited Apr. 14, 2020).

357. See supra Part II.D.

358. See, e.g., supra notes 138-61 and accompanying text.

359. See supra Part I.A. 
efforts. Eliminating — or at least reducing-implicit bias becomes an ex ante design choice rather than an ever-repeating Sisyphean stage of judicial decisionmaking. ${ }^{360}$ This may be both good and bad, precisely because online proceedings can reinforce impartiality without an explicit commitment to eliminating implicit or structural biases. Courts should adopt measures to reduce judicial exposure to group-identity-related traits and add structure to judicial deliberations as fairly simple prescriptions from this study. If courts take these steps, however, judges may feel relieved of their responsibility to become aware of such biases and the relationships of these biases to structure, process, and decision-making. ${ }^{361}$ Further, courts may lose focus on the need to uncover new sources of bias that may be associated with online engagement. ${ }^{362}$

At the same time, online "blinding" techniques appear to have real potential to succeed where other approaches to address bias have struggled, and we may be just fine with behind-the-scenes bias reduction, even if it comes at a cost of clouding our awareness of biases and openly discussing them less often. The time and effort required of judges — from undergoing bias training, to implementing its lessons in their deliberations, to preventing the automatic triggering of biases — are significant. Moreover, judicial decision-making occurs under circumstances that are quite susceptible to implicit biases-especially when it comes to civil infractions. Judges operate under extreme time pressure, handle a heavy caseload, and are often evaluated according to their ability to "close cases" rather than deliver justice. ${ }^{363}$ Indeed, these common conditions might account for the limited success of some measures to counter biases. ${ }^{364}$ Shifting to online proceedings avoids the trade-off between impartiality and efficiency. It could advance both objectives simultaneously. ${ }^{365}$

360. Obviously, one could design the platform to highlight relevant group-identity features, thereby ensuring their salience, much as in the face-to-face setting. But it is not certain that, even where salient, these features would have the same effect online.

361. See Mahoney, The Myth of Judicial Neutrality, supra note 12, at 811-19 (describing threats when courts do not focus on the sources of bias and its impact). We do not suggest that the solution lies in race (or gender or age) blindness generally, an approach that has been found problematic. See Reva B. Siegel, Discrimination in the Eyes of the Law: How "Color Blindness" Discourse Disrupts and Rationalizes Social Stratification, 88 CALIF. L. REV. 77,84 (2000). Rather, we suggest that online proceedings may be more successful than face-to-face settings in avoiding the effects of implicit bias despite the fact that some identity-related information is available to decision makers in court records. See, e.g., supra notes 184-88.

362. Research regarding discrimination in online settings ranges from online education to participation in the sharing economy. See, e.g., Rachel Baker et al., supra note 275; Benjamin Edelman \& Michael Luca, Digital Discrimination: The Case of Airbnb.com (Harvard Bus. Sch., Working Paper No. 14-054, 2014).

363. See Guthrie et al., supra note 166, at 35 (characterizing judges' time pressures as an "enormous challenge, often inducing less-than-optimal decision making”); JUDICIAL COUNCIL OF CAL., CTR. FOR FAMILIES, CHILDREN \& THE COURTS, HANDLING CASES INVOLVING SELF-REPRESENTED LiTIGANTS 101 (2019), https://www.courts.ca.gov/documents/benchguide_self_rep_litigants.pdf ("Under time pressure and stress of heavy and intense calendars, judges must determine how they can best perform their fact-finding and decision-making functions when the parties involved are not legally trained ....").

364. Geyh, supra note 1, at 514.

365. For a discussion of the possibility of overcoming the efficiency-fairness trade-off in dispute resolution when conducted online, see KATSH \& RABINOVICH-EINY, supra note 198, at 179. 
It is important to acknowledge that diminishing implicit biases is not a necessary consequence of using technology to resolve disputes; it is a product of specific design choices as they are implemented in a particular online platform in a particular dispute-resolution environment. 366 Technology is not bias neutral; we recognize that there are "values in the design" of digital technology 367 and accept the central role of design choices in developing and implementing technology. ${ }^{368}$ While all legal proceedings_-online and offline-are based on design at some level, the introduction of online proceedings has transformed this reality, situating design-related concerns at the forefront.

Matterhorn's design choices appear likely to dampen the impact of visible markers of group identity on judicial decision-making. Matterhorn's dashboard and workflow reduce the salience of parties' group identities, but they do not (and, practically, perhaps cannot) eliminate this information altogether. And yet judges' exposure to written on-screen information relevant to party identity on Matterhorn (e.g., date of birth) does not seem, in our data, to have the same effect as face-to-face exposure to the parties in open court. ${ }^{369}$ Under different design options, identity could be either more (video-based communication) or less (communication without any identity markers) pronounced. Such design

366. For example, race is conspicuous in videoconferencing proceedings, which are becoming more common in U.S. courts - particularly in light of the COVID-19 pandemic. See Aaron Haas, Videoconferencing in Immigration Proceedings, 5 PIERCE L. REV. 59, 62-64 (2006); Ryan Autullo, Texas Moving to Virtual Courts to Avoid Coronavirus Spread, STATESMAN (Mar. 20, 2020, 12:23 PM), https://www.statesman.com/news/20200 320/texas-moving-to-virtual-courts-to-avoid-coronavirus-spread; Hannah Brock, Michigan Courts Improve Virtual Services Due to COVID-19, ST. NEWS (Mar. 30, 2020), https://statenews.com/article/2020/03/michigancourts-improve-virtual-services-due-to-covid-19?ct=content_open\&cv=cbox_latest; Christina Vazquez, $M i$ ami-Dade Courts Readying 'Virtual' Hearings Due to COVID-19 Crisis, LOCAL10 (Apr. 2, 2020, 6:40 PM), https://www.local10.com/news/local/2020/04/02/miami-dade-courts-readying-virtual-hearings-due-tocovid-19-crisis/.

367. Helen Nissenbaum, Values in Technical Design, in Encyclopedia of SCIEnCE, TeChNOlogy, AND ETHICS lxvi, lxvi (Carl Mitcham ed., 2005); see also Ayelet Sela, e-Nudging Justice: The Role of Digital Choice Architecture in Online Courts, J. DisP. RESOL., 2019, at 127, 137 (noting that the setup of online courts-the intentional choices of the designers-influences how litigants and others will act).

368. See, e.g., Orna Rabinovich-Einy \& Ethan Katsh, Technology and the Future of Dispute Systems Design, 17 Harv. Negot. L. Rev. 151, 197-98 (2012); Lisa Toohey et al., Meeting the Access to Civil Justice Challenge: Digital Inclusion, Algorithmic Justice, and Human-Centered Design, 19 MACQUARIE L.J. 133, 152-54 (2019). For analyses of the values in design of dispute-resolution systems in general, see generally Carrie Menkel-Meadow, Are There Systemic Ethics Issues in Dispute System Design? And What We Should [Not] Do About It: Lessons from International and Domestic Fronts, 14 HARV. NEGOT. L. REV. 195 (2009), and Stephanie Smith \& Janet Martinez, An Analytic Framework for Dispute Systems Design, 14 HARV. NEGOT. L. REV. 123 (2009).

369. A different explanation may lie in the nature of identity online. As we note above, judges are exposed to parties' names as well as their gender and date of birth (in written form) - yet another design choice in Matterhorn's ODR process. Parties also have the opportunity to write their own statement to the court at the outset of the process. Perhaps judges are aware of substantial elements of parties' group identities, but the way in which identity operates in online communication is different than in physical settings. This could explain why judicial exposure to group-identity-related features in this format and medium does not appear to generate biased outcomes. Most of the writing on the changing notion of identity online has focused on the ways in which users perceive their own identity. See, e.g., DanaH Boyd, IT'S Complicated: ThE SOCIAL LIVES OF NETWORKED TEENS 29-53 (2014). Here, we suggest that the change in medium may change the ways in which people react to the identity of others. This is, as far as we know, uncharted territory that we hope to explore in future projects. 
choices could fine-tune the degree to which online platform technology reduces the threat of implicit bias in judicial decision-making. ${ }^{370}$ This is especially important when the advantages of reducing implicit biases must be balanced against losing relevant identity information.

Matterhorn's online proceedings may also curb unwarranted outcome disparities through their implicit translation of procedural rules into code and structured punishment options. Judicial discretion can be channeled in ways that may limit both implicit bias and structural bias. ${ }^{371}$ Online proceedings, just as with face-to-face hearings, can be designed to reduce the unintentional and wasteful randomness that can lead to group-based outcome disparities. Ex ante decisions can be made to ask the same questions in the same order, use identical language, and include proposed predetermined options for outcomes, for example, imposing structure and encouraging consistency. ${ }^{372}$ As was once famously stated in the early days of the Internet, "code is law." 373

While law is rich with procedural rules on the books, the reality of face-toface judicial proceedings today is quite different from what the dense corpus of procedural law might imply. ${ }^{374}$ Some have termed this variety of informal judicial practices_-employed in an attempt to close cases in a speedy and inexpensive manner- “judicial dispute resolution." 375 In some contexts, judges operate with very limited direction, often in the early phases of the process and often

370. Notwithstanding the significance of the design choices made in the Matterhorn platform, merely removing proceedings from the physical setting may lessen the degree of implicit bias, even if identity-related features are not concealed. Removal creates psychological distance between a judge and the parties in a case, which is more conducive to rule-based, as opposed to identity-based, decision-making. Avital Mentovich et al., Justice Without Borders: The Influence of Psychological Distance and Construal Level on Moral Exclusion, 42 PERSONALITY \& SOC. PSYCHOL. BULL. 1349, 1360 (2016).

371. OSTROM ET AL., supra note 8, at 3, 17; see, e.g., supra note 190 and accompanying text.

372. Indeed, this characteristic of coded solutions has also given rise to critiques against ODR that warn against its uniform approach as well as the "translation issues" associated with substituting complex legal rules with code. See Carrie Menkel-Meadow, Mediation 3.0: Merging the Old and the New, 2018 ASIAN J. ON MEDiATION 1, 14, 17. Similarly, Jean Sternlight recently questioned the ability of ODR to address the "malleability and unpredictability of human wants" through "box creation" and "box checking." Jean R. Sternlight, Pouring a Little Psychological Cold Water on Online Dispute Resolution, 2020 J. DisP. RESOL. 1, 14-17.

373. Lawrence Lessig, Code and Other Laws of Cyberspace 6 (1999); see also Joel R. Reidenberg, Lex Informatica: The Formulation of Information Policy Rules Through Technology, 76 TEx. L. REV. 553, 553-54 (1998).

374. The "vanishing trial" phenomenon has made trials a scarce occurrence and has given rise to "managerial judging" and other informal practices. See Marc Galanter, The Vanishing Trial: An Examination of Trials and Related Matters in Federal and State Courts, 1 J. EMPIRICAL LEGAL STUD. 459, 519-20 (2004); Marc Galanter \& Angela M. Frozena, A Grin Without a Cat: The Continuing Decline \& Displacement of Trials in American Courts, 143 DaEDALus 115, 126 (2014); Resnik, supra note 165, at 376-77.

375. Tania Sourdin \& Archie Zariski, Introduction to The Multi-Tasking Judge: Comparative Judicial Dispute Resolution 1, 2 (Tania Sourdin \& Archie Zariski eds., 2013); Michal Alberstein, Judicial Conflict Resolution (JCR): A New Jurisprudence for an Emerging Judicial Practice, 16 CARDOZO J. CONFLICT RESOL. 879, 898-905 (2015) (discussing various forms of judicial conflict resolution). 
by intervening "off the record," making any appeals doubtful. ${ }^{376}$ This phenomenon weakens structured judicial decision-making, a principal means for ensuring the positive aspect of impartiality, both ex ante and ex post. ${ }^{377}$ Absent such structure, biases become more likely to shape judicial decision-making. ${ }^{378}$ Matterhorn substitutes for informal hearings of civil-infraction cases, which sit at the center of judicial dispute resolution. ${ }^{379}$ The employment of this technology has introduced structure through preconfigured exchanges and options into what was, beforehand, a loose environment with few rules to guide judicial decision-making. While any particular rule or process configuration that a court selects may be subject to critique, guided discretion generally weakens the threat of outcome disparities in judicial decision-making.

Reducing outcome disparities was not a principal motivating factor in Matterhorn's original design, and particular design choices (such as whether to display certain party-related identity information on a particular screen or not) had more to do with how best to replicate and improve the judge's in-person experience and the preferences of the court in question. ${ }^{380}$ The primary considerations driving design choices were making available legally material information, system accessibility and ease of use, and efficient communication between judges and parties. ${ }^{381}$ In designing new systems, priorities and trade-offs ought to be explicitly identified and debated — who should have a voice in the design phase (which professions, types of users, etc.), what values and goals should be promoted (efficiency, fairness, legitimacy), and so on. Early design conversations should also anticipate the ongoing improvement of the system as we learn by studying the consequences of initial design choices. ${ }^{382}$

The potential of online hearing technology to reduce biases and counteract structural sources of disparities is exciting, but achieving such goals using online proceedings may put other legal values and goals at risk, some of which may

376. See Resnik, supra note 165, at 376-78 (examining the costs in terms of impartiality and other aspects of traditional judging as federal judges adopt a managerial role); Elizabeth G. Thornburg, The Managerial Judge Goes to Trial, 44 U. RiCH. L. REV. 1261, 1287-1315 (2010) (demonstrating that managerial judging has expanded beyond the preliminary stages of trials and can affect outcomes).

377. See supra Part I.C.

378. See supra Part I.C.

379. See supra Part II.A. As we note here and above, explicit design choices can reduce implicit bias, which may render the justice system better able to realize both positive and negative aspects of impartiality than the traditional legal and ethical framework.

380. See Persky, supra note 210; E-mail from M.J. Cartwright, supra note 237.

381. See Persky, supra note 210; E-mail from M.J. Cartwright, supra note 237.

382. Because all communication in online proceedings is exchanged and recorded digitally, these court processes create unique opportunities for learning about the connections between party characteristics, dispute contexts, procedural choices, and substantive outcomes. See, e.g., Bulinski \& Prescott, supra note 11, at 213-14 (" $[T]$ he systems can offer evolving guidance in the ongoing decision-rule creation and amendment process, thus fine-tuning the interactions between litigants and the court.”); O’Neil \& Prescott, supra note 182, at 223-24; Prescott, supra note 15, at 1999-2001. Our findings enrich the set of considerations designers of court processes can employ when choosing to move various proceedings online and illuminate some of the axes along which such processes should be evaluated and reformed over time. 
carry significant weight to policymakers. In the next Subpart, we touch on some of the possible costs of shifting judicial proceedings online, and we reflect on the ways in which they could be mitigated or addressed. We also identify a few potential unexpected benefits of the growth of online procedures.

\section{B. Beyond Impartiality: Costs Associated with Online Court Proceedings}

\section{Substantive Justice}

Online proceedings may reduce the impact of implicit and structural biases on litigation outcomes by reducing exposure to party-identity information, imposing structure, and replacing disparity-producing features. But, in doing so, remote interaction may veil the contextual and individual characteristics of the parties. One might argue that such traits appropriately influence judicial decisions in certain cases, and their removal reinforces formal rather than substantive equality. In fact, scholars have leveled similar objections against the "veil of ignorance" notion in philosophy. 383 This approach has been criticized for preferring an abstract principle, inevitably overinclusive and underinclusive, to the particular circumstances of individuals and their social context. ${ }^{384}$ Consequently, the failure of decision-making to take into account these details may run counter to the well-recognized principles of equity and mercy.

Unlike formal equality, equity recognizes the legal system's need to leave room for judicial discretion within the confines of the law to ensure that the consistent application of general principles across cases does not frustrate the realization of justice at the individual level. 385 Indeed, "equitable discretion is not understood by moral philosophers as a flouting of the law, but as a necessary part of making it whole."386 Mercy complements the role of equity by broadening further the scope of judicial discretion, pushing it beyond the letter of the law. ${ }^{387}$ In appropriate cases, merciful judges deviate from the confines of

383. Seyla Benhabib, The Generalized and the Concrete Other: The Koblberg-Gilligan Controversy and Feminist Theory, in FEMINISM As CRITIQUe: ON THE POLITICS OF GENDER 77, 88-91 (Seyla Benhabib \& Drucilla Cornell eds., 1987); see also Iris Marion Young, Impartiality and the Civic Public: Some Implications of Feminist Critiques of Moral and Political Theory, in Feminism As CRITIQUe: On THe POLiTICs OF Gender 57, 66 (Seyla Benhabib \& Drucilla Cornell eds., 1987). These approaches object to the identity-blind justice ideal, claiming that such an endeavor is infeasible and undesirable. Instead, they advance an agenda premised on the need to connect judging with identity, both with respect to judicial identity (translating into calls for diversifying the bench) and party identity (calling for judicial decision-making that is responsive to party group identity). Benhabib, supra, at 91-95; Young, supra, at 66-67.

384. See Andrea Roth, Trial by Machine, 104 GEO. L.J. 1245, 1285 (2016).

385. Equity, BALLENTINE'S LAw Dictionary (3d ed. 1969) (“The mitigating principles, by the application of which substantial justice may be attained in particular cases wherein the prescribed or customary forms of ordinary law seem to be inadequate.”)

386. Roth, supra note 384 , at 1285.

387. See Richard H. S. Tur, Defeasibilism, 21 OxFORD J. LEGAL STUD. 355, 366-67 (2001) (tracing the concept of mercy as fairness outside of the letter of the law to Roman times). 
rigid legal rules and principles in order to reach a just outcome. To many, abstract legal principles that do not allow for adequate levels of equity and mercy present a hollow and incomplete understanding of justice. ${ }^{388}$

More broadly, scholars have argued that the quest for abstract formal justice fails to consider the unique history, perspectives, and experiences of nondominant group members. ${ }^{389}$ Here, the critique shifts from a focus on the individual to the collective, particularly those historically disadvantaged or marginalized. ${ }^{390}$ Critics make the claim that the Rawlsian principles undergirding a traditional understanding of impartiality — autonomy, rationality, and equalityare themselves not impartial. ${ }^{391}$ One version of this claim is that these principles are necessarily steeped with Western culture's biases about historically disadvantaged groups, a belief that engenders deep skepticism toward the idea that such concepts can remedy the unfairness and injustice experienced by members of such groups in concrete cases. ${ }^{392} \mathrm{~A}$ second and related argument is that the Rawlsian understanding of impartiality as color- and gender-blindness fails to take into account the unique circumstances and experiences that shape the lives and choices of members of such groups. ${ }^{393}$ For example, feminists and communitarians have questioned the supremacy that Rawls attached to reason over feelings, empathy, connection, and community. ${ }^{394}$

Under this view, the pursuit of formal equality may ultimately serve to shore up existing inequalities under the guise of impartial decision-making. ${ }^{395}$ This critique seems particularly relevant in our context, where some of the biases we document in face-to-face settings appear to operate in ways that favor members of a sometimes powerless and marginalized group - the elderly. One could assert that by stripping cases of identity-related features, online procedures limit our legal system's ability to include relevant group-based perspectives. However, in today's courts, which are both highly overworked and operating in an

388. Roth, supra note 384, at 1285 ("Unlike equity, which is a necessary part of rendering overinclusive laws just, mercy is leniency granted by the grace of private persons beyond what justice alone demands or even allows."). This view seems to explain jury nullification—an acquittal based on the jury's view that applying formal law would violate its moral conscience. See Keith E. Niedermeier et al., Exceptions to the Rule: The Effects of Remorse, Status, and Gender on Decision Making, 31 J. APPLIED SOC. PSYCHOL. 604, 606-07 (2001); Alan W. Scheflin, Jury Nullification: The Right to Say No, 45 S. CAL. L. REV. 168, 181-83 (1972).

389. See Sheila Foster, Rawls, Race, and Reason, 72 FordHAM L. ReV. 1715, 1716-17 (2004); Susan Moller Okin, Justice and Gender: An Unfinished Debate, 72 FORDHAM L. REV. 1537, 1540 (2004).

390. E.g., Okin, supra note 389, at 550-51.

391. Foster, supra note 389, at 1717.

392. Id.

393. See Christopher Wolsko et al., Framing Interethnic Ideology: Effects of Multicultural and Color-Blind Perspectives on Judgments of Groups and Individuals, 78 J. PERSONALITY \& SOC. PSYCHOL. 635, 648-49 (2000); see also Jennifer A. Richeson \& Richard J. Nussbaum, The Impact of Multiculturalism Versus Color-Blindness on Racial Bias, 40 J. EXPERIMENTAL SOC. PSYCHOL. 417, 418 (2004) (confirming that a race-conscious rather than a raceblind approach would more effectively address racial problems).

394. See Young, supra note 383, at 61-63. at 49-50.

395. Foster, supra note 389, at 1717-18; see Menkel-Meadow, Portia in a Different Voice, supra note 135, 
increasingly informal manner to speed case closure, identity information seems more likely to become a source of implicit bias rather than the wellspring of a richer understanding of the unique experiences of dispossessed and vulnerable parties. More important, such theoretical claims are in tension with the empirical findings that demonstrate that biases favoring certain group members can be no less detrimental than negative biases since both positive and negative biases stem from, and reinforce, the same stereotypes. ${ }^{396}$

Appropriately structured online proceedings may offer an avenue for bridging the tension between the need to be sensitive to context and identity and the need to ensure judicial impartiality. Technology typically adds flexibility and options (since traditional avenues can be retained), and court ODR processes can be designed in myriad ways. For example, the design of online court technology could attempt to illuminate parties' idiosyncratic circumstances while also rendering implicit identity-based biases less influential. ${ }^{397}$ Moreover, when it is essential to incorporate group-identity information into judicial decision-making to achieve a just outcome, online systems could permit or encourage disclosure, either as a design feature or via complementary procedures. More broadly, configurable online systems allow for a much more tailored calibration of judicial exposure to party-identity details (e.g., by case type, underlying facts, or identity characteristics) than is possible with traditional one-size-fits-all face-to-face hearings. Online proceedings (and technology more generally) thus offer at least some hope of reducing biases while still achieving justice.

\section{Procedural Justice}

The qualities of legal proceedings and the way parties perceive them have been found to be key factors in how people experience and evaluate the legal system generally and judicial decision-making in particular. ${ }^{398}$ In fact, according to procedural-justice theory, the perceived fairness of legal proceedings, more than the favorability of their outcomes, are tightly linked to belief in the legitimacy of the legal system and to long-term commitment to the rule of the law. ${ }^{399}$ Perceptions of procedural fairness are anchored in a number of key factors, several of which are relevant to how members of the public are likely to appraise online proceedings as they become more common. The first has to do with the nature of the proceedings themselves - whether they are impartial, transparent,

396. See note 345 and accompanying text.

397. Bulinski \& Prescott, supra note 11, at 232-35 (discussing the ways in which ODR may provide a degree of anonymization while also providing relevant information, such as ability to pay).

398. Tom R. Tyler, What Is Procedural Justice?: Criteria Used by Citizens to Assess the Fairness of Legal Procedures, 22 LAW \& SOC’Y REV. 103, 128 (1988).

399. See id.; see also Tom R. Tyler, Psychological Perspectives on Legitimacy and Legitimation, 57 ANN. REV. PSYCHOL. 375, 378-80 (2006). 
and principled. 400 The second has to do with the qualities of any interpersonal treatment-whether the decision-making authority (in our context, judges) gave respectful and dignifying treatment to the involved parties. ${ }^{401} \mathrm{~A}$ third and last element, cutting across both concerns for fair decision-making procedures and interpersonal, respectful treatment, is the opportunity for voice-the ability of parties to present their story before a decision maker. ${ }^{402}$

Online proceedings and courts raise at least a few procedural justice-related challenges. To begin with, the shift online may generate tension between components of procedural fairness: online proceedings may promote impartiality, structure, and transparency, but they will also significantly reduce the interpersonal content of judicial decision-making. ${ }^{403}$ This is consequential, as research shows that people place higher value on the interpersonal element of procedural justice than the quality of decision-making. ${ }^{404}$ In addition, procedural-justice perceptions are necessarily subjective, and while the limited nature of interpersonal interactions online is evident, the potential impartiality benefits may be less obvious to parties; in fact, online court users may not be aware of them at all and, therefore, may attach little significance to such benefits. ${ }^{405}$ Finally, although there are reasons to believe that proceedings held in an online arena can

400. See Jonathan Jackson et al., Compliance and Legal Authority, in INTERNATIONAL ENCYCLOPEDIA OF THE SOCIAL \& BEHAVIORAL SCIENCES 456, 457-58 (James D. Wright ed., 2d ed. 2015).

401. Steven L. Blader \& Tom R. Tyler, A Four-Component Model of Procedural Justice: Defining the Meaning of a "Fair" Process, 29 PersonAlity \& SoC. PSyChOl. BulL. 747, 748 (2003).

402. Jackson et al., supra note 400, at 458 ("A key element of procedural justice is the implementation of voice practices. Voice means providing opportunities for individuals to participate in decision-making processes. In situations of everyday disagreements and conflicts it is important to provide opportunities for individuals to state their case before decisions concerning them are made. Informal dispute resolution mechanisms are popular in part because participating in decision making allows people to voice their own personal concerns, stating what they think the issues involved are, making suggestions for how they should be handled. Such opportunities for voice need not involve a formal or elaborate mechanism. Studies of police street stops, for example, indicate that when officers provide people an opportunity to tell their side of the story before they take action, people are much more likely to feel fairly treated.”).

403. See Sternlight, supra note 372, at 21 (discussing some of the limitations of online dispute resolution in terms of richness of communication).

404. See generally Tom R. Tyler \& Steven L. Blader, The Group Engagement Model: Procedural Justice, Social Identity, and Cooperative Behavior, 7 PERSONALITY \& SOC. PSYCHOL. Rev. 349, 357 (2003) ("[W]ithin the study of procedural justice, research has shifted from exclusively defining procedural fairness by the quality of decision-making procedures to broader definitions of procedural fairness that also consider the quality of people's interpersonal treatment when they are interacting with others. This is consistent with the prominent role that treatment criteria of procedural justice play in the group engagement model ....”).

405. Early survey research on the determinants of procedural-justice perceptions of online systems indicates that "ease of use" matters and may also substitute in some way for interpersonal interactions, given that ease of use is related to feelings toward court officials. See Youyang Hou et al., Factors in Fairness and Emotion in Online Case Resolution Systems, in ProceEdings of THE 2017 CHI CONFERENCE ON Human FACTORS IN COMPUTING SYSTEMS 2511, 2519 (2017) (“Ease of use is important in all online systems, but one important and novel finding here is that ease of use and perceptions of procedural justice interacted strongly in their relationship with emotion toward court officials. For online judicial systems, priority should be placed on ease of use that promotes a strong sense of procedural justice.”). For another analysis of the potential impact of ODR on procedural-justice perceptions, see Elayne E. Greenberg \& Noam Ebner, Strengthening Online Dispute Resolution Justice 29-30 (St. John's Sch. of Law, Legal Studies Research Paper Series, Paper No. 19-0032, 2019), http://ssrn.com/abstract=3434058 (stating that participants in ODR felt they 
fulfill a litigant's need to be heard, ${ }^{406}$ we know too little about how voice works in an online court setting. Together, these challenges may undermine the legitimacy of online proceedings in the public's eyes.

At the same time, the vast majority of procedural-justice research has been conducted in traditional face-to-face settings. The question of how individuals experience online proceedings remains very much open. Components of procedural fairness may change as interactions move online, perhaps reducing the significance of interpersonal interaction. ${ }^{407}$ It is also possible that online opportunities will prove to be more conducive to voice, allowing litigants to tell their stories from the comfort of their homes and at their own pace. ${ }^{408}$ Here also, the particular design choices made in online platforms could enhance—or diminish-opportunities for voice. In this context, it is important to remember that the ideal of the full adversarial proceeding is far removed from the reality of "mass justice" and speedy informal hearings in which voice is rigidly circumscribed. Furthermore, the expansion of procedural options to resolve disputes (including online hearings) can be seen as yet another layer of "process pluralism," offering parties a broad range of processes for various types of disputes, contexts, and preferences, which can ultimately enhance the public's perceptions of the fairness and effectiveness of the judicial system. ${ }^{409}$

\section{Access to Justice, the Digital Divide, and Structural Disparities}

The access-to-justice movement emerged in the 1960s, dedicated to making it easier for the poor to make use of the judicial system. ${ }^{410}$ The initial focus was, understandably, on reducing the direct and indirect financial costs associated

were "treated in a dignified manner" if the platform "clarified each process" and resolved conflicts "in a timely manner" and that they felt they "ha[d] an opportunity to express themselves" by "enter[ing] their information into the ODR platform, even though they did not engage with a human").

406. Bulinski \& Prescott, supra note 11, at 229-31 (written-communication benefits); O’Neil \& Prescott, supra note 182, at 221-22 (convenience benefits).

407. See supra note 405.

408. See Bulinski \& Prescott, supra note 11, at 229-31. Interestingly, enhanced procedural fairness could reduce both perceptions and the actual existence of judicial bias. Further research into procedural justice and outcome disparities in online proceedings could deepen our understanding of the connection between the elements of procedural justice, bias, and online court proceedings. See generally Kevin Burke \& Steve Leben, Procedural Fairness, in ENHANCING JustiCE: Reducing BiAs 229 (Sarah E. Redfield ed., 2017).

409. Menkel-Meadow, supra note 107, at 577 (“[P] eople judge their satisfaction with legal processes by their participation in and perceptions of fairness of those processes, irrespective of the outcomes."). A recent experiment conducted by Ayelet Sela provides support for such a hypothesis; she finds that online asynchronous communication - in both written and video formats - results in robust perceptions of procedural justice. Sela, supra note 133, at 363-84. Stanford University students participated in what they believed to be a test for a new online system for handling student violations of the university's honor code. Id. at 363-64. The highest levels of procedural justice were experienced by participants who communicated with the judge via text messages and received, in return, video messages from the judge. $I d$. at 377 . These findings suggest that not all online mediums may equally address procedural-justice needs.

410. See Mauro Cappelletti \& Bryant Garth, Access to Justice: The Newest Wave in the Worldwide Movement to Make Rights Effective, 27 BUFF. L. REV. 181, 197-98 (1978). 
with court processes, which presented a heavy burden for those who were economically disadvantaged. ${ }^{411}$ The access-to-justice agenda eventually came to encompass the design of legal proceedings, generating momentum for ideas related to small-claims courts, class actions, and ADR processes. ${ }^{412}$ Today, the potential of technology to improve access to justice is center stage, ${ }^{413}$ with technology both touted as an opportunity and criticized an obstacle. ${ }^{414}$

Technology, of course, can lower the costs, time, and travel necessary for participating in face-to-face legal proceedings. ${ }^{415}$ Yet, in its early stages at least, access to and familiarity with online technology were unequally distributed in society. ${ }^{416}$ Incorporating digital technology often proved more of a barrier than a boost for the population most in need of access. ${ }^{417}$ In recent years, as advances in mobile technology have made Internet access broadly available and improvements in the interface and language of digital platforms have made using them simpler and more engaging, ${ }^{418}$ handling one's claim online has become a realistic option for virtually everyone. And yet the digital divide remains. Technology and Internet access are broadly available, ${ }^{419}$ but patterns of use vary across socioeconomic strata. ${ }^{420}$ These patterns mirror existing social, cultural, and economic divisions, with some evidence indicating that marginalized groups—such as low-income racial minorities_ - use the Internet mostly for entertainment and

411. Id. at $196-97$.

412. Mauro Cappelletti, Alternative Dispute Resolution Processes Within the Framework of the World-Wide Access-to-Justice Movement, 56 MOD. L. REV. 282, 285, 288 (1993).

413. See Rabinovich-Einy \& Katsh, supra note 110, at 184-86.

414. Cappelletti \& Garth, supra note 410, at 196-227 (discussing the successive "waves" of approaches to access-to-justice problems).

415. Bulinski \& Prescott, supra note 11, at 222-28; Rabinovich-Einy \& Katsh, supra note 110, at 213.

416. James E. Cabral et al., Using Technology to Enhance Access to Justice, 26 HARV. J.L. \& TECH. 241, 258264 (2012); Rabinovich-Einy \& Katsh, supra note 110, at 180-81.

417. For a discussion of concerns over ODR and the digital divide, see, for example, Menkel-Meadow, Is ODR ADR?, supra note 135, and supra note 280. See also Toohey et al., supra note 368, at 145 (2019) (finding it "insufficient" in a digitally inclusive society for a person merely to have "access to a device or internet connection," but rather that "technological advancements must . . . take into consideration the sociological challenges faced by end users").

418. See Charles Arthur, How the Smartphone Is Killing the PC, GuARDian (June 5, 2011, 3:30 PM), https://www.theguardian.com/technology/2011/jun/05/smartphones-killing-pc. But see Amy J. Schmitz, Expanding Access to Remedies Through E-Court Initiatives, 67 BUFF. L. REV. 89, 159 (2019) (discussing the limits of cell-phone use for dispute resolution).

419. For some people and under certain circumstances, technology may encumber or limit access, rather than facilitate it. Although the digital divide has diminished in most respects in recent years, Internet access for members of disadvantaged groups remains at least somewhat lower than for white people. See Prescott, supra note 15, at 2011 \& n.86; Robert W. Fairlie, Have We Finally Bridged the Digital Divide? Smart Phone and Internet Use Patterns by Race and Ethnicity, FIRST MONDAY (Sept. 14, 2017), http:// firstmonday.org/ojs/in dex.php/fm/article/view/7919/6523.

420. Hyunwoo Yoon et al., Older Adults' Internet Use for Health Information: Digital Divide by Race/Ethnicity and Socioeconomic Status, 39 J. Appled GERONTOLOGY 105, 107-08 (2020); Fairlie, supra note 419. 
shopping. ${ }^{421}$ If true, those who might benefit most from making online proceedings available may be the least predisposed to take advantage of such opportunities and the least prepared to succeed if they do.

Furthermore, as we acknowledge above, social and economic cleavages may reappear within online proceedings-just as they do in face-to-face settings but in entirely different ways, possibly exacerbating (or mitigating) group-based outcome disparities. ${ }^{422}$ For instance, the relative ability of someone to make a convincing argument in a traditional face-to-face setting may track the litigant's socioeconomic position. How moving litigation online will affect the status quo is an empirical question. Current online court proceedings rely on asynchronous written communication, some of it unstructured and one-directional. Relative to open-court back-and-forth, this mode of communication better allows for receiving advice and assistance from friends and family members, might ease performance anxiety, and may highlight differences in narrative-writing abilities (instead of differences in oral-advocacy skills). ${ }^{423}$ To the extent these changes differentially affect different groups (e.g., white versus black, young versus old), then shifting online could upset existing, but perhaps unrecognized, disparities that may arise out of the traditional structure of legal hearings.

Indeed, as we stress, this dynamic — rather than eliminating implicit biascould explain why young people, who are more experienced in conveying brief messages online, appear to do relatively better in online proceedings. ${ }^{424}$ Likewise, our finding that the relative outcomes of black litigants improve online could be the result of online proceedings just being different—and different in a way that happens to benefit black litigants relative to others on average. But, at least in theory, improvements with respect to outcome disparities may come at the cost of access-to-justice goals. In our study, for example, we find that

421. See Fairlie, supra note 419; Jesse Washington, New Digital Divide Seen for Minorites on Internet, SF GATE (Feb. 13, 2011, 4:00 AM), https://www.sfgate.com/business/article/New-digital-divide-seen-for-mi norities-on-Internet-2459621.php. But see Andrew Perrin \& Erica Turner, Smartphones Help Blacks, Hispanics Bridge Some - but Not All - Digital Gaps with Whites, PEW RES. CTR. (Aug. 20, 2019), https://www.pewresearch. org/fact-tank/2019/08/20/smartphones-help-blacks-hispanics-bridge-some-but-not-all-digital-gaps-withwhites/.

422. See Part II.D (finding that seemingly neutral structure can lead to group-based disparities).

423. See supra notes 123-24. But see supra note 351 and accompanying text. During the COVID-19 pandemic that began in March 2020, many courts across the U.S. and worldwide simply shut down their physical courtrooms. Many courts held virtual hearings (typically employing videoconferencing technology) to allow real-time court proceedings to take place despite shelter-in-place orders and social-distancing requirements. See Nat'l Ctr. for State Courts, Coronavirus \& The Courts, TABLEAU PUB., https://public.tableau. com/profile/ncscviz\#!/vizhome/StateCourtResponsestoCOVID-19/CovidTheCourts (last updated May $14,2020)$. Clearly, under these procedural conditions, party demographics remain salient, proceedings are no more (and perhaps even less) structured than in-court proceedings, and the pressure to communicate effectively in the moment remains pronounced. Indeed, the COVID-19 experience demonstrates the importance of designing court processes carefully and the need to reflect on both the nature of available mediums and the role of party characteristics. While such careful calibration may not be possible in the midst of a pandemic, it is highly desirable during times of routine operation.

424. See supra notes $312-13$ and accompanying text. 
black court users are underrepresented in online proceedings, ${ }^{425}$ and yet the platform appears to work substantially in their favor. These findings may indicate that the mere implementation of online proceedings alone is insufficient to improve access to courts for marginalized populations.

Research shows that specific, targeted outreach can improve online court use for especially disadvantaged communities. ${ }^{426}$ Implementation of online proceedings may need to be coupled with a tailored outreach strategy, at least if policymakers view the disparity reductions we identify as associated with online proceedings as attractive. An alternative, more exhaustive (and more radical) approach could be adopted to guarantee higher uptake: making online proceedings the default arrangement for all users. The online tribunal in British Columbia uses such an approach, mandating the use of online proceedings in small claims and certain neighbor disputes. ${ }^{427}$ In the short run, mandatory online tribunals seem unlikely to take root in the United States, but a strategy built on introducing online court proceedings and actively encouraging their use by communities that experience outcome disparities in traditional proceedings may achieve the right balance in the face of a lingering digital divide. ${ }^{428}$

425. Black litigants account for $29 \%$ of all hearings prior to the implementation of online courts but only $15 \%$ of online proceedings in our sample. This is true at the individual court level, too. In the suburban court, black litigants account for $19 \%$ of all hearings before Matterhorn was implemented but only $8 \%$ of online hearings. In the urban court, black litigants account for $51 \%$ of all pre-Matterhorn hearings but only $26 \%$ of online proceedings.

426. Prescott, supra note 119, at 55-56, 60. Indeed, Toohey et al., supra note 368, advance this solution under the rubric of "legal design." Id. at 154 (arguing that legal design "encourage[s] an iterative and userfocused process of law reform and innovation that allows for miscalculations and mistaken assumptions to be made and corrected before a purported solution is released to an end user" and helps laypersons better understand "their rights and obligations in contexts such as an employment contract"). On legal design in traffic cases, see also Margaret Hagan, The Justice Is in the Details: Evaluating Different Self-Help Designs for Legal Capability in Traffic Court, 7 J. OpEN ACCESS L. (2019).

427. Shannon Salter, Chair, Civil Resolution Tribunal, Inaugural SCL Sir Brian Neill Lecture: Can Online Dispute Resolution Humanize the Justice System? (Dec. 7, 2018), https://www.scl.org/podcasts/ 10363-webinar-the-inaugural-scl-sir-brian-neill-lecture-can-online-dispute-resolution-humanize-the-justicesystem-by-shannon-salter. Besides its mandatory nature, the British Columbia tribunal works closely with litigants and groups representing the interests of various parties to help improve access to its online proceedings. See id. (describing the close work tribunal officials carry out with all parties, their commitment to having all information online at a sixth-grade reading level, and their promise to provide effective over-the-telephone assistance for inexperienced users).

428. In some contexts, research shows that online procedures increase access to justice- and not only for online users but also for parties using traditional processes in courthouses. See Prescott \& Sanchez, supra note 203 , at 53 . The added efficiency afforded by online courts permeates the entire courthouse and results in greater access across mediums and cases. Id. Prescott and Sanchez analyzed the effect of online proceedings in a small-claims court and found that litigants for all online-proceeding-eligible case types-including those who did not use the online platform-experienced longer case durations and lower probabilities of receiving default dispositions. $I d$. at 33 n.2. Both of those results may indicate greater interaction with the court and, therefore, an improvement in access to justice. Notably, prior to the implementation of online courts, litigants had to compete with one another to access court resources during specific hours, $i d$. at 36-37; online options seemingly lessened demand for in-person court resources, and the redistribution of newly available services benefited litigants who did not use the online platform. 


\section{CONCLUSION}

We have come to accept a world in which our system strives to be "impartial enough." In this system, judges follow legal and ethical prescriptions regarding judicial decision-making, and courts adopt structures that limit discretion and ensure equal application of the law. But our judicial system often fails to attain impartiality. Despite efforts to debias judges through training and awareness techniques, disparities in judicial decision-making persist, and traditional face-to-face procedures may also generate group-based structural disparities, potentially adding further to any systematic disparities across groups.

Online court processes may offer a new way to address these disparities. The adoption of online proceedings to date has been about efficiency and access: courts, judges, and parties trying to cope with an ever-growing caseload and complex rules and procedures. But the use of digital technology can transform legal processes. In particular, it has allowed remote online proceedings in which judges need not be exposed to parties' group-based identity traits, parties and judges can interact and make decisions in a more structured environment, and exchanges may be entirely written and occur asynchronously. Research suggests that such features may reduce group-based outcome disparities.

To explore the relationship between these online proceedings and groupbased outcome disparities, we studied over 5,000 traffic cases in multiple Michigan state courthouses, comparing outcomes from informal in-court hearings with those of an ostensibly equivalent online process. The online proceedings rely on asynchronous text communication, add structure to the process, and reduce the salience of social identity. We found that online proceedings reduce or eliminate the apparent age- and race-based disparities that we detect in traditional face-to-face hearings. Our results are consistent with the idea that online proceedings — at least the format we study — mitigate the implicit and structural biases inherent in traditional in-person court hearings. The exposure to identity information that inevitably triggers implicit biases in the physicalcourt environment becomes, in the online setting, a malleable function of design choices. Likewise, traditional features of court-based dispute resolution rooted in the fact that courts are a place where people meet and interact in person (e.g., oral advocacy) — but which may generate structural disparitiesare no longer necessary but merely optional.

Online proceedings entail their own weaknesses, however. Face-to-face judicial decision-making can better promote justice under certain circumstances. Nevertheless, under the varied procedural options available with online technology, courts can calibrate more carefully and easily when and where more traditional approaches would contribute to an equitable resolution and a just judicial system, breaking the all-or-nothing nature of face-to-face court settings, especially a judge's inevitable awareness of a litigant's identity traits. In addition, online proceedings support more structured procedures, which curb implicit 
and structural biases by limiting discretion and carefully controlling the ways in which parties interact. The wide range of design choices is vital to the potential of online proceedings; the right ones, in the right contexts, will make it possible to make our legal system impartial in a way it has never been.

In designing court proceedings, simply looking at efficiency is insufficient; we must also weigh the importance of access, equality, and legitimacy. Perhaps "the answer is not to forego mechanical proxies entirely. Machines can be allies in tackling complex problems not because they make things simpler, but because they enhance our own unique human experience with powers of perception, speed, and precision that humans could not dream of attaining unaided." ${ }^{429}$ Moreover, "[w]e should reject both a romanticized view of the virtues of unaided human justice and a fetishistic or statist view of the virtues of mechanical justice." 430 But progress begins with recognizing that human decision-making and court proceedings are subject to implicit and structural biases. Technology may be able to protect us and our institutions from unwarranted disparities, but to do that, it needs to be developed, tested, and refined.

429. Roth, supra note 384 , at 1300.

430. Id. at 1305 . 


\section{APPENDIX}

Table 1. Sample Descriptive Statistics

\begin{tabular}{|c|c|c|c|c|}
\hline Number of Cases & \multicolumn{2}{|c|}{ In-Person Hearings } & \multicolumn{2}{|c|}{ Online Hearings } \\
\hline Closed Pre-Matterhorn Launch & & 870 & & 0 \\
\hline Closed Post-Matterhorn Launch & & 1,843 & & 2,519 \\
\hline Total & & 2,713 & & 2,519 \\
\hline \multicolumn{5}{|l|}{ Litigant Age } \\
\hline Median & & 33 & & 35 \\
\hline Mean (Std. Dev.) & 36.9 & $(14.9)$ & 37.8 & $(14.3)$ \\
\hline Minimum & & 18 & & 18 \\
\hline Maximum & & 95 & & 86 \\
\hline \multicolumn{5}{|l|}{ Litigant Gender } \\
\hline Male & 1,662 & $(61.26 \%)$ & 1,423 & $(56.49 \%)$ \\
\hline Female & 1,051 & $(38.74 \%)$ & 1,096 & $(43.51 \%)$ \\
\hline \multicolumn{5}{|l|}{ Litigant Race } \\
\hline White & 1,988 & $(73.28 \%)$ & 2,095 & $(83.17 \%)$ \\
\hline Black & 680 & $(25.06 \%)$ & 384 & $(15.24 \%)$ \\
\hline Asian & 43 & $(1.58 \%)$ & 38 & $(1.51 \%)$ \\
\hline Native-American & 2 & $(0.07 \%)$ & 2 & $(0.08 \%)$ \\
\hline \multicolumn{5}{|l|}{ Zip-Code Socioeconomic Status } \\
\hline Low-Income & 354 & $(13.05 \%)$ & 305 & $(12.11 \%)$ \\
\hline Middle-Income & 2,139 & $(78.84 \%)$ & 1,866 & $(74.08 \%)$ \\
\hline High-Income & 220 & $(8.11 \%)$ & 348 & $(13.82 \%)$ \\
\hline
\end{tabular}


Table 2. Litigant Demographics and Court-Ordered Fines

\begin{tabular}{|c|c|c|c|c|}
\hline & (1) & (2) & (3) & (4) \\
\hline Online Hearing $(0=$ No, $1=$ Yes $)$ & $\begin{array}{l}-5.104 * * * \\
(1.197)\end{array}$ & $\begin{array}{l}-7.125^{* * *} \\
(1.498)\end{array}$ & $\begin{array}{l}-5.635^{* * *} \\
(1.495)\end{array}$ & $\begin{array}{l}-3.916^{* * *} \\
(1.253)\end{array}$ \\
\hline Age Above 35 Years $(0=$ No, $1=$ Yes $)$ & $\begin{array}{l}-3.391 \text { *** } \\
(0.912)\end{array}$ & $\begin{array}{l}-5.363 * * * \\
(1.659)\end{array}$ & $\begin{array}{l}-3.382^{* * *} \\
(0.913)\end{array}$ & $\begin{array}{l}-3.382^{* * *} \\
(0.911)\end{array}$ \\
\hline Gender $(0=$ Male, $1=$ Female $)$ & $\begin{array}{l}-1.095 \\
(0.848)\end{array}$ & $\begin{array}{l}-1.049 \\
(0.850)\end{array}$ & $\begin{array}{l}-1.738 \\
(1.583)\end{array}$ & $\begin{array}{l}-1.085 \\
(0.847)\end{array}$ \\
\hline Race $(0=$ Nonblack, 1 = Black $)$ & $\begin{array}{l}3.659 * * * \\
(1.351)\end{array}$ & $\begin{array}{l}3.590 * * * \\
(1.353)\end{array}$ & $\begin{array}{l}3.683^{* * *} \\
(1.352)\end{array}$ & $\begin{array}{l}6.416^{* * *} \\
(2.054)\end{array}$ \\
\hline Age Above $35 \times$ Online Hearing & & $\begin{array}{l}4.056^{* *} \\
(1.785)\end{array}$ & & \\
\hline Gender $\times$ Online Hearing & & & $\begin{array}{l}1.292 \\
(1.744)\end{array}$ & \\
\hline Race $\times$ Online Hearing & & & & $\begin{array}{l}-6.999 * * * \\
(2.330)\end{array}$ \\
\hline Constant & $\begin{array}{l}161.856^{* * *} \\
(10.079)\end{array}$ & $\begin{array}{l}163.325^{* * *} \\
(10.098)\end{array}$ & $\begin{array}{l}162.058^{* * *} \\
(10.111)\end{array}$ & $\begin{array}{l}161.193^{* * *} \\
(10.128)\end{array}$ \\
\hline \multicolumn{5}{|l|}{ Controls } \\
\hline Judge-ID Indicator & $\checkmark$ & $\checkmark$ & $\checkmark$ & $\checkmark$ \\
\hline Final-Charge Indicator & $\checkmark$ & $\checkmark$ & $\checkmark$ & $\checkmark$ \\
\hline Linear and Squared Time Trends & $\checkmark$ & $\checkmark$ & $\checkmark$ & $\checkmark$ \\
\hline Case Filed Month and Year Indicators & $\checkmark$ & $\checkmark$ & $\checkmark$ & $\checkmark$ \\
\hline Out-of-State Driver's License Indicator & $\checkmark$ & $\checkmark$ & $\checkmark$ & $\checkmark$ \\
\hline Case Closed Post-Matterhorn Indicator & $\checkmark$ & $\checkmark$ & $\checkmark$ & $\checkmark$ \\
\hline Charges-Reduced Indicator & $\checkmark$ & $\checkmark$ & $\checkmark$ & $\checkmark$ \\
\hline Local-Resident Indicator & $\checkmark$ & $\checkmark$ & $\checkmark$ & $\checkmark$ \\
\hline Mean Household Income by Zip Code & $\checkmark$ & $\checkmark$ & $\checkmark$ & $\checkmark$ \\
\hline No. of Observations & 5,232 & 5,232 & 5,232 & 5,232 \\
\hline
\end{tabular}

Notes: The table reports results from OLS regressions in which the outcome variable is the total fine (in dollars) that a litigant is ordered to pay the court after an online hearing or a face-to-face informal bearing. Heteroskedasticity-robust standard errors are reported in parentheses. The symbols *, **, and *** represent significance at the $10 \%, 5 \%$, and $1 \%$ level, respectively. 
Table 3. Litigant Demographics and Likelihood of Charge Reduction

\begin{tabular}{|c|c|c|c|c|}
\hline & (1) & (2) & (3) & (4) \\
\hline Online Hearing $(0=$ No, $1=$ Yes $)$ & $\begin{array}{l}7.613^{* * *} \\
(0.817)\end{array}$ & $\begin{array}{l}7.679 * * * \\
(1.044)\end{array}$ & $\begin{array}{l}7.372^{* * *} \\
(0.940)\end{array}$ & $\begin{array}{l}6.963 * * * \\
(0.791)\end{array}$ \\
\hline Age Above 35 Years $(0=$ No, $1=$ Yes $)$ & $\begin{array}{l}1.158^{*} \\
(0.093)\end{array}$ & $\begin{array}{l}1.165 \\
(0.116)\end{array}$ & $\begin{array}{l}1.159 * \\
(0.094)\end{array}$ & $\begin{array}{l}1.160^{*} \\
(0.094)\end{array}$ \\
\hline Gender $(0=$ Male, 1 = Female $)$ & $\begin{array}{l}1.113 \\
(0.092)\end{array}$ & $\begin{array}{l}1.112 \\
(0.092)\end{array}$ & $\begin{array}{l}1.084 \\
(0.111)\end{array}$ & $\begin{array}{l}1.113 \\
(0.092)\end{array}$ \\
\hline Race $(0=$ Nonblack, $1=$ Black $)$ & $\begin{array}{l}0.729 * * * \\
(0.075)\end{array}$ & $\begin{array}{l}0.729 * * * \\
(0.075)\end{array}$ & $\begin{array}{l}0.729 * * * \\
(0.075)\end{array}$ & $\begin{array}{l}0.637^{* * *} \\
(0.080)\end{array}$ \\
\hline Age Above $35 \times$ Online Hearing & & $\begin{array}{l}0.982 \\
(0.164)\end{array}$ & & \\
\hline Gender $\times$ Online Hearing & & & $\begin{array}{l}1.082 \\
(0.184)\end{array}$ & \\
\hline Race $\times$ Online Hearing & & & & $\begin{array}{l}1.646 * * \\
(0.376)\end{array}$ \\
\hline Baseline Odds & $\begin{array}{l}0.389 * \\
(0.205)\end{array}$ & $\begin{array}{l}0.388^{*} \\
(0.205)\end{array}$ & $\begin{array}{l}0.391 * \\
(0.206)\end{array}$ & $\begin{array}{l}0.403^{*} \\
(0.213)\end{array}$ \\
\hline \multicolumn{5}{|l|}{ Controls } \\
\hline Judge-ID Indicator & $\checkmark$ & $\checkmark$ & $\checkmark$ & $\checkmark$ \\
\hline Original-Charge Indicator & $\checkmark$ & $\checkmark$ & $\checkmark$ & $\checkmark$ \\
\hline Linear and Squared Time Trends & $\checkmark$ & $\checkmark$ & $\checkmark$ & $\checkmark$ \\
\hline Case Filed Month and Year Indicators & $\checkmark$ & $\checkmark$ & $\checkmark$ & $\checkmark$ \\
\hline Out-of-State Driver's License Indicator & $\checkmark$ & $\checkmark$ & $\checkmark$ & $\checkmark$ \\
\hline Case Closed Post-Matterhorn Indicator & $\checkmark$ & $\checkmark$ & $\checkmark$ & $\checkmark$ \\
\hline Local-Resident Indicator & $\checkmark$ & $\checkmark$ & $\checkmark$ & $\checkmark$ \\
\hline Mean Household Income by Zip Code & $\checkmark$ & $\checkmark$ & $\checkmark$ & $\checkmark$ \\
\hline No. of Observations & 5,155 & 5,155 & 5,155 & 5,155 \\
\hline
\end{tabular}

Notes: The table reports results from logit regressions in which the dichotomous outcome variable is equal to one if the litigant's original charges are amended to lower charges after an online bearing or a face-to-face informal hearing and equal to zero otherwise. Estimates are shown as odds ratios (i.e., exponentiated coefficients of the logistic regression) for all but the interaction term, which is a ratio of odds ratios. Heteroskedasticity-robust standard errors are reported in parentheses. The symbols *, **, and *** represent significance at the 10\%, 5\%, and 1\% level, respectively. 